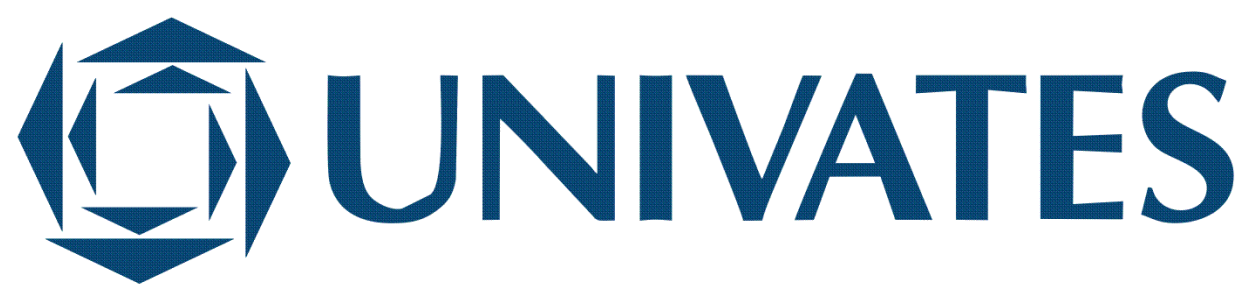

UNIVERSIDADE DO VALE DO TAQUARI

CURSO DE ENGENHARIA CIVIL

\title{
DIMENSIONAMENTO DE UM SISTEMA DE ESGOTAMENTO SANITÁRIO NA MICROBACIA DO ARROIO BARRACÃO, MUNICÍPIO DE GUAPORÉ-RS
}

Fernando Frigo Migliorini

Lajeado, novembro de 2019. 
Fernando Frigo Migliorini

\title{
DIMENSIONAMENTO DE UM SISTEMA DE ESGOTAMENTO SANITÁRIO NA MICROBACIA DO ARROIO BARRACÃO, MUNICÍPIO DE GUAPORÉ-RS
}

\begin{abstract}
Monografia apresentada à disciplina de Trabalho de Conclusão de Curso II, do curso de Engenharia Civil da Universidade do Vale do Taquari - Univates, como parte dos requisitos para a obtenção do título de graduação do curso.
\end{abstract}

Orientador: Prof. Me. Marcelo Luis Kronbauer

Lajeado, novembro de 2019. 


\section{DIMENSIONAMENTO DE UM SISTEMA DE ESGOTAMENTO SANITÁRIO NA MICROBACIA DO ARROIO BARRACÃO, MUNICÍPIO DE GUAPORÉ-RS}

A Banca examinadora abaixo o Trabalho de Conclusão de Curso apresentado na disciplina de Trabalho de Conclusão de Curso II, da Universidade do Vale do Taquari - Univates, como parte da exigência para a obtenção do grau de bacharel em Engenharia Civil:

Prof. Me. Marcelo Luis Krombauer - Orientador Universidade do Vale do Taquari - Univates

Prof. Dr. Gustavo Reisdörfer

Universidade do Vale do Taquari - Univates

Prof. Me. Adilson Becker Junior

Universidade de Santa Cruz do Sul - UNISC

Lajeado, novembro de 2019. 


\section{AGRADECIMENTOS}

Inicialmente agradeço a Deus por ter uma família de boa índole, unida e cheia de afeto, aos bons amigos que me acompanharam nesta jornada, e pelas boas oportunidades que Ele me proporcionou.

Agradeço a minha mãe Maria Frigo, que hoje não está mais aqui entre nós, mas que foi uma pessoa guerreira e batalhadora, sempre me incentivou a ir em busca dos meus ideais, mas nunca esquecendo da honestidade e humildade. Ela, que dedicou sua vida a mim, sempre me incentivou aos estudos, e continua me mandando forças positivas, ao lado de Deus.

Agradeço a minha noiva Makelin Strapazzon por toda a paciência e dedicação que demostrou durante todo este tempo de graduação, me incentivando, me auxiliando em diversos trabalhos acadêmicos e, principalmente, cuidando de mim. Agradeço também meus sogros, Aurélio Strapazzon e Leonilse Strapazzon, por todo o incentivo, dedicação e carinho que me deram.

Por fim, e não menos importante, agradeço aos professores que deixaram sua marca em meu caminho, em especial, ao meu orientador, Marcelo Luis Kronbauer, pela dedicação e apoio, sem os quais este trabalho não seria possível. 


\section{RESUMO}

O Brasil vivencia atualmente um déficit de infraestruturas e atividades no que se refere ao saneamento básico, e quando aliado à falta de investimento nessa área, há uma interferência na qualidade de vida da população, bem como na preservação do meio ambiente. $O$ fato de haver a ausência de coleta, transporte e tratamento de esgotos acaba por disseminar diversas doenças, e também compromete a qualidade dos recursos hídricos. Deste modo, este trabalho exibiu o estudo de concepção para a implantação da rede coletora de esgoto, no município de Guaporé, localizado no Rio Grande do Sul. Compreendendo que esta área não possui sistema coletivo de esgotamento sanitário, em que os esgotos são dispostos à tratamento individual, rudimentares, e até mesmo lançados em corpos receptores sem nenhum tipo de tratamento. Deste modo o presente trabalho analisa a melhor alternativa de traçado para as redes e dimensionar todo o sistema de coleta e transporte dos efluentes sanitários gerados na área central do município, efetuando uma estimativa dos custos de implementação da rede. Para atender as vazões de esgoto da área central do município foram traçados 17.072 metros de rede, divididos em três trechos principais, os quais recebem contribuição de trechos secundários, em que sua vazão final chegou a $21,38 \mathrm{~L} / \mathrm{s}$.

Palavras-chave: Saneamento, Esgotamento sanitário, dimensionamento, redes coletoras, Custos. 


\section{ABSTRACT}

Brazil is currently experiencing a deficit of infrastructure and activities with regard to basic sanitation, and when coupled with the lack of investment in this area, there is interference in the quality of life of the population, as well as the preservation of the environment. The lack of sewage collection, transportation and treatment eventually disseminates various diseases, and also compromises the quality of water resources. Thus, this work showed the conception study for the implantation of the sewage collection system, in the municipality of Guaporé, located in Rio Grande do Sul. individual treatment, rudimentary, and even thrown into recipient bodies without any treatment. Thus, the present work analyzes the best alternative for tracing networks and dimensioning the entire system of collection and transportation of sanitary effluents generated in the central area of the municipality, making an estimate of the costs of implementing the network. To meet the sewage flows of the central area of the city were drawn 17,072 meters of network, divided into three main sections, which receive input from secondary sections, where its final flow reached $21.38 \mathrm{~L} / \mathrm{s}$.

Keywords: Sanitation, Sanitary sewage, sizing, collection networks, Costs. 
Precisamos dar um sentido humano às nossas construções. E, quando o amor ao dinheiro, ao sucesso nos estiver deixando cegos, saibamos fazer pausas para olhar os lírios do campo e as aves do céu. 



\section{LISTA DE FIGURAS}

Figura 1 - Partes constituintes de um sistema de esgotos sanitários ...................... 28

Figura 2 - Rede coletora do tipo perpendicular .................................................. 38

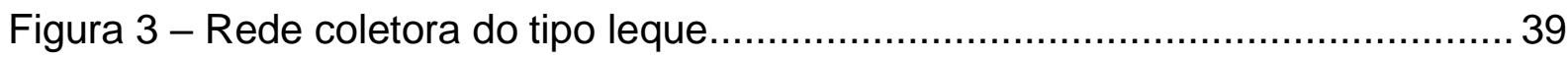

Figura 4 - Rede coletora do tipo radial ou distrital ................................................. 40

Figura 5 - Mapa da localização do município de Guaporé do Rio Grande do Sul ....52

Figura 6 - Limites territoriais do município de Guaporé/RS .................................. 53

Figura 7 - Mapa de localização das microbacias da área urbana do município de

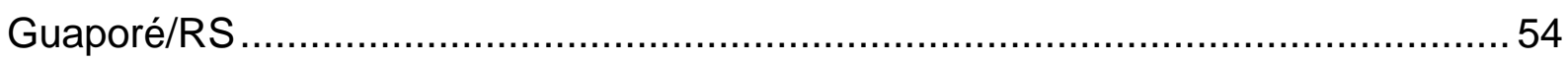

Figura 8 - Microbacias da área urbana do município de Guaporé/RS..................... 56

Figura 9 - Projeção da rede coletora de esgoto dimensionada ............................. 75

Figura 10 - Detalhamento de alguns pontos dos trechos 1, 4, 5, 26 e 19 da rede de

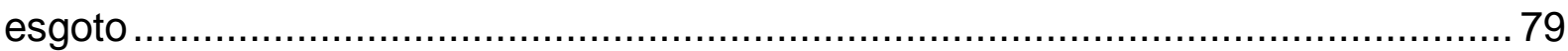

Figura 11 - Detalhamento de alguns pontos dos trechos 2, 68, 77 e 82 da rede de esgoto 80

Figura 12 - Detalhamento de alguns pontos dos trechos 3, 19, 26 e 55 da rede de esgoto 82

Figura 13 - Detalhamento de alguns pontos dos trechos 2, 3, 32 e 75 da rede de esgoto 85

Figura 14 - Localização da estação de tratamento 92 


\section{LISTA DE GRÁFICOS}

Gráfico 1 - Percentual dos moradores urbanos com acesso a esgoto sanitário apropriado e água encanada 34 


\section{LISTA DE QUADROS}

Quadro 1 - Tipos de sistemas urbanos de esgotamento.................................26 


\section{LISTA DE TABELAS}

Tabela 1 - Abastecimento de água e coleta de esgotos no Brasil (\%) .....................31

Tabela 2 - Dados do tratamento de esgoto no município de Guaporé/RS ............... 36

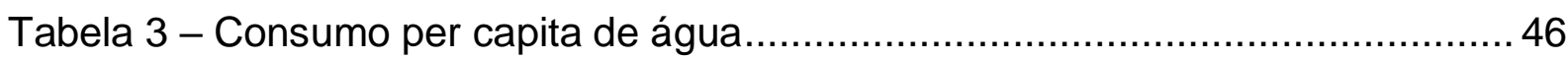

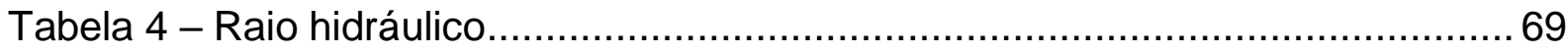

Tabela 5 - Dados censitários por bairros para Guaporé/RS................................. 74

Tabela 6 - Levantamento dos principais dados dos trechos 1 ............................. 78

Tabela 7 - Levantamento dos principais dados dos trechos 2 .............................. 81

Tabela 8 - Levantamento dos principais dados dos trechos 3 .............................. 83

Tabela 9 - Levantamento dos principais dados dos trechos 9 …......................... 83

Tabela 10 - Levantamento dos principais dados dos trechos 19 .......................... 84

Tabela 11 - Levantamento dos principais dados dos trechos 32 .......................... 84

Tabela 12 - Levantamento dos principais dados dos trechos 45 .......................... 85

Tabela 13 - Levantamento dos principais dados dos trechos 26 e $49 \ldots \ldots \ldots \ldots \ldots \ldots \ldots . . . .86$

Tabela 14 - Levantamento dos principais dados dos trechos 55 ......................... 86

Tabela 15 - Levantamento dos principais dados dos trechos 62 ............................ 87

Tabela 16 - Levantamento dos principais dados dos trechos 82 .......................... 87

Tabela 17 - Coletores com excesso de profundidade ................................................. 89

Tabela 18 - Trechos com tensão trativa ajustada para atender 1,0 Pa ...................90 


\section{LISTA DE ABREVIATURAS E SIGLAS}

ABES - Associação Brasileira de Engenharia Sanitária e Ambiental

ABNT - Associação Brasileira de Normas Técnicas

BNH - Banco Nacional de Habitação

CESB - Companhias Estaduais de Saneamento Básico

CMMAD - Comissão Mundial sobre Meio Ambiente e Desenvolvimento

ETE - Estação de Tratamento do Esgoto

FGTS - Fundo de Garantia do Tempo de Serviço

IBGE - Instituto Brasileiro de Geografia e Estatísticas

IDESE - Índice de Desenvolvimento Socioeconômico

NBR - Norma Brasileira Regulamentadora

PAC - Programa de Aceleração do Crescimento

PLANASA - Plano Nacional de Saneamento

PLANSAB - Plano Nacional de Saneamento Básico

PNAD - Pesquisa Nacional por Amostra de Domicílios

PV - Poço de Visita

SIAB - Sistema de Informação de Atenção Básica

SFS - Sistema Financeiro de Saneamento

SNIS - Sistema Nacional de Informações sobre Saneamento

TIL - Tubo de Inspeção e Limpeza 


\section{SUMÁRIO}

1 INTRODUÇÃO

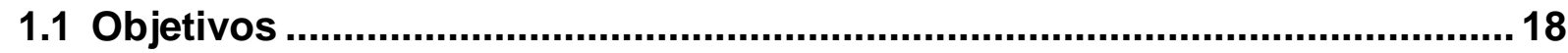

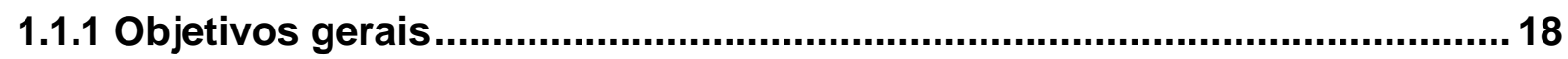

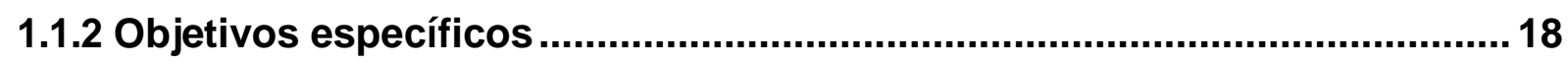

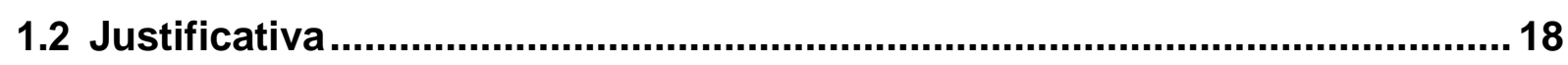

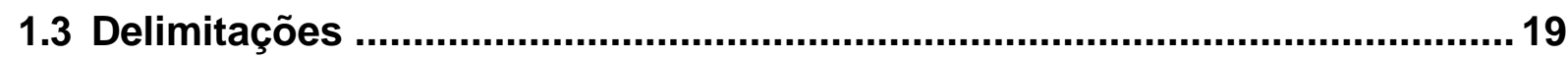

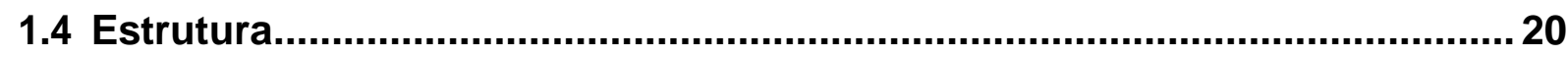

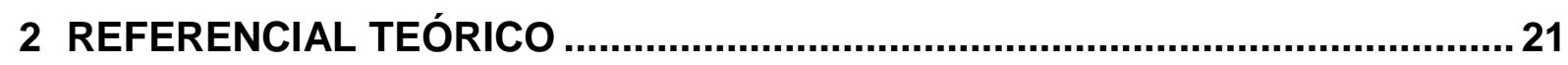

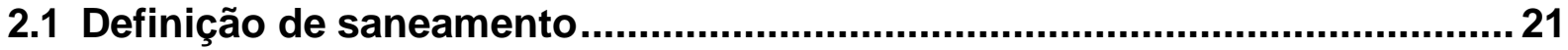

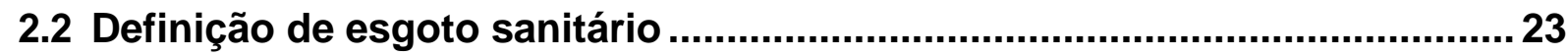

2.3 Tipos de coleta e tratamento de esgotos sanitários ......................................24

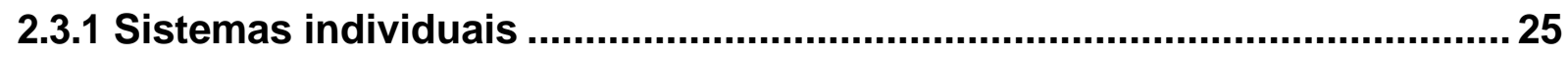

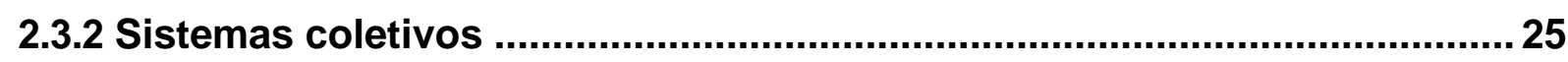

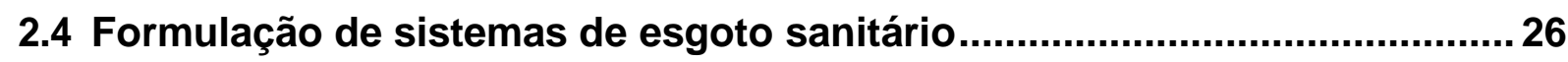

2.5 Partes que constituem o sistema de esgotamento ........................................2

2.6 Histórico do esgoto sanitário no Brasil ........................................................28

2.7 A situação do esgoto sanitário no Brasil ........................................................30

2.8 Situação do esgoto sanitário no Rio Grande do Sul ......................................32

2.9 Situação do esgoto sanitário em Guaporé......................................................34

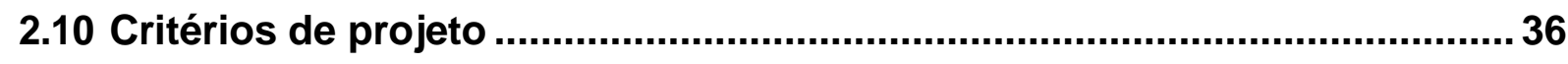

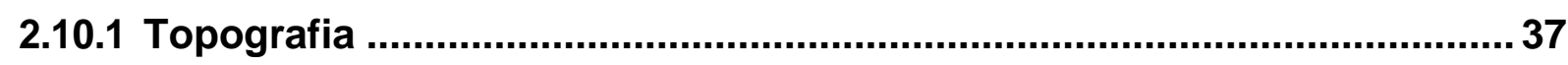

2.10.2 Modelos de traçado de rede coletora ........................................................ 38 
2.10.3 Profundidade da rede de esgotamento............................................... 40

2.11 Materiais das tubulações de esgoto ............................................................ 41

2.11.1 Tubos de PVC...................................................................................... 42

2.11.2 Tubos de ferro fundido ................................................................... 43

2.12 Fundamentos do processo de cálculo ................................................. 43

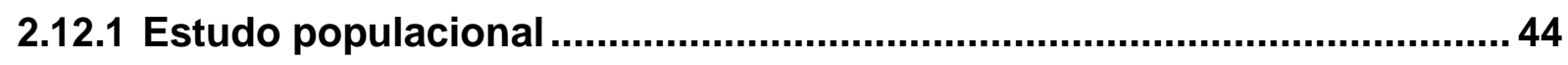

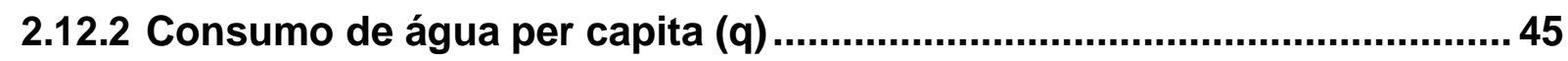

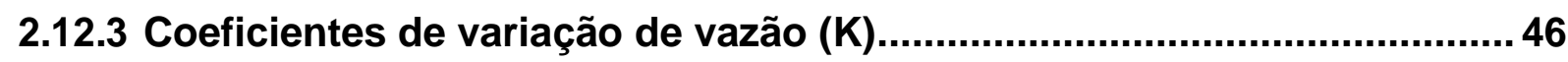

2.12.4 Taxa de infiltração............................................................................... 47

2.12.5 Declividade mínima................................................................................ 48

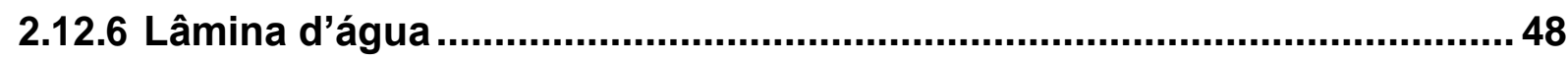

2.12.7 Tensão trativa.......................................................................................... 49

2.12.8 Velocidade crítica e velocidade máxima ............................................. 49

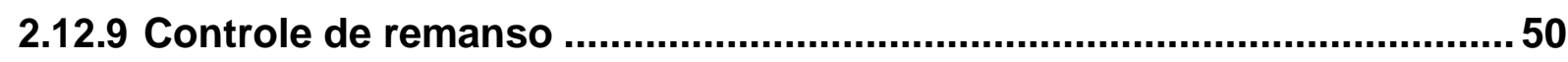

2.12.10 Determinação das vazões de esgoto .................................................. 50

3 METODOLOGIA........................................................................................ 51

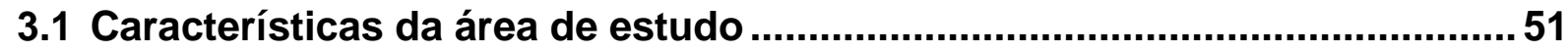

3.2 Limites territoriais .................................................................................... 52

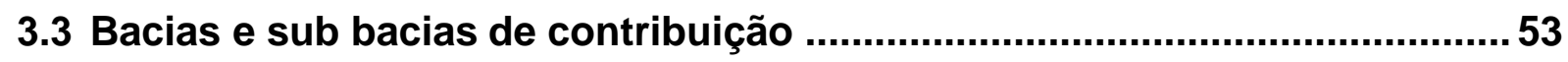

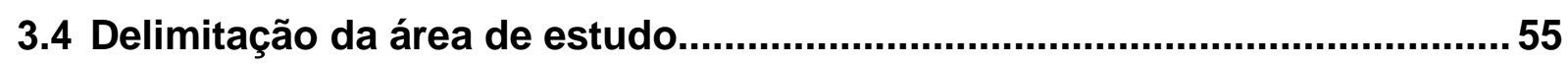

3.5 Cálculo da população através do método aritmético.................................57

3.6 Cálculo da população por meio do método geométrico ..............................58

3.7 Estimativa de consumo de água per capita $(q)$.......................................... 59

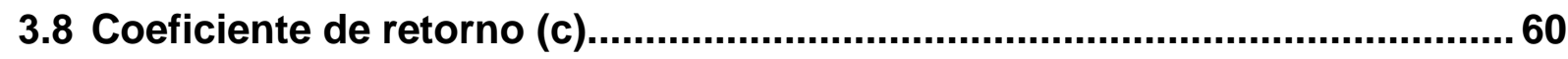

3.9 Determinação dos coeficientes de variação de vazão $(k)$........................... 60

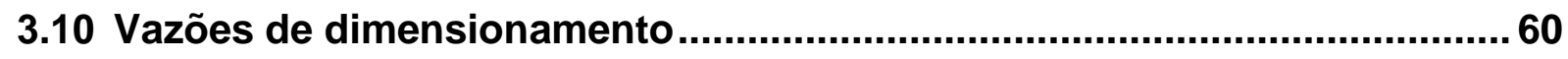

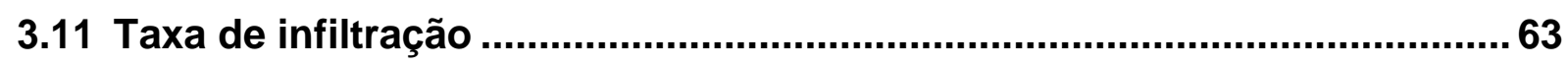

3.12 Taxa de contribuição linear..................................................................63 63

3.13 Determinação das vazões mínimas por trechos de rede...........................64

3.14 Diâmetro mínimo ..................................................................................... 65

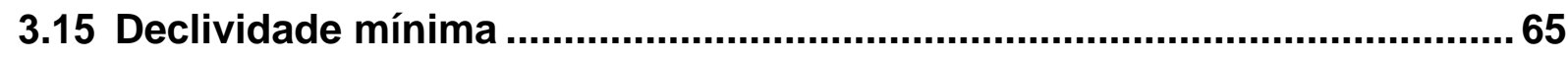

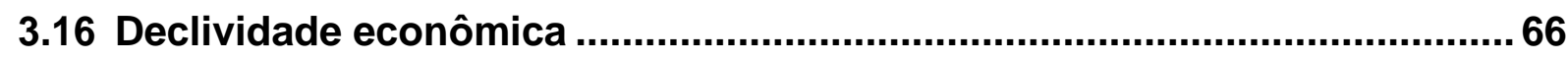

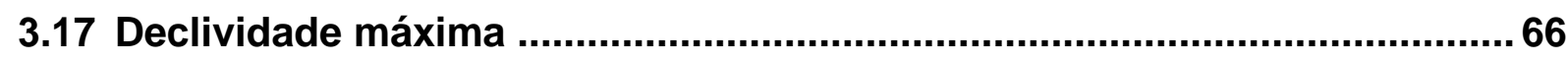




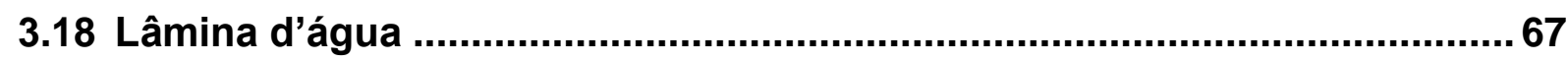

3.19 Verificação de tubulações..................................................................... 68

3.20 Determinação do raio hidráulico em função Y/D.................................... 68

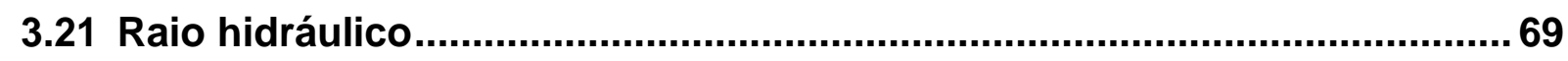

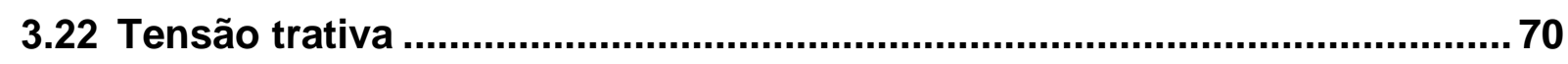

3.23 Velocidade crítica e velocidade máxima ................................................... 70

3.24 Controle de remanso ................................................................................... 71

3.25 Estação de tratamento de esgoto........................................................... 72

3.26 Estimativa de custos da rede coletora de esgoto .................................. 72

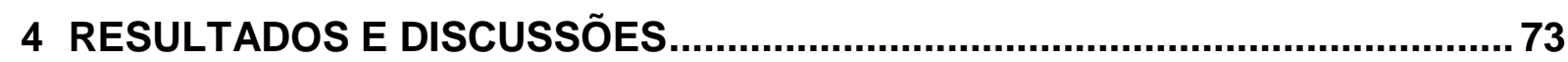

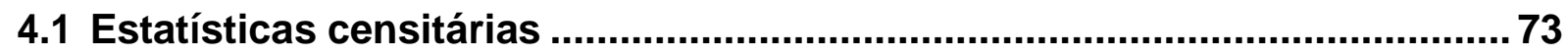

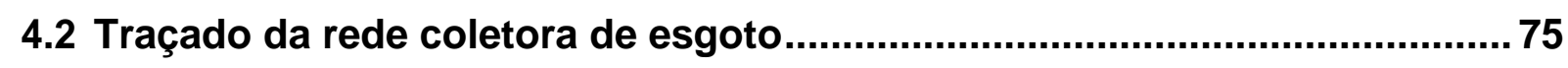

4.3 Análise dos trechos................................................................................. 77

4.4 Análise geral da declividade do terreno..................................................... 89

4.5 Análise geral das profundidades................................................................ 89

4.6 Comparação entre velocidade final e critica para atender a tensão trativa 90

4.7 Critérios da tensão trativa....................................................................... 92

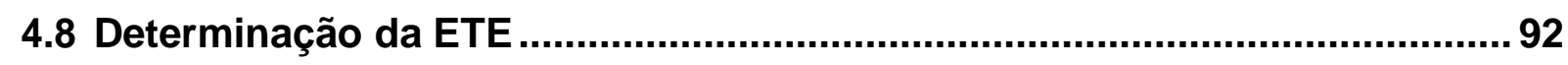

4.9 Custos da rede coletora ....................................................................... 93

5 CONSIDERAÇÕES FINAIS ................................................................... 94

REFERÊNCIAS BIBLIOGRÁFICAS ............................................................... 96

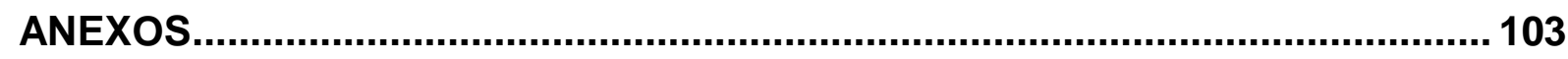




\section{INTRODUÇÃO}

Barroso (2002) diz que o saneamento básico é um dos fundamentais fatores perante a incansável busca por uma justiça socioambiental, caracterizando o mínimo existencial para uma boa qualidade de vida, onde o sistema brasileiro enfrenta diversos fatores físicos, jurídicos, financeiros e administrativos para sua implementação e desenvolvimento.

A constituição brasileira assegura o direito ao saneamento básico, através da Lei Federal 11.445 estabelecida em janeiro de 2007, que institui as atividades abrangidas pelo saneamento básico. Sendo este definido como um conjunto de serviços com infraestrutura de tratamento e posterior distribuição de água, coleta e tratamento de esgotos, controle de águas pluviais, e também a coleta e destinação de resíduos sólidos. A lei ainda determina a obrigatoriedade da elaboração de um plano de saneamento básico pelos municípios, onde visa a qualidade de vida dos habitantes.

Através da Lei $11.445 / 2007$, foi determinado um instrumento que viabiliza o planejamento e a prestação de serviços, para assegurar a saúde pública. Mas devido a necessidade de grandes investimentos nesta área, se torna precária a garantia de condições ao acesso e de qualidade dos serviços, gerando com isso, um enorme déficit no processo de inserção ao saneamento. Onde no âmbito da esfera pública, deve assegurar os serviços citados acima, de maneira que a sociedade possa usufruir de forma digna esses elementos que são cruciais a sobrevivência humana (SANTANA, 2014). 
Conforme dados das Nações Unidas, em 2009 cerca de 2,5 bilhões de pessoas não possuíam acesso a saneamento apropriado, sendo esta situação responsável por aproximadamente 1,8 milhões de óbitos por ano no mundo. Belli et al. (2002) relatam por meio de dados da ABES - Associação Brasileira de Engenharia Sanitária e Ambiental - que $80 \%$ das doenças que comprometem os brasileiros e $65 \%$ das internações são decorrentes da condição precária do saneamento básico.

Segundo Leoneti et al (2011), o Brasil, no decorrer de sua história, está marcado por desigualdades sociais, bem como por um elevado déficit em questão do acesso de saneamento básico. O abastecimento de água na zona urbana compreende $93,3 \%$ dos domicílios, mas somente $65 \%$ da população têm acesso a coleta de esgoto apropriada, tendo coleta de esgoto, seguida de tratamento ou uso de fossa séptica.

Tiscoski (2009) relata que os serviços de saneamento estão conectados com a melhora da qualidade de vida, juntamente com a proteção ao meio ambiente. Porém o acesso universal aos benefícios do saneamento é ainda uma meta a ser obtida por toda a sociedade, que demanda um envolvimento mutuo dos segmentos sociais em conjunto com o poder público.

Analisando o caso, fica evidente a importância de novos estudos de saneamento básico, especialmente em questão de esgotamento sanitário, que necessitam de investimentos sustentáveis e que promovam a melhora da qualidade de vida dos habitantes e à preservação do meio ambiente.

Portanto, este trabalho tem como intuito propor uma visão viável, técnica e econômica de um sistema de esgotamento sanitário da cidade de Guaporé, no interior do Rio Grande Do Sul, em que esta cidade conta apenas com sistema de esgotamento sanitário do tipo individual, ou seja, realizado em cada lote habitacional. Em virtude de o município não contar com um sistema coletivo para tratamento de efluentes, tornase viável esta pesquisa em vista que a cidade cresceu demasiadamente nas últimas décadas. 


\subsection{Objetivos}

\subsubsection{Objetivos gerais}

O objetivo geral é organizar um estudo de viabilidade para execução de um sistema de esgotamento sanitário para a área urbana do Município de Guaporé - Rio Grande do Sul, com foco na microbacia do Arroio Barracão.

\subsubsection{Objetivos específicos}

Os objetivos específicos são:

- Diagnosticar a atual situação do município no quesito de esgotamento sanitário na sua área urbana, através de uma avaliação do plano diretor municipal;

- Avaliar a topografia da cidade e definir as bacias de esgotamento;

- Realizar o dimensionamento da rede coletora de esgotamento sanitário da região da microbacia do Arroio Barracão;

- Avaliar a necessidade de instalação de estações elevatórias;

- Avaliar a questão técnica e financeira para execução das redes.

\subsection{Justificativa}

Para a efetivação de um projeto de rede coletora de esgotos, deve-se levar em consideração toda a infraestrutura da cidade, visto que a mesma possui um plano de esgotamento sanitário, mas que pelo passar dos anos e com o crescimento populacional elevado, o mesmo torna-se defasado, necessitando de novas ideias e técnicas para bem atender a população. 
O Plano Municipal de Saneamento Básico - PMSB (2017), relata que o município de Guaporé, possui um sistema de esgotamento sanitário do tipo individual, ou seja, efetivado em cada lote habitacional. O município não tem um sistema coletivo para tratamento de esgoto. Hoje, além do sistema individual estabelecido em cada lote habitacional, a exigência para os novos loteamentos é a disposição da rede coletora de esgoto de separador absoluto, definida por rede seca, sendo que até a implantação de um sistema coletivo para tratamento, esta continuará inutilizada, com sua funcionalidade somente como espera.

A zona urbana do município tem uma propriedade peculiar, pois na época da estruturação do município, arquitetaram-se galerias subterrâneas, com a ideia de implementar um sistema de coleta mista dos efluentes pluviais e domésticos. Por isso, as habitações antigas possuem fossa séptica com extravasador para o pluvial. Mas, hoje em dia são liberadas obras com este sistema, e depois do tratamento na fossaséptica, seguida de filtro anaeróbio, o efluente é despejado em coletor misto (cloacal e pluvial).

Estes coletores únicos foram feitos em tijolos, com área de seção transversal de $1,0 \mathrm{~m}^{2}$, passando junto às ruas e avenidas do município, com algumas galerias cortando as quadras no sentido centro-norte da cidade. Em galerias mais recentes, os diâmetros das tubulações têm a variação entre 1,20 até 0,40 metros.

\subsection{Delimitações}

$\mathrm{Na}$ atualidade, há uma grande preocupação com relação ao meio ambiente, sendo que o cuidado com o futuro do planeta exige do homem uma atenção especial em questão dos resíduos descartados na natureza, tendo em vista um planeta sustentável e habitável para as futuras gerações.

De tal modo, a dificuldade da implantação de saneamento básico no país é um problema enfrentado a décadas. O problema é ainda maior com relação aos sistemas de esgotamento sanitário, pela disposição do esgoto de forma imprópria, não tendo o 
devido tratamento, porém, o problema tem início na dificuldade de obter verbas para tais finalidades.

Portanto, o presente trabalho contemplará somente a parte do Estudo de Concepção de um sistema para realização de coleta e condução de efluentes sanitários, sendo dimensionada somente a rede coletora, e definida a posição das Estações de Tratamento de Esgoto, e seus emissários e a demanda gerada (quantitativo de efluente), limitando-se apenas para a área central do município, dentro da micro bacia do Arroio Barracão, tendo em vista a elevada densidade populacional e o maior índice de poluição nesta área.

\subsection{Estrutura}

O presente trabalho é composto por três divisões: Introdução, Revisão Bibliográfica, Material e Métodos, Resultados e Discussões e Considerações Finais.

O capítulo da introdução revisa e contextualiza o saneamento básico, focando na área de esgotamento sanitário.

A Revisão Bibliográfica é designada a apresentar o embasamento nas questões de hidráulica de fluidos, mais especificamente para transporte destes em condutos, bem como os conceitos sobre o sistema de saneamento básico.

E no item de Material e Métodos são elencados dados específicos para o dimensionamento desse sistema, como estudo populacional, dados topográficos e também o método a ser utilizado para tal cálculo.

No item de Resultados e Discussão é abordado a descrição dos cálculos feitos, conforme proposto no tópico de Materiais e Métodos.

Por fim, na Conclusão se dará o encerramento do trabalho, levando em consideração o que foi sugerido nos objetivos. 


\section{REFERENCIAL TEÓRICO}

Para obter uma compreensão do tema realizou-se um levantamento dos conceitos indispensáveis para um novo plano de redes coletoras de esgotos sanitários. Utilizando as normas da ABNT NBR 9648/1986, NBR 9649/1986, NBR 14486/2000 como base, juntamente com a Lei 11445/2007, bem como bibliografia pertinente ao tema e o Plano Diretor elaborado para o Município de Guaporé. Serão expostos conceitos referentes a concepção de um plano para esgoto sanitário, que seja viável para o município.

\subsection{Definição de saneamento}

A ideia de saneamento básico foi estabelecida ao longo da história da humanidade, devido às condições sociais e de materiais disponíveis de cada época, levando em consideração que suas ações e investimentos sempre estiveram relacionados com o setor da saúde pública (FUNASA, 2006).

O saneamento é definido por Kobiyama et al (2008), como sendo um conjunto de serviços e ações que tem por objetivo chegar a níveis de alta salubridade ambiental, propiciando assim melhores condições de vida tanto nos meios urbano e rural. 
Conforme a Organização Mundial da Saúde (OMS) corresponde ao saneamento básico à função de domínio de todo o meio físico do homem, que desempenham insalubridade sobre o seu bem-estar mental, social ou físico (SANTOS, 2007). O autor ainda considera que este sistema possa compreender um conjunto de medidas que vise à preservação ou modificação das condições do meio ambiente, tendo como intenção a promoção da saúde e prevenção de doenças. No âmbito atual, é possível verificar um serviço que é dito como meio de sustentabilidade, proposto para atender as necessidades da população, por meio de serviços de proteção à saúde e de desenvolvimento socioeconômico.

Saker (2007) faz a definição de saneamento básico como sendo um conjunto de serviços públicos que corresponde a infraestrutura, manejo de águas pluviais urbanas, manejo de resíduos sólidos de drenagem, instalações de esgotamento sanitário e abastecimento de água, bem como de limpeza urbana.

Com a aprovação da Lei 11.445/2007, a área de saneamento teve um marco legal e passou a contar com novas expectativas de investimento por conta do Governo Federal. Fundamentado na sustentabilidade econômica, eficiência, segurança, controle social, regularidade e qualidade, tendo em vista a universalização dos serviços, para ser possível à realização do Plano Municipal de Saneamento Básico PMSB nos municípios, para que seja possível assegurar os serviços que tornam a vida urbana segura e saudável.

De acordo com Wagner et al. (2013), o saneamento está ligado ao meio ambiente e a saúde pública. Porém, a grande maioria da população brasileira não tem acesso a este bem comum e de direito de todos. Em diversos locais ainda não há abastecimento de água potável, o tratamento do esgoto é praticamente inexistente e a coleta dos resíduos é insuficiente. Por conta disso, se dá o grande surgimento de problemas na área do meio ambiente e da saúde.

A escassez de saneamento básico resulta em diversas falhas de infraestrutura urbana e habitação, juntamente com outros casos que tornam agravante a questão socioambiental das cidades, deixando as condições de vida mais precárias, para a maioria dapopulação (SOUZA, 2002). No Brasil, o saneamento básico é aceito como um serviço de política social, essencial para a saúde pública e ambiental. Tornando- 
se assim uma meta social por ser indispensável à vida humana e a proteção ao meio ambiente, evidenciando seu caráter público e o Estado mantendo o dever a sua promoção (FUNASA, 2006).

\subsection{Definição de esgoto sanitário}

Segundo a NBR 9648 (ABNT, 1986), compreende-se por esgoto sanitário o despejo líquido composto por esgotos doméstico, contribuição pluvial parasitária, esgoto industrial e água de infiltração. Essa norma também fala que, o esgoto doméstico é o despejo líquido resultado da utilização da água para necessidades fisiológicas e higiene. Já o esgoto industrial é o líquido formado através dos procedimentos industriais, e que devem respeitar os padrões de lançamento estabelecidos. A norma também determina que a contribuição pluvial parasitária é a parcela do escoamento superficial absorvida de maneira inevitável pelo sistema de esgoto sanitário, e a água de infiltração é a água vinda do subsolo, não desejável ao sistema separador e que entra nas canalizações.

Conforme Pereira (2006), pode-se assegurar que as águas utilizadas nas atividades humanas e posteriormente descartadas possuem propriedades que tornam impróprio seu consumo, bem como seu retorno ao meio ambiente. De maneira geral, é designada de água residuária e representa diferenças que variam conforme seu uso.

Segundo Barros (1995), os esgotos são gerados através da utilização da água para abastecimento. Deste modo, a água residuária é a massa líquida que exibe partículas, compostos químicos ou microrganismos que tornam indevida sua utilização ou reaproveitamento, assim, sendo necessário o tratamento antes de seu reuso ou destinação final. Como exemplos, os efluentes de processos industriais ou esgotos domésticos, e os líquidos percolados em células de aterros sanitários e chorume. $\mathrm{Na}$ engenharia é empregada a designação esgoto sanitário para a água residuária vindas de esgoto doméstico, águas de infiltração que ingressam indevidamente nas tubulações coletora e ao esgoto industrial. 
Oliveira (2003) diz que, o esgoto é formado por excretas humanas (urina e fezes), por águas servidas oriundas do uso doméstico, industrial, comercial e por águas pluviais. O esgoto doméstico normalmente representa a maior parte do esgoto sanitário, sendo composto por dejetos fecais e águas servidas vindas de cozinhas, banheiros, prédios comerciais, outras instalações hidro sanitárias de residências, instalações públicas, e também contribuições de hospitais e demais locais de serviços de saúde.

De acordo com as propriedades, o esgoto sanitário pode ser dividido em fraco, médio e forte, sendo influenciado na vazão e concentrações por fatores controláveis, como boas condições do abastecimento de água, processo construtivo de rede coletora, e por fatores que exibem difícil controle, como as condições climáticas, características socioeconômicas e hábitos higiênicos, etc. Conforme Von Sperling (1996), o esgoto doméstico contém em torno de 99,9\% de água, e somente 0,01\% de sólidos orgânicos, suspensos e dissolvidos, bem como microrganismos. Por conta desta fração é evidente a necessidade de tratamento dos esgotos. A coleta, tratamento bem como a destinação final se tornam indispensáveis, pois se trata de um efluente rico em carga orgânica e fundamental poluente de rios em centros urbanos.

O tratamento de esgoto tem por objetivo reduzir ou eliminar a contaminação das águas, pois a água utilizada em nossas casas ao não ser tratada é encaminhada diretamente a rede de esgoto, entrando posteriormente em contato com os rios, ocasionando assim a contaminação das águas e por consequência também entramos em contato (FARIA, 2007).

\subsection{Tipos de coleta e tratamento de esgotos sanitários}

Conforme a FUNASA (2006), a disposição apropriada dos dejetos representa uma importante medida de saúde pública, onde pode ser constituída por uma solução individual ou coletiva, dependendo da densidade populacional da área beneficiada. 


\subsubsection{Sistemas individuais}

Conforme Von Sperling (2005), este sistema é adotado para residências unifamiliares, e incidem no despejo dos esgotos domésticos produzidos em uma unidade habitacional, habitualmente em fossa séptica, acompanhada de aparelho de penetração no solo (irrigação subsuperficial, sumidouro). Esses sistemas podem funcionar de maneira satisfatória e podem ser viáveis no âmbito econômico, mas as habitações devem ser esparsas (grande porcentagem de área livre ou em área rural), em que o solo ofereça boas condições de infiltração, nível de água subterrânea em profundidade apropriada, evitando deste modo o risco de contaminação das águas superficiais e subterrâneas.

\subsubsection{Sistemas coletivos}

Por conta da maior concentração demográfica, as soluções individuais apresentam dificuldades para seu emprego. O espaço solicitado para a infiltração torna-se elevado, e em muitos casos, maior que o disponível. Deste modo, os sistemas coletivos para rede de esgotos começam a ser mais recomendados como forma de solução em locais com alta densidade populacional, como em meios urbanos. Esta solução é feita através da inserção de canalizações para onde são lançados os esgotos, e conduzidos até seu destino, para que seja feito o tratamento sanitário adequado (VON SPERLING, 2005).

Segundo Tsutiya e Sobrinho (2011), pode-se classificar os sistemas de esgotamento sanitário em três tipos, conforme a Quadro 1: 
Quadro 1 - Tipos de sistemas urbanos de esgotamento:

\begin{tabular}{|l|l|}
\hline $\begin{array}{c}\text { Classificação dos sistemas urbanos de } \\
\text { esgotamento }\end{array}$ & \multicolumn{1}{|c|}{ Descrição } \\
\hline Sistema unitário & $\begin{array}{l}\text { Consiste em realizar a coleta de esgotos } \\
\text { domésticos, de águas pluviais e de escoamentos } \\
\text { industriais unindo-os em um único coletor; }\end{array}$ \\
\hline Sistema separador parcial & $\begin{array}{l}\text { Uma quantia das águas de chuva, originárias de } \\
\text { telhados e pátios são encaminhadas juntamente } \\
\text { com águas residuárias e águas de infiltração do } \\
\text { subsolo até um sistema de coleta e transporte de } \\
\text { esgoto único; }\end{array}$ \\
\hline Sistema separador absoluto & $\begin{array}{l}\text { O esgoto doméstico e o industrial ficam } \\
\text { totalmente apartados da drenagem pluvial, } \\
\text { constituindo desta maneira, dois sistemas } \\
\text { independentes. }\end{array}$ \\
\hline
\end{tabular}

Fonte: Tsutyia e Sobrinho (2000), adaptado pelo autor.

\subsection{Formulação de sistemas de esgoto sanitário}

A NBR 9648 (ABNT, 1986) determina que o estudo de concepção para um sistema de esgoto sanitário, deve considerar as diferentes partes de um sistema, separadas em arranjos organizados de maneira a constituírem um todo integrado que devem ser quantitativa e qualitativamente comparáveis entre si, de modo a determinar o melhor acondicionamento, do ponto de vista técnico, econômico, social e financeiro.

Tsutiya e Sobrinho (2011) falam que a concepção é definida ainda na etapa inicial de projeto, tendo os seguintes objetivos:

- Estimativa e quantificação dos fatores que determinam o sistema de esgotos;

- Pré-dimensionamento das unidades do sistema;

- Realização de análise do sistema existente, verificando a situação vigente e prevendo uma situação futura;

- Determinação dos parâmetros principais de projeto; 
- Apuração das melhores alternativas mediante a comparação econômica, técnica e ambiental;

- Definição das diretrizes de projeto e avaliação da demanda de serviço que precisam ser executados em fase de projeto.

A NBR 9649 (ABNT, 1986) que trata sobre projeto para redes coletoras de esgoto sanitário, estabelece os principais parâmetros para definição dos sistemas a serem instalados.

\subsection{Partes que constituem o sistema de esgotamento}

Conforme Tsutiya e Sobrinho (2000), a compreensão do sistema precisará ampliar às suas diversas partes, relacionadas e determinadas a seguir, conforme representadas na Figura 1:

a) Tubo coletor: envolve o conjunto de canalizações propostas a receber contribuição em qualquer ponto no decorrer do seu comprimento;

b) coletor principal: coletor em que o diâmetro é superior ao mínimo estipulado para a rede;

c) coletor tronco: canalização com diâmetro maior, onde recebe somente as contribuições de vários coletores de esgoto, os transportando a um interceptor ou emissário;

d) Interceptor: canalização que ganha a contribuição dos coletores tronco e de alguns emissários;

e) Emissário: conduto final do sistema de coleta, que tem por finalidade distanciar os efluentes da rede para o local de escoamento ou de tratamento, ganhando reforços somente na extremidade do montante;

f) Sifão invertido: designa-se à transposição de obstáculo através da tubulação de esgoto, e tem seu funcionamento sob pressão; 
g) Estação elevatória: instalação estabelecida para a condução do esgoto do nível de chegada, até nível de recalque ou saída;

h) Corpo receptor: corpo de água em que são lançados os esgotos tratados;

i) Estação de tratamento: instalações apontadas para a realização da depuração dos esgotos, antes do despejo ao corpo receptor.

Figura 1 - Partes constituintes do sistema de esgoto sanitário
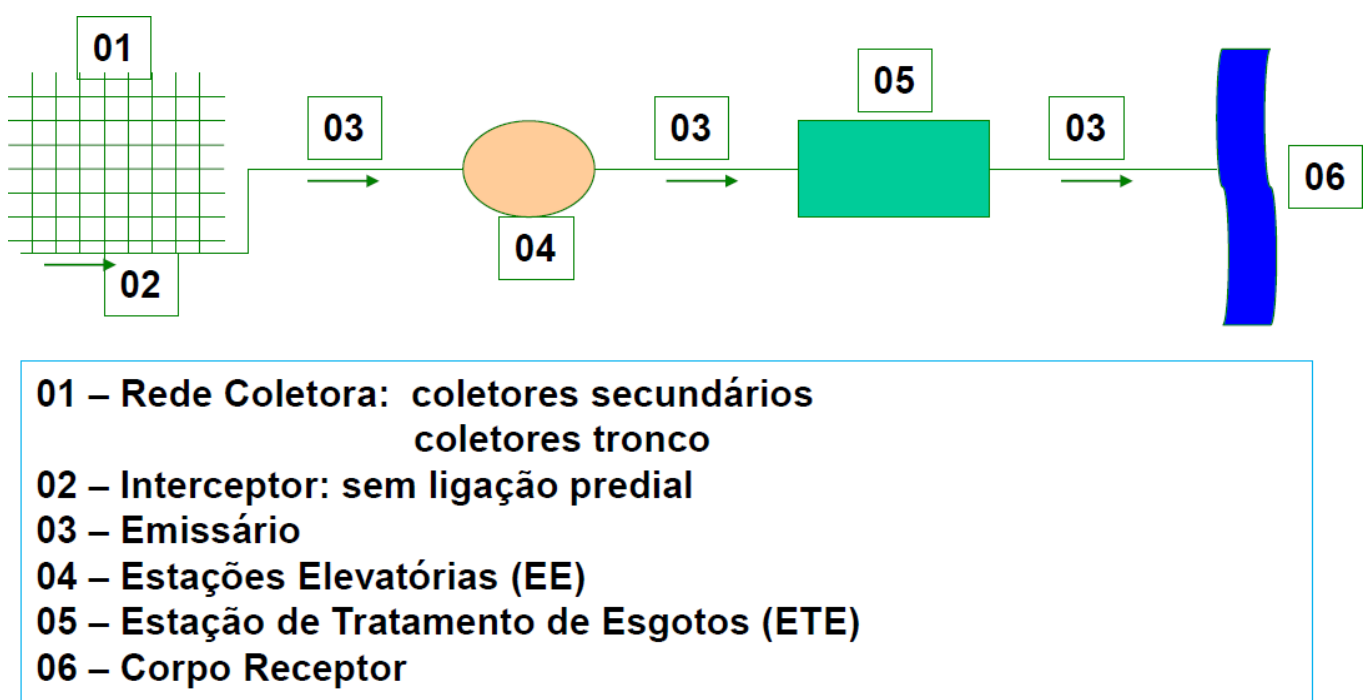

Sifão Invertido

Fonte: Knapik e Cubas (2016).

\subsection{Histórico do esgoto sanitário no Brasil}

A discussão acerca do saneamento no país, conforme falam Pereira, Souza e Silva (2010), teve início no período colonial, em meados do século XVI, tempo marcado pelo desenvolvimento da sociedade brasileira, em que a economia dependia da utilização intensiva de recursos naturais e das monoculturas do açúcar, café, borracha e pau-brasil. Neste tempo, através da miscigenação das etnias indígenas, negra e branca, em que cada povo tinha seus próprios costumes sanitários, o 
esgotamento sanitário ocorria apenas dos serviços de escravos, denominados "tigres", que eram designados a eliminar os dejetos gerados e retidos em potes das residências.

A chegada da família real, em 1808, acelerou o crescimento da população, onde aumentou em poucos anos, de 50.000 para 100.000 até 1822 . Por isso, a demanda por abastecimento de água se elevou, consequentemente provocando o acumulo de dejetos e resíduos no meio ambiente. Nessa época, as obras de saneamento eram tidas como soluções apenas individuais, sendo destinadas a drenagens de terrenos e à disposição de chafarizes em determinadas cidades (PEREIRA; SOUZA; SILVA, 2010).

Em meados do século XIX, foram feitas as primeiras interferências em favor do saneamento das cidades do Brasil, tendo em vista resolver os problemas de epidemias enfrentadas no período. Já em 1853, D. Pedro II juntamente com médicos e higienistas, começou os processos para construção de um sistema de esgotamento sanitário para o Rio de Janeiro, que na época era a capital do país. E em 1863, esta se tornou uma das únicas cidades do mundo a possuir um sistema de esgoto (REZENDE; HELLER, 2002).

Em meados dos anos 70, foi inserido o Sistema Nacional de Saneamento, juntamente ao Plano Nacional de Saneamento (PLANASA), através do Fundo de Garantia do Tempo de Serviço (FGTS) e do Banco Nacional da Habitação (BNH). O PLANASA foi a política mais categórica que foi posta em prática no país e sua implementação foi viabilizada através dos recursos do FGTS (ARRETCHE, 2004).

Conforme a ABES (2008), em conjunto com o PLANASA, foram designadas as Companhias Estaduais de Saneamento Básico (CESB). Partindo da hipótese de que as CESB seriam mais aptas a obter a universalização dos serviços de esgoto e água do que os municípios. O governo federal da época levou grande parte dos municípios a conceder às CESB, para a prestação dos serviços de saneamento como meio para garantir o ingresso aos recursos do Sistema Financeiro do Saneamento (SFS), com a intenção de que os municípios que não concordassem ao plano dificilmente conseguiriam recursos para investimento. Dessa maneira, aderir ao plano significava desistir da autonomia do município sobre os serviços de saneamento. 
Com o intuito de mudar esse panorama, em 2007 surge a Lei Nacional do Saneamento Básico 11.445/2007, que representa uma admirável ação do governo, formalizando uma nova era na área de saneamento do país. Ao entrar em vigor a lei, admitiu-se como obrigação da sociedade brasileira a universalização do saneamento básico. Ainda em 2007, com a concepção do Programa de Aceleração do Crescimento (PAC) pelo governo, procurando manter a prioridade nos investimentos em infraestrutura, abrangendo a área de saneamento.

Após o Decreto 7.217/2010, ocorreram avanços significativos no setor, onde o decreto que regulamenta a Lei 11.445/2007, institui normas nacionais para o saneamento básico, em conjunto com a Política Federal de saneamento Básico do Brasil. A lei mencionada define as competências no que diz respeito ao exercício de sua titularidade, regulação, planejamento e gestão. Desta forma dando maior autonomia aos municípios, onde estes têm o dever de elaborar de um plano de saneamento básico para a cidade. Ainda, fica a critério do município a responsabilidade de definir o monitoramento de indicadores sobre a execução e também sobre a gestão desses serviços.

\subsection{A situação do esgoto sanitário no Brasil}

No país, o desenvolvimento das ações de saneamento, conforme a história vinculou-se aos aspectos econômicos e de interesses dominantes, assim sendo, os investimentos feitos não superaram as carências sociais do país. De tal modo, os investimentos que tiveram prioridade nesse departamento foram de abastecimento de água, em detrimento de ações menos vantajosas, fragmentando a visão do saneamento, manifestando-se institucionalmente numa hipotética interação entre governos estaduais e municípios (REZENDE; HELLER, 2002).

Conforme Pereira (2003), o número significativo de municípios que não possuem coleta e tratamento de esgotos acontece pois o saneamento não é tido como prioridade, faltando dessa maneira, uma política eficaz para que sejam direcionadas ações nessa área, fazendo com que os programas de saneamento tenham caráter individual e localizando-se em municípios específicos, e algumas questões político- partidário- 
administrativas atrapalham a formulação de uma política única de implantação de infraestrutura sanitária nos municípios, prejudicando a aquisição de recursos para esses investimentos. A presença de serviços de saneamento básico nos espaços urbanas do país aumentou significativamente nas últimas décadas, como se pode observar na Tabela 1.

Tabela 1 - Abastecimento de água e coleta de esgotos no Brasil (\%)

\begin{tabular}{|l|c|c|c|c|c|c|}
\hline \multirow{2}{*}{ SERVIÇO } & \multicolumn{7}{|c|}{ ANO } \\
\cline { 2 - 7 } & $\mathbf{1 9 6 0}$ & $\mathbf{1 9 7 0}$ & $\mathbf{1 9 8 0}$ & $\mathbf{1 9 9 0}$ & $\mathbf{2 0 0 0}$ & $\mathbf{2 0 1 0}$ \\
\hline ABASTECIMENTO DE ÁGUA & $41,8 \%$ & $60,5 \%$ & $79,2 \%$ & $86,3 \%$ & $89,8 \%$ & $91,9 \%$ \\
\hline ESGOTAMENTO SANITÁRIO & $26,0 \%$ & $22,2 \%$ & $37,0 \%$ & $47,9 \%$ & $56,0 \%$ & $58,9 \%$ \\
\hline
\end{tabular}

Fonte: IBGE, Censos Demográficos 1960, 1970, 1980, 1990, 2000 e 2010.

Contudo, referente ao saneamento básico nota-se que, este desenvolvimento não está ocorrendo na maior parte das cidades brasileiras, pois o déficit que existe neste setor ainda é enorme, o que resulta em estragos ao meio ambiente e à condição de vida da humanidade. Um estudo dirigido pelo IBGE (2012), diz que em 2011, cerca de $78 \%$ das cidades brasileiras não tinham um Plano Municipal de Saneamento Básico (PMSB). Ainda, esta pesquisa relata que $60,5 \%$ dos municípios não tinham acompanhamento para às licenças referentes ao abastecimento de água, drenagem e manejo de águas pluviais urbanas e esgotamento sanitário.

No conjunto que é designado ao saneamento básico, a situação mais preocupante é a do esgotamento sanitário. Ainda, conforme o IBGE (2010), no ano de 2008 , somente $55,2 \%$ dos municípios brasileiros possuíam serviço de esgotamento 
sanitário por meio de rede coletora. Atualmente no Brasil por mais que a coleta de esgotos tenha se expandido nos últimos anos, seu tratamento ainda é ineficiente, necessitando de um aumento da rede coletora de esgoto, e um aumento considerável dos esgotos tratados, para reduzir os impactos ambientais e promover a qualidade de vida dos habitantes.

Em 2017 apenas $41,5 \%$ dos 5.570 municípios brasileiros afirmaram ter um Plano Municipal de Saneamento Básico. Já em relação a Política Municipal de Saneamento Básico esse número é ainda menor, onde apenas 38,12\% declararam ter (IBGE 2017).

Conforme apresenta a pesquisa feita pelo IBGE (2017), após o Decreto 7.217 de 21 de junho de 2010, houve um aumento na Política Municipal de Saneamento Básico. Sendo que, somente em cidades mais populosas a taxa referente a regulamentação do (PMSB) ultrapassa os $60 \%$. Por outro lado, as maiores taxas de crescimento foram registradas entre os municípios que possuem uma população relativamente baixa, até 5000 habitantes, mostrando um aumento de $72,2 \%$, onde em 2011 apenas 277 municípios tinham determinada política de saneamento, e em 2017 esse número subiu para 477 munícipios, mostrando assim uma mudança significativa em relação a esses aspectos.

\subsection{Situação do esgoto sanitário no Rio Grande do Sul}

Conforme a Pesquisa Nacional por Amostra de Domicílios - PNAD (2011), que investiga anualmente as características gerais da população brasileira no quesito da educação, trabalho, rendimento, habitação e, etc., no ano de 2011, no Estado, apenas $26 \%$ das casas tinham rede coletora de esgoto. Essa situação é ainda mais precária, pois esta estatística faz referência apenas à existência do serviço no município, e não considera a extensão da rede, o número de domicílios atendidos ou se o esgoto é tratado depois de recolhido, além da qualidade do atendimento. Segundo o Sistema de Informação da Atenção Básica - SIAB (2013), no mês de fevereiro de 2013 haviam 
no estado, ao menos 75.810 casas que destinavam o esgoto sanitário para valas a céu aberto.

Informações do Sistema Nacional de Informações sobre Saneamento - SNIS (2012), apontam que apenas $34,52 \%$ do esgoto total gerado no Estado é coletado, sendo tratado desse total coletado, somente um volume de $42,77 \%$ ao ano. Quando se trata da água consumida para essas tarefas e o esgoto sanitário produzido, o índice é ainda mais baixo, onde apenas $15,96 \%$ do volume total são tratados. Através dos dados apresentados fica evidenciado as ações a serem implementadas por órgãos públicos encarregados pelo saneamento, para poder superar o alto déficit tanto na coleta, como no tratamento de esgoto sanitário.

O principal problema em relação ao saneamento no Estado, relatado pela Fundação Estadual de Estatística do Rio Grande do Sul - FEE (2017), está relacionado com a escassez de coleta e posterior tratamento de esgoto sanitário, visto que o Estado realiza a coleta em média de $50 \%$ do esgoto gerado, porém, realiza tratamento em apenas 13\%. Nesse contexto ingressam as cidades de Canoas e Gravataí, que figuram entre os 20 piores índices comparados com municípios mais populosos do país (IBGE, 2017).

A Lei 11.445/2007 evidencia o grande desafio proposto ao Estado no sentido de universalizar os serviços de esgotamento sanitário pelo Plano Nacional de Saneamento Básico (PLANSAB), onde as metas a serem alcançadas no índice de cobertura de domicílios com rede coletora ou fossa séptica varia de $81 \%$ para o ano de 2018 até os $99 \%$ em 2033. 


\subsection{Situação do esgoto sanitário em Guaporé}

Conforme o Plano Municipal de Saneamento Básico de Guaporé - PMSB (2017), no ano de 1991, 81,6\% dos habitantes urbanos apresentavam acesso à rede de esgoto apropriada (fossa séptica ou rede geral), sendo que em 2010 esse índice subiu para $96,9 \%$.

Gráfico 1 - Percentual dos moradores urbanos com acesso a esgoto sanitário apropriado e água encanada no município de Guaporé/RS

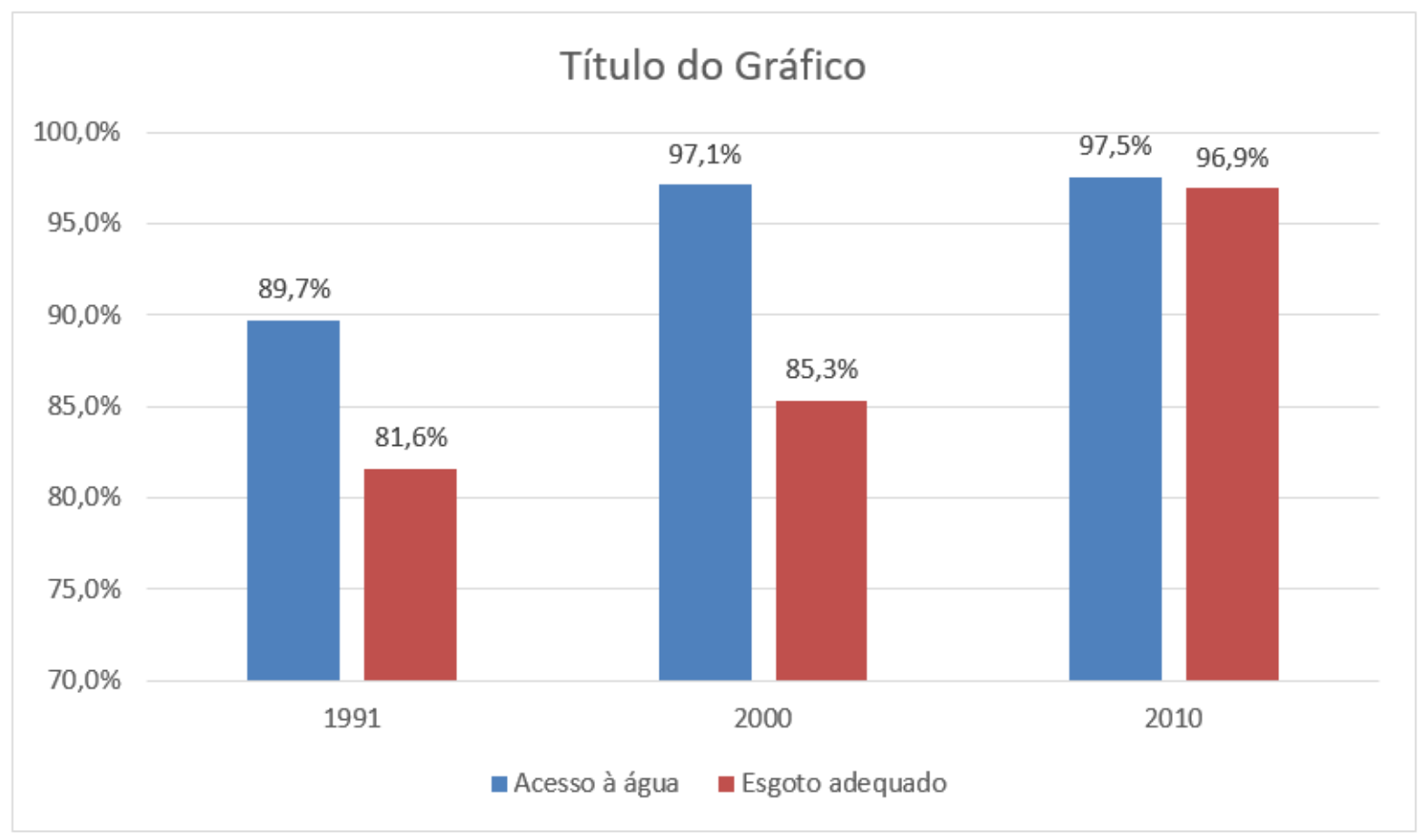

Fonte: PMSB (2017).

Segundo o IBGE (2010), 64\% dos domicílios urbanos da cidade contavam com rede geral ou pluvial de esgoto, $33 \%$ possuíam fossa séptica, e somente $2 \%$ tinham fossa rudimentar ou com o despejo em rios e lagos. Destaca-se que a rede geral se refere a rede pluvial mista e não abrange necessariamente um tipo de destinação apropriada para o esgotamento sanitário.

Conforme o PMSB (2017) destaca, a drenagem pluvial do município recebe os esgotos sanitários, ou seja, o sistema é misto. Ainda, o sistema de drenagem pluvial foi ampliado ao longo do tempo, não tendo um projeto global de dimensionamento, 
resultando em redes subdimensionadas e sem as devidas atualizações com a realidade, bem como como crescimento da cidade. Logo, o dimensionamento da rede pluvial deve considerar as vazões de esgotos mais vazão das chuvas, que não se constatou. Além disso, no estudo realizado, a vazão de esgoto que colabora para a drenagem pluvial é de aproximadamente de 5.424.000 L/dia, provocando uma sobrecarga ainda maior para as redes de microdrenagem.

Ainda conforme o PMSB (2017), identificou-se a existência de aporte de efluente industrial, tratado e não tratado, lançado diretamente na rede pluvial. Este volume não pôde ser estimado por ser uma atividade ilegal, não sendo impossível a contabilização do real acréscimo de efluentes industriais na rede de microdrenagem. Existem graves falhas na infraestrutura, conservação e manutenção, com pontos de deterioração dos materiais, e também condutos pluviais com problemas de assoreamento, lançamento de lixo e presença de resíduos. Esses fatores são agravados por conta do crescimento da cidade, dos desmatamentos para a urbanização, do aumento do grau de impermeabilização do solo, das ocupações impróprias em localidades sob influência das águas, bem como da erosão (PMSB, 2017).

De maneira geral, o sistema que existe na cidade, faz com que as águas escoem por meio de inclinações contidas nas ruas, conduzindo-as para a sarjeta, e por meio da força gravitacional, escoam pelas laterais destas vias, tomando a direção das bocas de lobo ou caixas coletoras com grades, sendo transportadas por meio de tubos subterrâneos para áreas baixas, desaguando em um curso hídrico (PMSB, 2017).

A cidade de Guaporé não possui sistema coletivo de tratamento de efluentes (esgoto). O esgotamento sanitário da cidade é do modelo individual, ou seja, efetivado em cada lote habitacional, onde conforme Von Sperling (1995), os sistemas individuais são propícios para residências unifamiliares. E hoje em dia, além do sistema individual estabelecido em cada lote habitacional, exige-se de loteamentos novos a colocação da rede coletora de esgoto, do modelo separador absoluto (rede seca), pois, até a implantação do sistema coletivo de tratamento, esta permanecerá inutilizada, feita somente como espera. 
Conforme dados do IBGE (2010), o município de Guaporé possui 7.632 domicílios, desses 6.892 domicílios estão em área urbana e 740 em área rural. Ainda, segundo o IBGE, o cenário do esgotamento sanitário de Guaporé era composto pelo que se descreve na Tabela 2.

Tabela 2 - Dados do tratamento de esgoto no município de Guaporé/RS

\begin{tabular}{|l|c|c|}
\hline \multirow{2}{*}{ Tratamento } & \multicolumn{2}{c|}{ Área Urbana e Rural } \\
\cline { 2 - 3 } & \% de domicílios & No de domicílios \\
\hline Fossa-séptica rudimentar (poço negro) & 4 & 330 \\
\hline Fossa-séptica (FS) & 37 & 2.786 \\
\hline Fossa-séptica (FS) + Filtro Anaeróbico (FA) & 0 & 0 \\
\hline Fossa-séptica (FS) + clorador & 0 & 0 \\
\hline Sem tratamento (a céu aberto em solo ou curso hídrico) & 2 & 159 \\
\hline Outro (Rede coletora mista) & 57 & 4.344 \\
\hline \multicolumn{1}{|c|}{ Total } & $\mathbf{1 0 0}$ & $\mathbf{7 . 6 1 9}$ \\
\hline
\end{tabular}

Fonte: IBGE (2010).

Guaporé não possui um sistema coletivo para tratamento de efluentes (esgoto), portanto, o único meio de tratamento que existe são os sistemas individuais, por lote habitacional, através de fossa-séptica, filtro anaeróbio e instalação em rede pluvial mista na maior parte dos casos, bem como em sumidouros, quando há possibilidade (PMSB, 2017).

\subsection{Critérios de projeto}

Para que seja possível a realização de um estudo de concepção e o dimensionamento de redes coletoras de esgoto, é necessário que haja alguns critérios de projeto a serem seguidos para direcionar os estudos e pesquisas. 


\subsubsection{Topografia}

O termo "Topografia" decorre do grego "topos" (lugar) e "graphen" (descrever), isto é, o traçado exato de um ambiente. Todo e qualquer projeto de arquitetura ou engenharia tem como fundamento a determinação do contorno, extensão e posição referente a uma porção limitada de terreno por meio de plantas ou cartas. Os sistemas de Esgotamento Sanitário são desenvolvidos através do terreno sobre o qual assentam e o qual é essencial seu conhecimento detalhado, tanto na fase do projeto, bem como na execução. A topografia é que permite esse conhecimento, através de métodos e instrumentos, assegurando a adequada implantação da obra (BORGES, 1977).

A força da gravidade é responsável para que os sistemas de redes coletoras de esgoto funcionem, assim, é de fundamental importância a realização do registro topográfico do local de projeto, mas também que na fase da construção da obra os traçados ou levantamentos de campo sejam respeitados. Os procedimentos para a efetivação de um levantamento topográfico são definidos pela NBR 13.133 (ABNT, 1996), que determina as condições exigíveis para sua execução de forma a obter:

- Noção geral do terreno: limites, relevo, localização, área, posicionamento, confrontantes e amarração;

- Dados sobre o terreno (coordenadas, cotas) para estudos preliminares de projetos;

- Dados sobre o terreno (cotas, coordenadas) para anteprojetos ou projetos básicos;

- Dados sobre o terreno (cotas, coordenadas) para projetos executivos.

Ainda, segundo Tsutiya e Sobrinho (2011), a realização do estudo do traçado, necessita da planta topográfica planialtimétrica na escala adequada, com nivelamento dos pontos em que precisam ser projetados os órgãos acessórios. 


\subsubsection{Modelos de traçado de rede coletora}

Tsutiya e Sobrinho (2000) destacam que, o esquema das redes coletoras de esgoto está fortemente unido a morfologia da área de projeto, procurando tirar proveito dos declives que existem, através dos efeitos da gravidade. Portanto, é possível ter os tipos de rede a seguir:

- Perpendicular: Esse traçado acontece quando a cidade é atravessada ou circundada por cursos d'água. Portanto, a rede de esgoto é composta de diversos coletores tronco independentes, com traço perpendicular ao fluxo d'água, e um interceptor marginal recolhe os efluentes dos coletores tronco e os encaminha ao destino apropriado (FIGURA 2).

Figura 2 - Rede coletora do tipo perpendicular

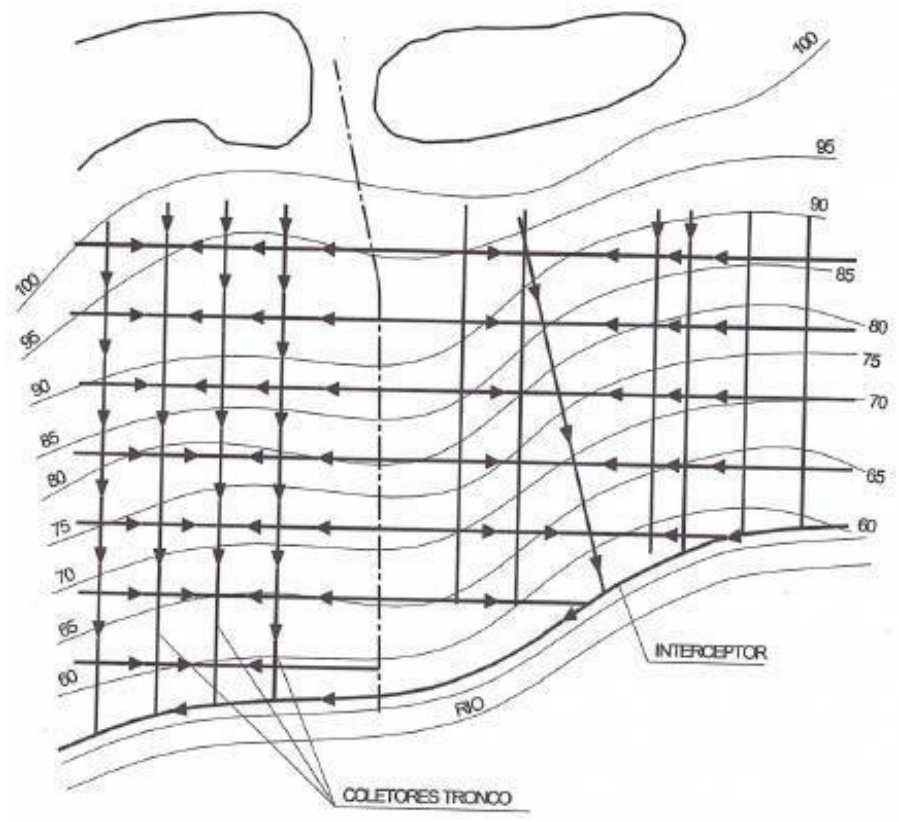

Fonte: Tsutya e Sobrinho (2011).

- Leque: O traçado leque é normalmente colocado em áreas acidentadas. Onde os coletores percorrem aos fundos dos vales ou através da parte 
baixa das bacias, recebendo os coletores secundários, dando forma a um traçado em que se assemelha a espinha de um peixe (FIGURA 3).

Figura 3 - Rede coletora do tipo leque

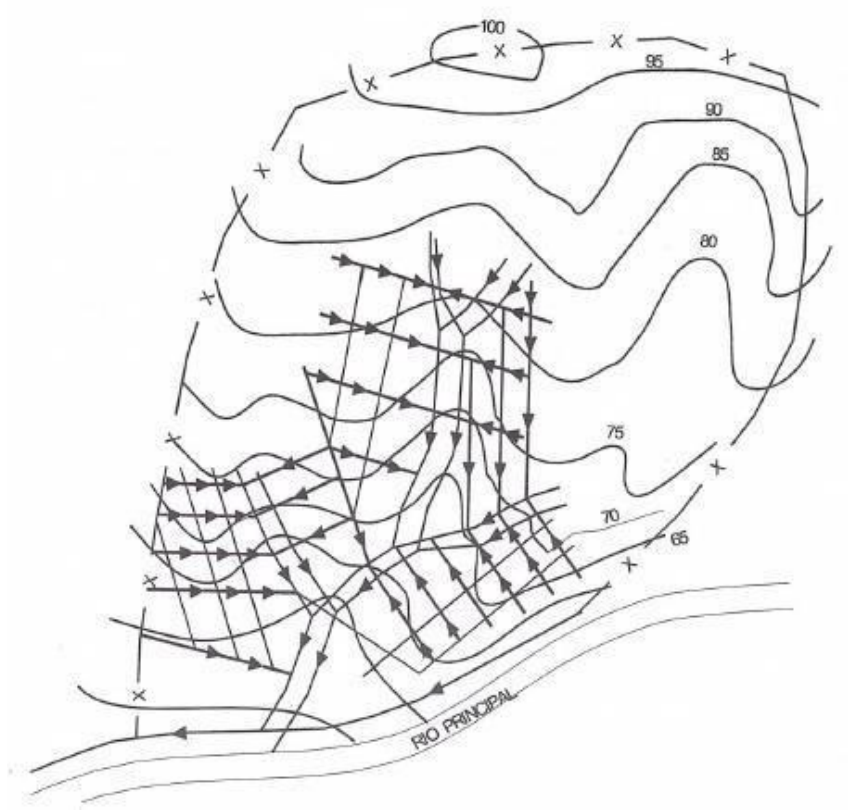

Fonte: Tsutya e Sobrinho (2011).

- Radial ou Distrital: Essa configuração de traçado é normalmente empregada em cidades com áreas planas. Sendo a área dos pontos mais baixos desmembrada em setores independentes, para onde são direcionados os esgotos a serem recalcados ao destino final (FIGURA 4). 
Figura 4 - Rede coletora do tipo radial ou distrital

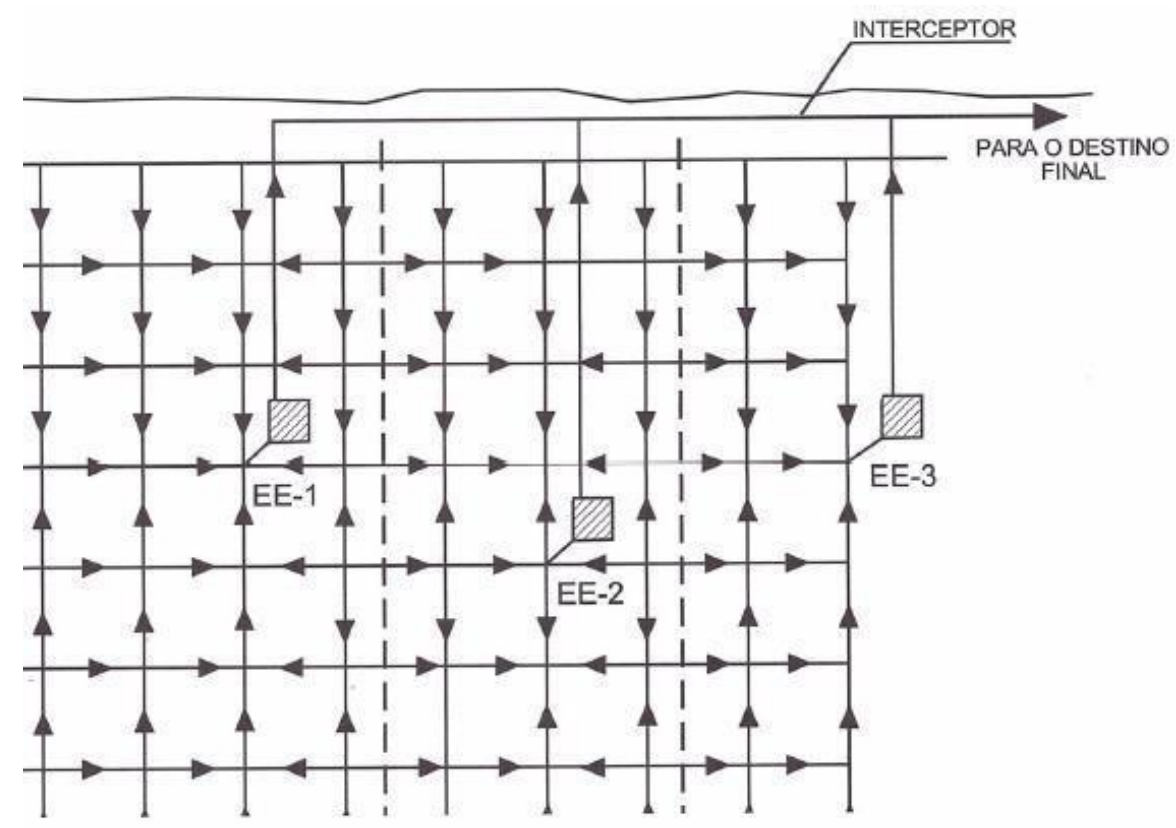

Fonte: Tsutya e Sobrinho (2011).

\subsubsection{Profundidade da rede de esgotamento}

Conforme o manual de saneamento da FUNASA (2006), a mínima profundidade da tubulação precisa permitir a recepção dos efluentes por gravidade, bem como resguardar a tubulação por conta do tráfego de veículos e demais impactos. Tsutiya e Sobrinho (2011) destacam que, a profundidade mais adequada para um sistema é a que acomoda a coleta e afastamento dos esgotos com o emprego coerente da tecnologia disponível e também de recursos financeiros.

Para determinar onde uma rede possa ser traçada é de fundamental importância o conhecimento das profundidades mínimas e máximas. Sendo necessário a realização de planos de sondagens, para a obtenção dos principais fatores em relação ao conhecimento da presença de solos de baixa resistência, rochas, nível do lençol freático e outros fatores de análise do subsolo. Fatores esses que possibilitam o estabelecimento das profundidades máximas e mínimas, alémdos serviços para orçamento e execução da obra (RECESA, 2008). 
A NBR 9649 (ABNT, 1986) estabelece que, a profundidade precisa ser determinada de maneira a permitir o escoamento do esgoto sanitário das residências ao longo das ruas que ela está assentada, e para que atenda as condições de recobrimento mínimo, de forma a proteger a tubulação. Onde o recobrimento não pode ser inferior a $0,90 \mathrm{~m}$ para coletor assentado na via de tráfego, garantindo um recobrimento mínimo, visando proteger os coletores contra cargas externas, e para aqueles assentados no passeio público seu recobrimento não deve ser inferior a 0,65 $\mathrm{m}$.

Tsutiya e Sobrinho (2000) indicam que, a profundidade máxima da tubulação comumente chega de 4,0 $\mathrm{m}$ a 4,5 m, mas a profundidade mais apropriada é de 1,5 $\mathrm{m}$ até 2,5 m. Ainda, cabe ressaltar que maiores profundidades só devem ser aceitas mediante a justificativa técnica e econômica, visto que acima de 4,0 m de profundidade é aconselhável a projeção de coletores para auxiliar nas coletas das ligações prediais.

A profundidade máxima tem relação com a economia do sistema no que diz respeito às condições de execução e realização de manutenção da rede pública e de ligações prediais, utilizando-se $4,5 \mathrm{~m}$ como valor de referência (NETTO; FERNÁNDEZ, 2015).

Alguns aspectos são levados em conta para a projeção da rede coletora, entre eles está a presença de interferências, os planos diretores de urbanização, o local em que a tubulação se encontra na via pública e a possibilidade do aproveitamento de canalizações já existem (TSUTIYA; SOBRINHO, 2011).

\subsection{Materiais das tubulações de esgoto}

Recesa (2008) fala que, hoje em dia no Brasil, o PVC (policloreto de vinila) é o material mais usados nas obras para sistemas de coleta e condução de esgoto. E para linhas de recalque, são usados tubos de aço ou ferro fundido.

É de fundamental importância fazer a avaliação de vários fatores para a escolha correta do tipo de material a ser usado para a rede de esgotos. Dentre esses fatores 
se destacam: as condições locais, as características dos esgotos, os procedimentos usados na construção (RECESA, 2008).

Conforme Tsutiya e Sobrinho (2011) no momento da seleção do material devese analisar as seguintes particularidades:

- Disponibilidade de diâmetros necessários;

- Resistência a cargas externas;

- Fácil transporte;

- Resistência à abrasão, bem como ao ataque químico;

- Custo do material;

- Custo de transporte;

- Custo de assentamento.

\subsubsection{Tubos de PVC}

A NBR 14486 (ABNT, 2000) implanta as exigências para tubos de PVC para rede coletora e ramais prediais enterrados para realizar a condução dos esgotos sanitários e escoamentos industriais, em que temperatura do fluido não exceda $40^{\circ} \mathrm{C}$.

Para Tsutiya e Sobrinho (2011), esse material é a principal opção de emprego nos tubos para coleta e transporte de esgoto, por conta da alta resistência à corrosão, diversidade de diâmetros existentes, ao seu baixo custo, ampla disponibilidade e facilidade de transporte, e a vida útil do material.

Os tubos de PVC possuem 6,0 m de comprimento e os diâmetros variam de 100 a 400 mm, sendo que há variação conforme cada fabricante (RECESA, 2008). 


\subsubsection{Tubos de ferro fundido}

Conforme Tsutiya e Sobrinho (2011), os tubos de ferro fundido são bastante usados em linhas de recalque de elevatórias. Para passagem livre são usados em travessias aéreas, passagem por rios, e se há necessidade de tubulações que aguentem cargas elevadas. Os diâmetros disponíveis para esse material são de 100, $150,200,250,300,350,400,500,600,700,800,900,1000,1100$ e 1200 mm, com extensão de $6 \mathrm{~m}$.

Recesa (2008) expõe os benefícios na utilização de tubos de ferro fundido, dentre elas:

- Resistência a altas pressões;

- Existência de distintos tipos de revestimento externo para corrosividade do solo;

- Para qualquer tipo de serventia, existe um conjunto de conexões e peças disponíveis;

- Alta resistência às cargas externas, permitindo grandes e pequenas alturas de recobrimento;

- Garantia de $100 \%$ de estanqueidade por vários fabricantes, não admitindo infiltrações ou vazamentos;

- Dependendo do efluente a ser transportado, o recobrimento interno pode ser distinto.

\subsection{Fundamentos do processo de cálculo}

Conforme Telles (2014), a rede coletora de esgoto é constituída por um conjunto de condutos conectados entre si, cobrindo as ruas do local a que serve, podendo ser nomeadas de redes simples as que são constituídas de uma canalização única por rua, ou ainda, sendo denominadas de redes duplas, as que possuem canalização distribuída uma em cada calçada, onde que em cada nó, ou ponto de 
singularidade é colocado um órgão acessório como um poço de limpeza nas cabeceiras.

Telles (2014) ainda relata que, considerando a extensão total da rede, a população para receber esgotamento de início e de fim de plano, juntamente com o consumo de água per capita, coeficiente de máxima vazão diária $\left(\mathrm{K}_{1}\right)$ e coeficiente de máxima vazão horária $\left(\mathrm{K}_{2}\right)$, e também a taxa de infiltração e o coeficiente de retorno, é possível determinar a vazão de coleta linear (I/s.m), para início e final de plano admitindo que seja uniforme no decorrer do trecho. Há uma acumulação nos trechos das cabeceiras para as pontas das vazões calculadas, alcançando seu maior valor no trecho mais próximo ao ponto final da rede. Desta maneira, tendo as vazões de início e fim de plano para cada trecho calcula-se o diâmetro, a declividade, a tensão trativa e a velocidade crítica ao longo do escoamento, onde todos esses itens terão seus conceitos abordados a seguir, e posteriormente no capítulo da metodologia, serão expostas suas equações ou parâmetros estipulados por norma.

\subsubsection{Estudo populacional}

Após ser definido o horizonte de projeto, a primeira variável a ser analisada em um Plano de Saneamento é a questão da população que será atendida pelo projeto de esgotamento sanitário num determinado período adotado. Assim, permitindo deduzir uma vazão de esgotos atual e futura, ano por ano até o fim de plano e a saturação, que destinará ao tratamento apropriado (NUVOLARI, 2011).

A atividade certamente mais difícil de um planejamento urbano, é a determinação do índice de atendimento, pois se faz necessário um estudo populacional e demográfico, na tentativa de prever o crescimento populacional de uma cidade, onde este inclui diversas incertezas, tendo em vista o grande número de variáveis que envolvem estes fatores, dificultando sua projeção de forma correta (CORSAN, 2009).

Recesa (2008) alerta para a importância de se realizar a projeção da população, baseando-se no estudo de ocupação e uso do solo, desta forma não extrapolando a 
população de projeto com áreas que por ventura não venham a ser povoadas no futuro. Para isso, são usadas projeções tendo por base de cálculos matemáticos baseados em dados populacionais pré-existentes, como dados censitários do IBGE, tomando por base dois métodos existentes para este cálculo, que são os cálculos da população por meio do método aritmético e os cálculos através do método geométrico.

\subsubsection{Consumo de água per capita (q)}

Entende-se por consumo per capita a quantidade de água consumida por uma pessoa em suas atividades rotineiras, evidenciando assim a relação do consumo de água e a contribuição para a rede de esgotos. A contribuição per capita de uma região é obtida dividindo-se o total de consumo de água por dia, pela quantidade de população servida (FUNASA, 2015).

No Brasil se utiliza o consumo per capita dos projetos para fornecimento de água como parâmetros para dimensionar os sistemas de esgotamento sanitário. Porém, deve ser considerado para o dimensionamento do sistema de esgoto o consumo de água per capita, onde não se inclui as perdas de água (TSUTIYA; SOBRINHO, 2011).

Depois de uma revisão bibliográfica, define-se valores típicos para o consumo de água "per capita" para populações com ligações domiciliares, conforme a Tabela 1 (VON SPERLING, 1995). 
Tabela 3 - Consumo per capita de água

\begin{tabular}{|l|l|l|}
\hline Porte da Comunidade & $\begin{array}{l}\text { Faixa da população } \\
\text { (habitantes) }\end{array}$ & $\begin{array}{l}\text { Consumo per capita } \\
\text { (I/hab.dia) }\end{array}$ \\
\hline Povoado rural & $<5.000$ & $90-140$ \\
\hline Vila & $5.000-10.000$ & $100-160$ \\
\hline Pequena localidade & $10.000-50.000$ & $110-180$ \\
\hline Cidade média & $50.000-250.000$ & $120-220$ \\
\hline Cidade grande & $>250.000$ & $150-300$ \\
\hline
\end{tabular}

Fonte: Von Sperling (1995).

O consumo "per capita" é um parâmetro que sofre variações dependendo de diversos fatores, como por exemplo, a quantidade de micromedição do sistema de abastecimento de água, os hábitos higiênicos e culturais da comunidade, os controles exercidos sobre o consumo, as instalações e equipamentos hidráulico-sanitários dos imóveis, a temperatura média da região, a renda familiar, entre outros. Deve-se levar em conta também, para o cálculo das demandas de sistemas de abastecimento de água, as possibilidades de crescimento econômico pelo aumento da renda das populações ou PIB per capita, pois, o aumento do consumo de água está diretamente ligado a tais crescimentos (FERREIRA E MARTINS, 2005).

\subsubsection{Coeficientes de variação de vazão (K)}

Nuvolari (2011) cita que os coeficientes de variação de vazão referem-se ao escoamento de esgoto doméstico, componente do esgoto sanitário. Sendo que a água de consumo doméstico tem comando direto do usuário, portanto, há uma variação de vazões conforme as demandas mensais, horárias e sazonais.

Von Sperling (2005) ressalta que, em questão das variações horárias das vazões de esgoto, é preciso lembrar que, em sistemas coletivos, as flutuações são amortecidas ao longo da rede coletora. Compreende-se que, quanto maior for a rede, menores as chances das vazões de pico se superporem ao mesmo tempo na entrada da estação de tratamento de esgotos (ETE). Por esta razão, em sistemas coletivos, o tempo de 
residência na rede coletora tem ampla influência no amortecimento dos picos de vazão.

Metcalf \& Eddy (1991) destacam que, para uma mesma população, a vazão de esgoto doméstico tem variação em relação as horas do dia (variações horárias), com os dias (variações diárias) e meses, sendo estimados os coeficientes (Qmáx = K1 e K2Qméd) para se obter vazões máximas, e Qmín = K3Qméd para vazões mínimas de contribuição:

a) Coeficiente do dia de maior consumo (K1) - é a relação entre o valor do consumo máximo diário de água no decorrer de um ano e o consumo médio diário de água referente a este mesmo ano;

b) Coeficiente da hora de maior consumo (K2) - coeficiente de máxima vazão horária;

c) Coeficiente de mínima vazão horária (K3).

Azevedo Netto et al. (1998), indicam que os valores usuais de K1 e K2 para projetos de sistemas públicos de abastecimento d'água são K1 variando de 1,1 a 1,4 e K2 de 1,5 a 2,3. Já a NBR 9.649 (ABNT,1986) menciona que, na ausência de valores alcançados por meio de medições, éaconselhado o uso de $\mathrm{K} 1=1,2, \mathrm{~K} 2=1,5$ e K3 = 0,5 para projeto de sistemas de esgotamento sanitário.

\subsubsection{Taxa de infiltração}

Hanai e Campos (1997) dizem que, nos sistemas de esgotamento a infiltração subterrânea ocorre quando estes estão alocados abaixo do nível do lençol freático, sobretudo se o nível é alto de maneira natural, ou por conta das excessivas precipitações pluviométricas sazonais. Tsutyia e Sobrinho (2011) mencionam que, as águas de infiltração são subterrâneas provenientes do subsolo, que penetram de maneira indesejada nas canalizações da rede coletora por diversos meios, podendo ser através das tubulações defeituosas, por juntas mal executadas, pelas estruturas 
dos poços de visita e das estações elevatórias, ou ainda, através das paredes das tubulações.

\subsubsection{Declividade mínima}

A função da declividade mínima é de assegurar o deslocamento e o transporte dos sedimentos no sentido do fluxo do esgoto, garantindo assim que não fiquem depositadas impurezas no sistema (NUVOLARI, 2014). Portanto, a declividade a ser empregada deverá proporcionar uma tensão trativa média igual ou acima de 1,0 Pa (NBR 9649 - ABNT, 1986).

Visando garantir a autolimpeza das tubulações ao menos uma vez ao dia, a partir do início do plano, a declividade mínima que atende esta regra conforme NBR 9649 (ABNT, 1986), deve considerar um coeficiente de Manning com $n=0,013$, já a CORSAN (2016), estabelece para seus projetos um coeficiente de rugosidade de $n=$ 0,010, o qual segundo a norma deve ser justificado.

\subsubsection{Lâmina d'água}

Os coletores, interceptores e emissários são projetados para trabalhar como condutos livres, em que a pressão atmosférica age na superfície hidráulica. Estabelecendo parâmetros diferentes daqueles das redes de água e linhas de recalque, em que são dimensionadas para atuar como conduto forçado, onde a pressão interna é maior que a atmosférica (NETTO; FERNÁNDEZ, 2015).

A NBR 9649 (ABNT,1986) define que os coletores sejam projetados para realizar um trabalho com lâmina d'água de no máximo $75 \%$ do diâmetro da tubulação, e a parte superior dos condutos com destino a ventilação do sistema e às imprevisões e flutuações eventuais de nível. Tsutiya e Sobrinho (2011) dizem que o escoamentoé 
admitido em regime permanente e uniforme, em que a declividade da linha de energia é igual à declividade do conduto e equivale à perda de carga unitária.

\subsubsection{Tensão trativa}

A tensão trativa é definida segundo Takahashi (1983), como sendo uma tensão tangencial que a parede do conduto sofre pelo escoamento do líquido. As tubulações são dimensionadas com o intuito de garantir que as condições de escoamento tenham um esforço tangencial mínimo entre a superfície do tubo e do líquido a ser escoado, gerando assim, uma autolimpeza da tubulação pelo menos uma vez ao dia (TSUTIYA; SOBRINHO, 2011).

A NBR 9649 (ABNT, 1986) estabelece o valor de 1,0 Pascal para a tensão trativa, para que ocorra a autolimpeza dos tubos uma vez ao dia pelo menos, sendo esta suficiente para arrastar uma partícula com 1,0 mm de diâmetro (NUVOLARI, 2014).

\subsubsection{Velocidade crítica e velocidade máxima}

Tsutiya (2000) menciona que, em caso de escoamento de esgoto, a noção da combinação água-ar é importante, especialmente quando a tubulação é disposta com grande declividade, pois dessa maneira, o grau de entrada de bolhas de ar na passagem poderá ser alto, aumentando a altura da lâmina de água. Este aumento pode alterar a forma do escoamento dentro do conduto livre, onde este poder ser 
destruído devido as pressões geradas (TSUTIYA; SOBRINHO, 2011).

\subsubsection{Controle de remanso}

Tsutiya e Sobrinho (2011) citam que, quando a cota do nível d'água na saída de algum poço de visita (PV) estiver acima das cotas dos níveis d'água de entrada, deve-se verificar a influência do remanso no trecho de montante, assegurando as condições de autolimpeza e de escoamento livre.

\subsubsection{Determinação das vazões de esgoto}

Após ser definido o caminho da rede, o alcance do plano e a estimativa das populações inicial e final deve ser determinado as vazões dos esgotos. Conforme Tsutya e Sobrinho (2011), devem ser consideradas para a determinar a vazão de esgotos, parâmetros como a contribuição per capita, a população da área de projeto, coeficientes de vazão, coeficiente de retorno, lançamento de esgotos industriais na rede coletora e águas de infiltração. 


\section{METODOLOGIA}

Será apresentado neste capítulo os métodos de cálculo e parâmetros que serão considerados para o desenvolvimento do projeto de dimensionamento da rede de esgoto sanitário, baseando-se na planilha da CORSAN, para definir a sequência dos cálculos.

Portanto, o presente trabalho será desenvolvido de maneira analítica, com dados obtidos através da planilha adaptada da CORSAN, disponível no Anexo A, com resultados de pesquisas como: estudo populacional, levantamento de bacias hidrográficas, e a planta cartográfica da região obtida através do Plano Diretor Municipal. Será realizado um levantamento das bacias de drenagem e exutórios naturais da área em estudo, levantamento altimétrico (cota e distância entre pontos) para o traçado da rede a ser proposta, utilizando como ferramenta o software AutoCAD e, por meio de planilha de cálculo (software Excel), serão dimensionados os trechos de rede para a Micro Bacia do Arroio Barracão.

\subsection{Características da área de estudo}

O município de Guaporé situa-se na encosta superior do nordeste do Rio Grande do Sul, destacado na Figura 5 na cor vermelha, e está localizado na Serra Geral, possuindo um relevo bastante acidentado em uma área de 297,659 km², com uma altitude máxima de 769 m e mínima de 200 m em relação ao nível do mar, 
estando a uma distância de $210 \mathrm{~km}$ de Porto alegre, capital do estado, onde seu principal acesso é feito pela RS 129.

Figura 5 - Mapa da localização do município de Guaporé no Rio Grande do Sul.

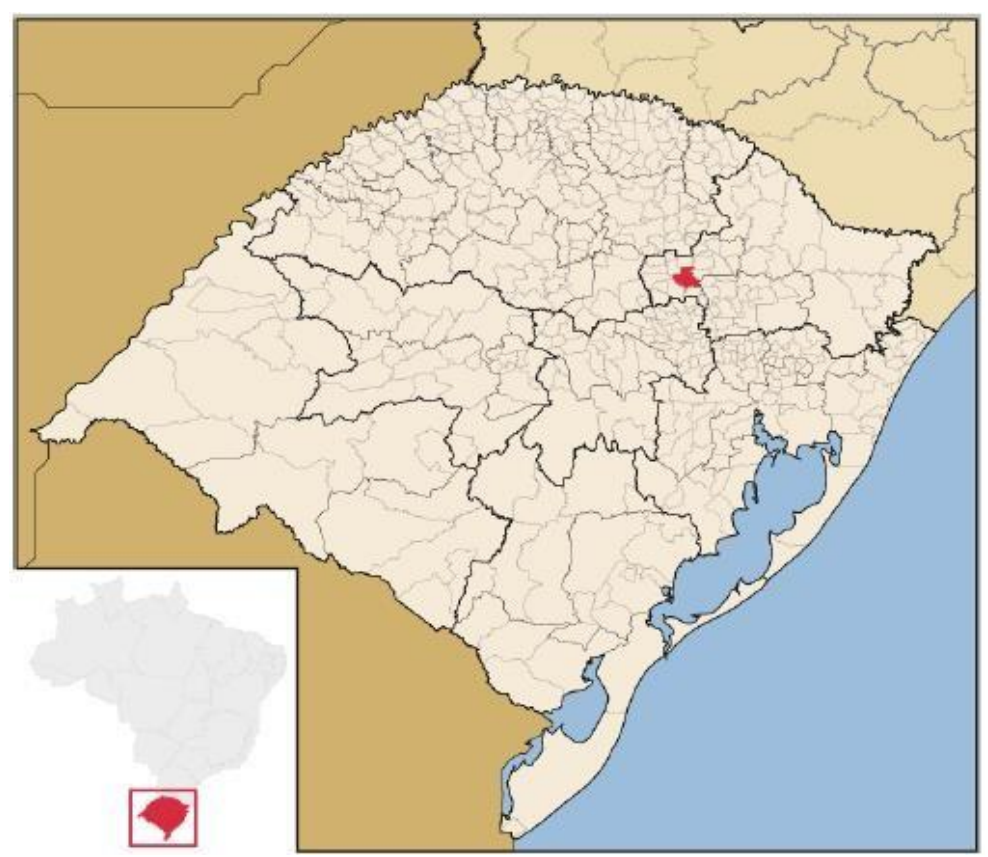

Fonte: PMSB (2017).

Em questão do regime climático, pode-se afirmar que os sistemas polares são os maiores dinamizadores do clima do estado, em conjunto com os sistemas tropicais. Contudo, por meio da relação destes com os fatores geográficos locais e regionais, é determinado a variabilidade dos elementos climáticos. A gênese das chuvas está ligada aos sistemas frontais.

\subsection{Limites territoriais}

Situado no Planalto Meridional, a cidade de Guaporé limita-se ao Norte, com Serafina Corrêa, Nova Bassano e União da Serra; ao Sul, com Dois Lajeados e Anta 
Gorda; a Leste, com Vista Alegre do Prata e Fagundes Varela; e a Oeste com Arvorezinha, como visualiza-se na Figura 6.

Figura 6 - Limites territoriais do município de Guaporé/RS

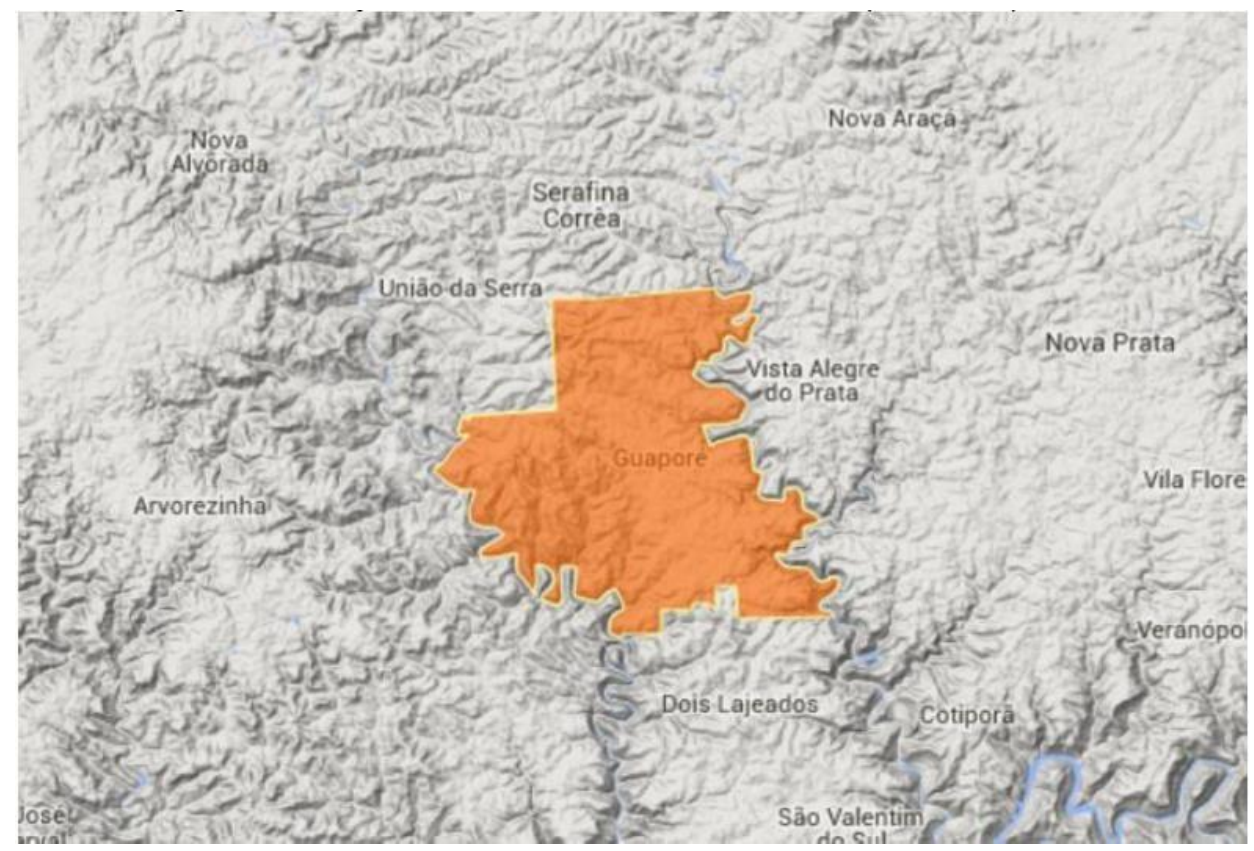

Fonte: PMSB (2017).

\subsection{Bacias e sub bacias de contribuição}

No Rio Grande do Sul, a bacia hidrográfica Taquari-Antas está situada na região nordeste, contendo uma área de $26.428 \mathrm{~km}^{2}$, contemplando 98 municípios, abrangendo de maneira total ou parcial, tornando-se assim, a segunda maior do Estado.

Guaporé pertence a Bacia Hidrográfica do Taquari-Antas, e as sub bacias do Rio Carreiro e Rio Guaporé, localizada na região nordeste do Rio Grande do Sul, nas coordenadas $-28^{\circ} 10^{\prime} \mathrm{S}$ e $-29^{\circ} 57^{\prime} \mathrm{S}$; $-49^{\circ} 56^{\prime} \mathrm{W}$ e $-52^{\circ} 38^{\prime} \mathrm{W}$,

Para a realização do presente trabalho, foram obtidas as delimitações das subbacias hidrografias presentes no município de Guaporé, conforme Figura 7: 
Figura 7 - Mapa de localização das microbacias área urbana do município de Guaporé/RS

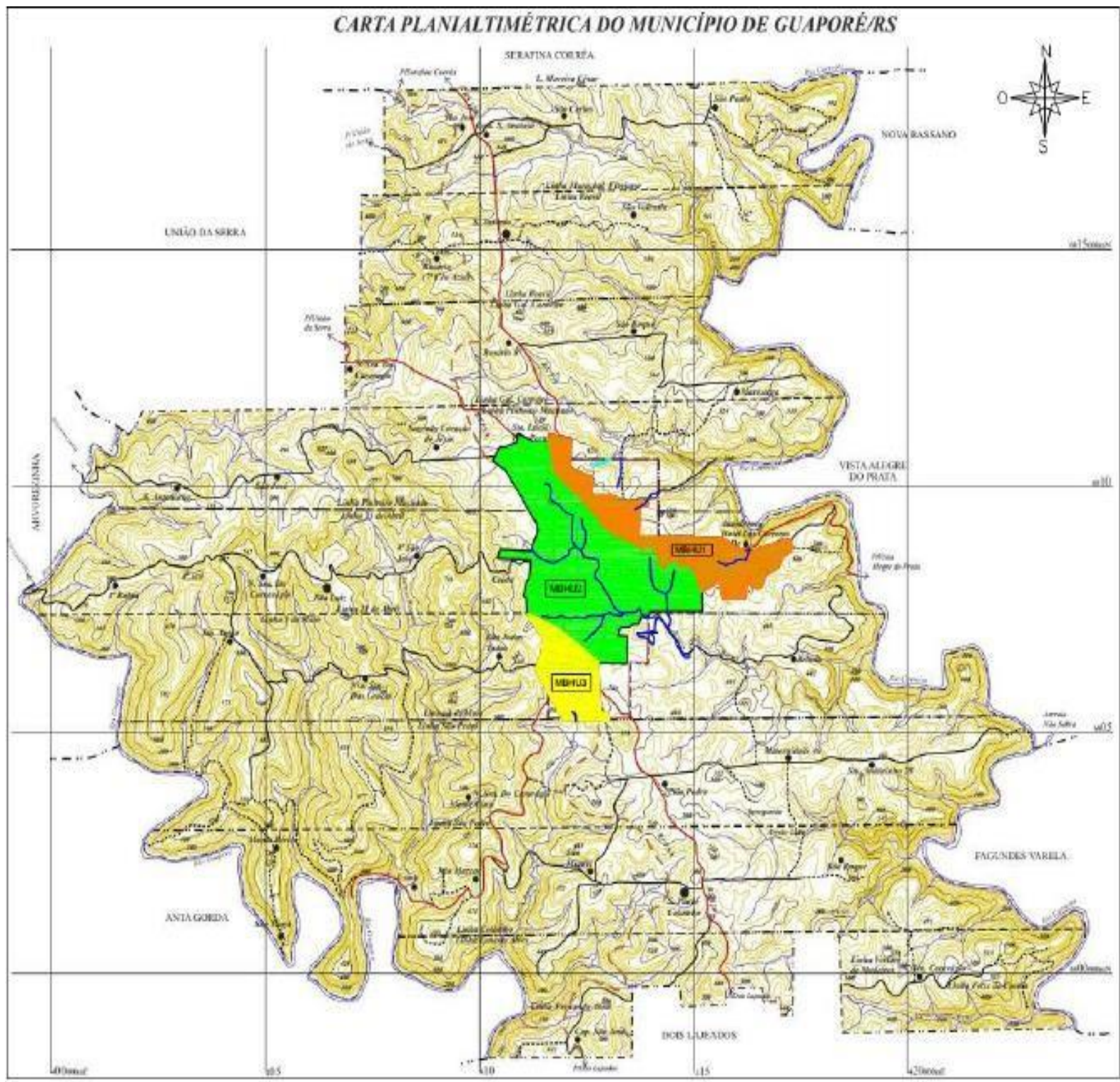

MBHU1 - Microbacia Hidrográfica do Rio Carreiro - veias do Avroio Taquara

MBH2 - Microbacia Hidrografica do Amcio Barracho

MBH3 - Microbacia Hidrográíca do Arrcio Berto

Fonte: PMSB (2017).

Verifica-se no mapa (Figura 7) a existência de três microbacias, em que a MBHU1 possui nascentes correndo da parte urbana para a parte rural da cidade, confluindo com o Rio Carreiro, de grande importância para a região; a MBH2 tendo como recurso hídrico o Arroio Barracão, o qual tem as suas nascentes situadas na zona rural do município, recebendo aporte de água na zona urbana proveniente de 
pequenas veias de água de afloramentos e que será o foco deste estudo; e a MBH3 tem nascentes de água que correm para o Arroio Bento, na área rural do município.

A zona urbana do município localiza-se dentro da microbacia do Arroio Barracão, local que é destinado para o crescimento urbano, disposição e tratamento de resíduos, bem como outras atividades licenciadas em que se enquadram com potencial poluidor elevado e degradação ambiental.

O município localiza-se entre duas sub bacias, com divisor de águas pela estrada - RS 129 e pela via férrea. A leste, a bacia do Rio Carreiro, abrange sete sub bacias, e na parte oeste, a bacia do Rio Guaporé envolve outras 6 sub bacias.

O rio Carreiro está localizado a leste do munícipio fazendo divisa com Vista Alegre do Prata e Fagundes Varela, o qual recebe efluentes originários da zona urbana de Guaporé. Este rio possui vários afluentes, como os arroios Brasil Duvidoso, Taquara, Leão, Trajano e Barracão, sendo que os arroios Barracão e Taquara cortam a zona urbana do município.

Sobre a sub bacia Rio Guaporé, esta limita-se com Arvorezinha e Anta Gorda, onde seus principais afluentes são os, arroios Barraca, Bento, Bíscaro e Tacangava.

\subsection{Delimitação da área de estudo}

O arroio Barracão surge na Linha 5a Pinheiro Machado, Capela São Judas, e seu percurso é de $3 \mathrm{~km}$ por dentro da cidade, do centro até o cemitério tendo distância de $2 \mathrm{Km}$ e, do cemitério chegando até o Carreiro possuindo $8 \mathrm{Km}$ de extensão. Em 1962, este arroio teve um trecho de sua distribuição canalizada na área urbana.

Nesta microbacia encontra-se quase toda sede urbana e população da cidade, portanto, o local fica preestabelecido para ocupação e eventual crescimento urbano, tendo em vista a topografia propícia para tanto.

Entende-se que para a definir as microbacias hidrográficas, é necessário ter por base as curvas de nível, considerando os divisores de águas, como é possível observar na Figura 8. 
Figura 8 - Microbacias da área urbana do município de Guaporé/RS.

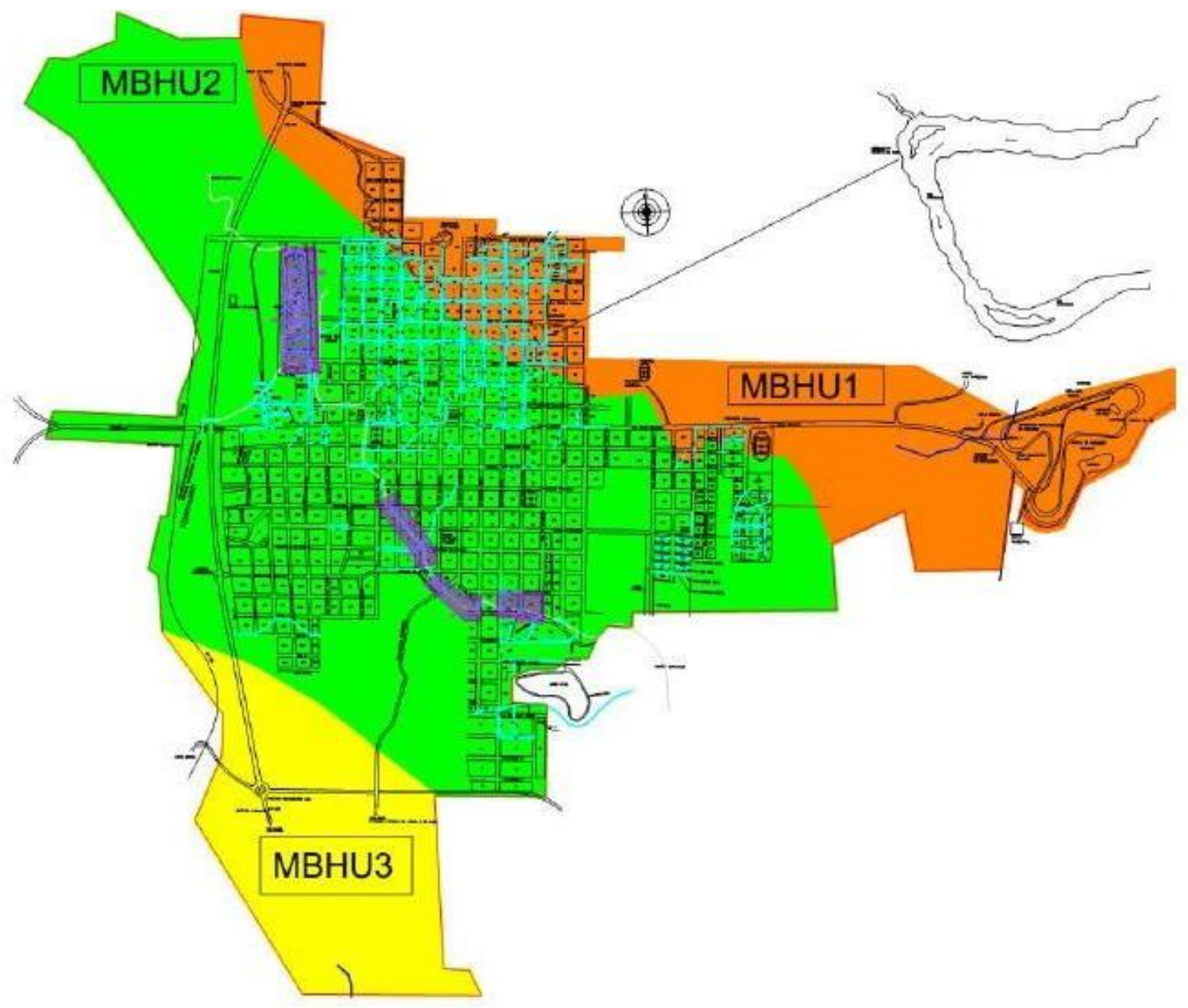

Microbacia Hidrográfica do Rio Carreiro

MBHU1 - Microbacia Hidrográfica do Rio Carreiro

MBHU2 - Microbacia Hidrográfica do Arroio Barracăo

MBHU3 - Microbacia Hidrográfica do Arroio Bento

Fonte: PMSB (2017). 
Portanto, o presente estudo terá foco na área delimitada em verde e nomeada MBHU2, pois é a área com maior densidade populacional do município e com maior índice de poluição.

\subsection{Cálculo da população através do método aritmético}

Essa metodologia é aplicada para estimativas de curto prazo e considera que a população apresente uma taxa de crescimento linear para os anos seguintes, por meio de dados conhecidos (VON SPERLING, 2005). Sendo calculado o incremento populacional nesse período, pela equação 01 :

$$
K_{a}=\frac{P_{1}-P_{0}}{t_{1}-t_{0}}
$$

Onde:

$\mathrm{K}_{\mathrm{a}}-\mathrm{Taxa}$ constante;

P - População futura (habitantes);

$P_{1}$ - População no último censo (habitantes);

$\mathrm{P}_{0}$ - População no penúltimo censo (habitantes);

$\mathrm{t}_{1}$ - Ano do último censo;

to - Ano do penúltimo censo.

Com a determinação da taxa constante é possível realizar a projeção da população futura. Através da equação 2 : 
$P=P_{0}+K_{a} \cdot\left(t_{1}-t_{0}\right)$

Onde:

$\mathrm{K}_{\mathrm{a}}-\mathrm{Taxa}$ constante;

P - População futura (habitantes);

$P_{1}-$ População no último censo (habitantes);

Po - População no penúltimo censo (habitantes);

$t_{1}-$ Ano do último censo;

to-Ano do penúltimo censo.

\subsection{Cálculo da população por meio do método geométrico}

Este método é utilizado para estimativas de curto prazo, em que a taxa de crescimento da população é proporcional com à população que existe num determinado período (VON SPERLING, 2005). Podendo ser representada pela equação 3:

$$
\mathrm{K}_{\mathrm{g}}=\frac{\ln \mathrm{P}_{1-} \operatorname{InP_{0}}}{\mathrm{t}_{1}-\mathrm{t}_{0}}
$$

A partir da determinação da taxa de crescimento se estima a população futura. A qual é obtida pela equação 4: 
$P=P_{0} \cdot e^{K_{g}\left(t_{1}-t_{0}\right)}$

Onde:

$\mathrm{K}_{\mathrm{g}}-\mathrm{Taxa}$ constante;

P - População futura (habitantes);

$P_{1}-$ População no último censo (habitantes);

Po - População no penúltimo censo (habitantes);

$\mathrm{t}_{1}$ - Ano do último censo;

to-Ano do penúltimo censo.

\subsection{Estimativa de consumo de água per capita (q)}

De acordo com o manual de saneamento da FUNASA (2015), o valor de consumo de água per capita pode variar conforme o tamanho da população e o porte da comunidade. Essa relação pode ser verificada abaixo:

- População final até 6.000 habitantes: de 100 a 150 L/hab./dia;

- População final até de 6.000 até 30.000 habitantes: de 150 a 200 L/hab./dia;

- População final de 30.000 até 100.000 habitantes: de 200 a 250 L/hab./dia;

- População final acima de 100.000 habitantes: de 250 a 300 L/hab./dia. 


\subsection{Coeficiente de retorno (C)}

Determinado pela NBR 9649 (ABNT, 1986), o coeficiente de retorno é a relação média entre os volumes de esgoto gerado e de água consumida. Recomenda-se um valor de 0,8 para o coeficiente de retorno.

\subsection{Determinação dos coeficientes de variação de vazão (K)}

Os coeficientes de variação de vazão são definidos pela NBR 9649 (ABNT, 1986), onde o coeficiente de máxima vazão diária $\left(K_{1}\right)$, corresponde ao dia que de maior consumo teoricamente, apontando um valor de 1,20. Para o coeficiente de máxima vazão horária $\left(K_{2}\right)$ a mesma norma estipula um valor de 1,50 , sendo que este é o fator mais significativo a se considerar, pois refere-se à hora do dia que tenha o máximo consumo. Por fim, o coeficiente de mínima vazão horária $\left(K_{3}\right)$ que relaciona a vazão mínima com a média anual, tendo um valor recomendado de 0,5.

\subsection{Vazões de dimensionamento}

Para realizar o dimensionamento de uma rede coletora é necessário a realização do cálculo das vazões de início e fim de plano, onde a capacidade que o coletor precisa atender é determinada pela vazão máxima de final de plano. E a vazão máxima horária em um dia qualquer (não se faz referência ao dia com maior consumo) do início de plano é usada para averiguar se as condições de autolimpeza do coletor são satisfatórias (TSUTIYA; SOBRINHO, 2011). 
a) Vazão de início de plano

Determina-se essa vazão através da equação 5:

$Q_{i}=Q_{d, i}+Q_{i n f, i}+Q_{c, i}$

Onde:

$Q_{i}$ - Vazão de esgoto sanitário inicial (L/s);

Qd,i- Vazão doméstica de início de plano (L/s);

Qinf,i- Vazão de infiltração de início de plano (L/s).

Qc,i- Vazão concentrada de início de plano (L/s).

- Sendo a vazão doméstica de início de plano calculada conforme a equação 6:

$Q_{d, i}=\frac{P_{i} \cdot q_{i} \cdot C \cdot K_{2}}{86400}$

Onde:

Qd,i- Vazão doméstica inicial de plano (L/s);

$P_{i}-$ População inicial (habitantes);

qi- Consumo de água per capita inicial (L/hab.d);

C - Coeficiente de retorno;

$K_{2}$ - Coeficiente de máxima vazão horária. 
b) Vazão de final de plano

Essa vazão é definida pela equação 7:

$Q_{f}=Q_{d, f}+Q_{i n f, f}+Q_{c, f}$

Onde:

Qf - Vazão de esgoto sanitário final (L/s);

Qd,f - Vazão doméstica de final de plano (L/s);

Qinf,f - Vazão de infiltração de final de plano (L/s);

$Q_{c, f}-$ Vazão concentrada de final de plano (L/s).

- A vazão doméstica de final de plano é obtida através da equação 8:

$$
Q_{d, f}=\frac{P_{f} \cdot q_{e, f} \cdot c \cdot K_{1} \cdot K_{2}}{86400}
$$

Onde:

$Q_{\mathrm{d}, \mathrm{f}}-$ Vazão doméstica final de plano (L/s);

$P_{f}-$ População final (habitantes);

q - Consumo de água per capita final (L/hab./d);

C - Coeficiente de retorno;

$\mathrm{K}_{1}$ - Coeficiente de máxima vazão diária; 
$\mathrm{K}_{2}$ - Coeficiente de máxima vazão horária.

\subsection{Taxa de infiltração}

A NBR 9649 (ABNT, 1986), adverte para a utilização de 0,05 a 1,0 L/s.km de taxa de infiltração para redes coletoras de esgotos. De acordo com as diretrizes de projeto da CORSAN (2016), a companhia aplica para seus dimensionamentos de projetos a taxa de infiltração mínima que é de $0,05 \mathrm{~L} / \mathrm{s} . \mathrm{km}$. Sendo justificada conforme condições locais como: caracterização do subsolo, altura do nível de água do lençol freático, tipo de junta utilizada, tipo de material da tubulação, utilizada e a qualidade da execução da rede.

\subsection{Taxa de contribuição linear}

a) Taxa de contribuição linear para o início do projeto

Para definir essa taxa, deve-se considerar a taxa de infiltração, como mostra a equação 9:

$$
t_{i}=\frac{Q_{d, i}}{\Sigma_{L}}+t_{i n f}
$$

Onde:

$t_{i}$ - Taxa de contribuição inicial de projeto (L/s.m);

$Q_{d, i}-$ Vazão doméstica inicial de plano (L/s);

$\Sigma\llcorner-$ Comprimento total da rede coletora $(m)$; 
tinf - Taxa de contribuição (L/s.m).

b) Taxa de contribuição linear para final de projeto

A taxa de contribuição linear de final de projeto, também deve ser calculada levando em conta a taxa de infiltração, como na equação 10:

$$
t_{f}=\frac{Q_{d, f}}{\Sigma_{L}}+t_{i n f}
$$

Onde:

$t_{f}-$ Taxa de contribuição final de projeto (L/s.m);

$Q_{d, f}-$ Vazão doméstica final de plano (L/s);

$\Sigma_{L}-$ Comprimento total da rede coletora $(m) ;$

tinf - Taxa de contribuição (L/s.m).

\subsection{Determinação das vazões mínimas por trechos de rede}

Nos casos em que inexistir dados pesquisados, comprovados com devida procedência a NBR 9649 (ABNT,1986), recomenda o uso da vazão mínima de 1,5 L/s para cada trecho. 


\subsection{Diâmetro mínimo}

A NBR 9649 (ABNT,1986) sugere que as redes de esgotos não devem possuir diâmetros inferiores a DN 100 mm, contudo a CORSAN utiliza em suas redes tubos de PVC com diâmetro mínimo de DN 150 mm.

\subsection{Declividade mínima}

Por determinação da NBR 9649 (ABNT, 1986) a declividade mínima para um coeficiente de Manning $n=0,013$, é calculada conforme a equação 11 :

$$
I_{\min }=0,0055 \cdot Q_{i}^{-0,47}
$$

Onde:

$$
\begin{aligned}
& \text { Imin - Declividade mínima }(\mathrm{m} / \mathrm{m}) \text {; } \\
& Q_{i} \text { - Vazão inicial (L/s). }
\end{aligned}
$$

Já com coeficiente de Manning $n=0,010$ para PVC a declividade mínima é determinada através da equação 12:

$$
I_{\min }=0,006122 \cdot Q_{i}^{-\left(\frac{6}{13}\right)}
$$


Em que:

$I_{\min }$ - Declividade mínima $(\mathrm{m} / \mathrm{m})$;

$Q_{i}-$ Vazão inicial (L/s).

\subsection{Declividade máxima}

Tsutiya e Sobrinho (2011) destacam que, a declividade máxima admissível é aquela que tenha uma velocidade final igual a 5,0 m/s para a vazão final de plano, podendo ser calculada pela equação 13:

$$
I_{\max }=4,65 \cdot Q_{f}^{-0,67}
$$

Em que:

Imax - Declividade máxima $(\mathrm{m} / \mathrm{m})$; 
Qf - Vazão de jusante do trecho no final do plano (L/s).

\subsection{Lâmina d'água}

Os diâmetros que acatam o resultado $Y / D=0,75$, são calculados através das equações 14 e 15, respectivamente para tubos ferro fundido e PVC, onde seus coeficientes podem ser obtidos no Anexo B e Anexo C.

$$
\begin{aligned}
& D=\left(0,0463 \cdot \frac{Q^{f}}{\sqrt{1}}\right)^{0,375} \\
& D=\left(0,0283 \cdot \frac{Q f}{\sqrt{1}}\right)^{0,375}
\end{aligned}
$$

Onde:

$$
\begin{aligned}
& \text { D - Diâmetro }(\mathrm{m}) \\
& \mathrm{Q}_{\mathrm{f}} \text { - Vazão no final de plano }(\mathrm{L} / \mathrm{s}) ; \\
& \text { I - Declividade }(\mathrm{m} / \mathrm{m}) \text {. }
\end{aligned}
$$

Não se limita a lâmina d'água mínima, por conta do critério de tensão trativa assegurar a autolimpeza nas tubulações de esgoto (TSUTIYA; SOBRINHO, 2011). 


\subsection{Verificação de tubulações}

Em 1981 o engenheiro irlandês R. Manning elaborou a fórmula mais conhecida até hoje para dimensionamento de condutos livres, onde os sistemas devem considerar que os dutos são canais circulares e condutos livres. A fórmula de Manning para as seções de tubulações é calculada através da equação 16:

$V=\frac{1}{n} \cdot R_{H}^{2 / 3} \cdot I^{1 / 2}$

Sendo:

V - Velocidade média na seção $(\mathrm{m} / \mathrm{s})$;

$\mathrm{n}$ - Coeficiente de Manning;

$\mathrm{R}_{H}$ - Raio hidráulico $(\mathrm{m})$;

I - Declividade (m/m).

\subsection{Determinação do raio hidráulico em função de Y/D}

Após encontrar o valor da lâmina líquida, passa-se para a Tabela 4, a qual auxilia para a determinação do raio hidráulico em função de Y/D. 
Tabela 4 - Raio hidráulico Y/D

\begin{tabular}{|c|c|}
\hline Y/D & Beta $=$ RH/D \\
\hline 0,025 & 0,016 \\
\hline 0,050 & 0,033 \\
\hline 0,075 & 0,048 \\
\hline 0,100 & 0,064 \\
\hline 0,125 & 0,079 \\
\hline 0,150 & 0,093 \\
\hline 0,175 & 0,107 \\
\hline 0,200 & 0,121 \\
\hline 0,0225 & 0,134 \\
\hline 0,250 & 0,147 \\
\hline 0,300 & 0,171 \\
\hline 0,350 & 0,194 \\
\hline 0,400 & 0,215 \\
\hline 0,450 & 0,234 \\
\hline 0,500 & 0,250 \\
\hline 0,550 & 0,265 \\
\hline 0,600 & 0,278 \\
\hline 0,650 & 0,288 \\
\hline 0,700 & 0,297 \\
\hline 0,750 & 0,302 \\
\hline 0,775 & 0,304 \\
\hline 0,800 & 0,304 \\
\hline 0,825 & 0,304 \\
\hline 0,850 & 0,304 \\
\hline 0,875 & 0,301 \\
\hline 0,900 & 0,299 \\
\hline 0,925 & 0,294 \\
\hline 0,950 & 0,287 \\
\hline 0,975 & 0,277 \\
\hline 1,000 & 0,250 \\
\hline
\end{tabular}

Fonte: Tsutiya e Sobrinho (2000).

\subsection{Raio hidráulico}

O raio hidráulico é determinado pela relação entre a área molhada e o perímetro molhado. Sendo determinado pela equação 17:

$$
\mathrm{R}_{\mathrm{H}}=\frac{\mathrm{A}}{\mathrm{P}}
$$


Em que:

Rh - Raio Hidráulico;

A - Área molhada $\left(\mathrm{m}^{2}\right)$;

P - Perímetro molhado (m).

\subsection{Tensão trativa}

A tensão trativa pode ser definida pela equação 18:

$\sigma_{\mathrm{t}}=\mathrm{y} \cdot \mathrm{R}_{\mathrm{H}} \cdot \mathrm{I}$

Em que:

$\sigma_{\mathrm{t}}-$ Tensão trativa $\left(\mathrm{kgf} / \mathrm{m}^{2}\right)$;

$\gamma$ - Peso específico $\left(\mathrm{kgf} / \mathrm{m}^{3}\right)$;

$R_{H}$ - Raio hidráulico (m);

I - Declividade $(\mathrm{m} / \mathrm{m})$.

\subsection{Velocidade crítica e velocidade máxima}

Calcula-se a velocidade crítica de cada trecho e compara-se com sua velocidade final. Seguindo critérios estabelecidos pela NBR 9649 (ABNT,1986), se a velocidade final apurada no alcance do projeto, for maior que a velocidade crítica, a lâmina d'água deve ocupar somente $50 \%$ do diâmetro do coletor. Esta medida é 
adotada em consequência da probabilidade da emulsão de ar no líquido que aumenta a área molhada no conduto. Mas, é necessário ressaltar que a norma indica que a declividade máxima aceitável é a correspondente à velocidade final de $5,0 \mathrm{~m} / \mathrm{s}$. (ABNT, 1986). Portanto calcula-se conforme a equação 19:

$$
\mathrm{V}_{\mathrm{C}}=6 \cdot \sqrt{\mathrm{g} \cdot \mathrm{R}_{\mathrm{H}}}
$$

$$
\begin{aligned}
& \text { Em que: } \\
& \text { g - Aceleração da gravidade }\left(\mathrm{m} / \mathrm{s}^{2}\right) \\
& \text { Rh - Raio Hidráulico para a vazão final }(\mathrm{m}) \text {. }
\end{aligned}
$$

\subsection{Controle de remanso}

Verifica-se a influência do remanso no trecho de montante através da equação 20:

$$
\mathrm{H}=\mathrm{hj}-\mathrm{hm}
$$

Sendo:

H - Desnível entre a lâmina da tubulação de entrada mais baixa e a tubulação de saída;

hj - Cota da lâmina d'água da tubulação de entrada mais baixa no PV. hm - Cota da lâmina d'água da tubulação de saída do PV. 


\subsection{Estações de tratamento de esgoto}

São um conjunto de técnicas associadas às unidades de tratamento, com a finalidade de remover os poluentes dos esgotos, os quais podem causar uma deterioração da qualidade dos corpos d'água. Nas estações de tratamento, são realizadas operações e processos que promovem a separação dos poluentes em suspensão e a água a ser despejada no corpo receptor, fazendo o condicionamento dos resíduos retidos (BARATTA, 2004).

\subsection{Estimativa de custo da rede coletora de esgoto}

O grau de urbanização é um fator que pode influenciar diretamente nos custos das redes, podendo encontrar interferências, como: redes de drenagem, redes de distribuição de água, redes telefônicas e elétrica e travessias (de rodovias, ferrovias e córregos) entre outros casos particulares, além dos custos adicionais de recomposição de calçadas e asfalto. Outro fator é o tipo do solo em que as redes serão inseridas, onde para cada solo existem diferentes tecnologias de execução, influenciando diretamente nos custos (PACHECO, 2011).

Conforme estipulado por Pacheco (2011), para implantação de uma rede coletora de esgoto em casos onde o solo é desfavorável e existe uma alta urbanização, seu custo ao metro linear é de $R \$ 307,03$ para rede com tubulação de diâmetro 150 mm e para diâmetro de 200 mm é de $\mathrm{R} \$ 336,39$. 


\section{RESULTADOS EDISCUSÕES}

Neste capítulo se dará a realização de todo o processo de cálculos e resultados do traçado da rede coletora de esgoto na bacia do Arroio Barracão, este traçado disponível no Anexo D, que foi projetado para a área central da cidade de GuaporéRS, a planilha com todos os cálculos pode ser verificada no Anexo E. Para delimitar a área de estudo e projeto foi realizada a análise populacional por bairro, bem como as curvas de níveis da cidade, tudo isso para que o projeto seja viável técnica e economicamente. $O$ dimensionamento da rede coletora precisa atender a vazão inicial e final de projeto, em que seu sistema de coleta será do tipo separador absoluto, orientado em função das condições de escoamento por gravidade.

\subsection{Estatísticas censitárias}

No estudo, foi utilizado a tabela que disponibiliza o crescimento populacional por bairro nos anos de 2000 e de 2010, disponível nos dados Censitários do IBGE, estando estes dispostos na Tabela 5, e por meio de uma análise da densidade demográfica realizou-se a delimitação da área em que a rede de esgoto iráabranger, consequentemente esta área coincidiu com o bairro centro da cidade. Este bairro foi escolhido por possuir a maior população da cidade, e por conta de que a execução de um sistema de coletor absoluto normalmente se limita a locais com mais população. 
Tabela 5 - Dados censitários por bairros para Guaporé/RS

\begin{tabular}{c|c|c}
\hline Bairro & $\mathbf{2 0 0 0}$ & $\mathbf{2 0 1 0}$ \\
\hline Canecão & 724 & 907 \\
\hline Centro & 3332 & 3757 \\
\hline Ferroviário & 178 & 1704 \\
\hline Imaculada Conceição & 1442 & 1419 \\
\hline Nossa Senhora da Paz & 1295 & 1556 \\
\hline Nossa Senhora da Saúde & 1315 & 2009 \\
\hline Pinheirinho & 1682 & 2933 \\
\hline Planalto & 2471 & 3027 \\
\hline São Cristóvão & 2214 & 1349 \\
\hline São José & 1257 & 1700 \\
\hline Santo André & 1542 & 20.614
\end{tabular}

Fonte: IBGE - Censo Demográfico, 2000, 2010.

Através destes dados censitários foi possível realizar a projeção populacional da área central de Guaporé para 20 anos, por meio dos métodos aritmético e geométrico. O método aritmético, com projeção de 4.990 habitantes e o geométrico com 5.322 habitantes. Portanto, o estudo de concepção realizou a projeção do sistema utilizando o dado de 5.322 habitantes como sendo a projeção populacional crítica até o ano de 2039.

A partir da projeção populacional e da análise das cartas topográficas do município foi efetuado o levantamento da área em que a rede coletora irá abranger.

\subsection{Traçado da rede coletora de esgoto}

O sistema foi dividido em 82 trechos, com extensão total de 17.072 metros, onde os que possuem mais que uma ligação, foram destacados com cores diferentes e devidamente identificados para facilitar a sua visualização, como pode ser visto na Figura 10. 
Figura 9 - Projeção da rede dimensionada

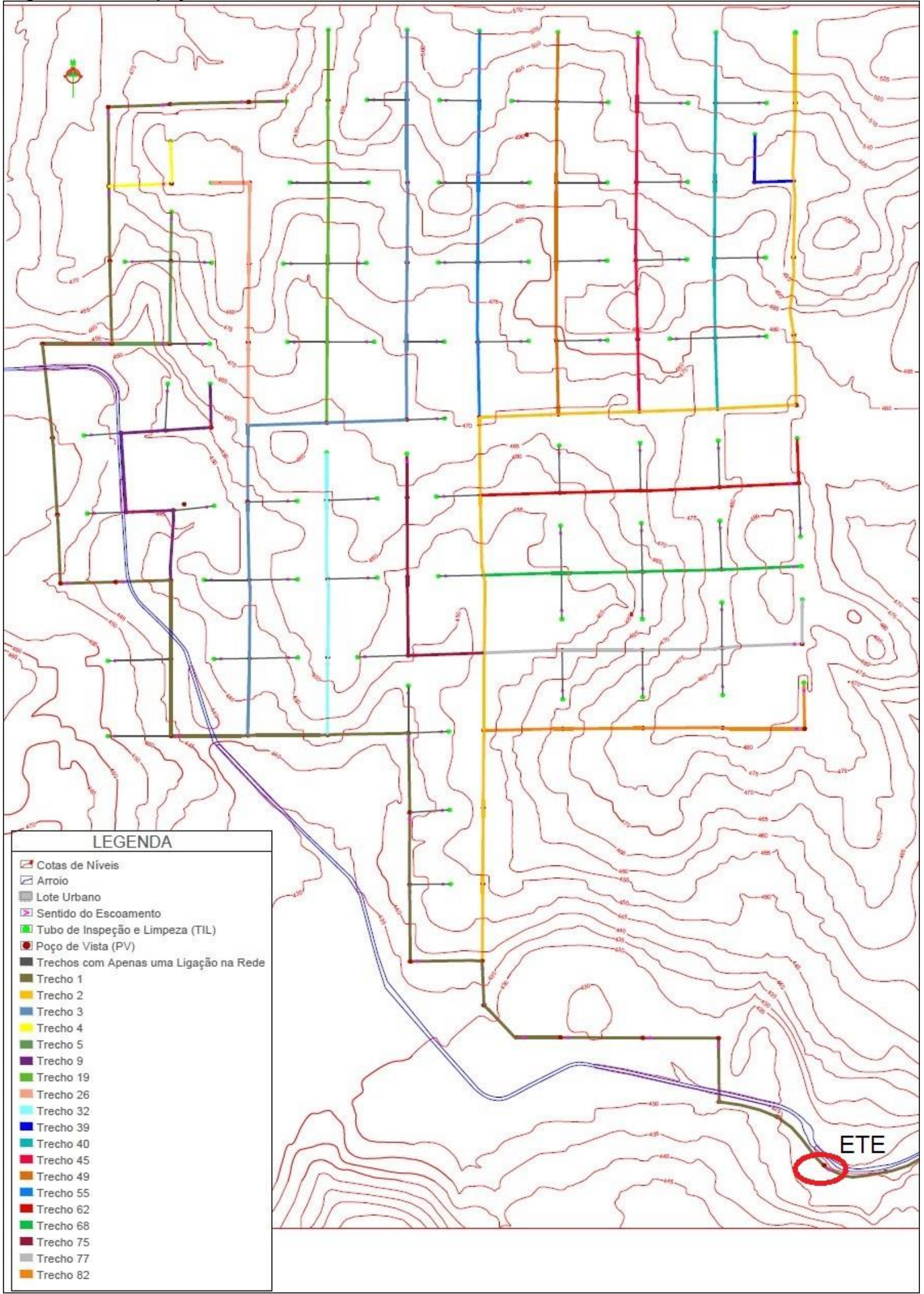

Fonte: Autor, (2019). 
A rede foi dimensionada com três trechos principais, que recebem as contribuições das ligações secundárias e destinam até a Estação de Tratamento do Esgoto (ETE). Definindo em seguida que nos 82 pontos iniciais da rede seriam instalados Tubos de Inspeção e Limpeza (TIL), pelo motivo da vazão de esgoto ser baixa nesses pontos, tornando-se viável a sua instalação por questões econômicas, pois permitem apenas a introdução de equipamentos de limpeza. Enquanto que nos 108 pontos das ligações centrais serão instalados Poços de Visitas (PV), em razão da vazão de esgoto ser maior nesses pontos, podendo acarretar em obstruções da rede, neste caso seu uso é mais recomendado, pois permitem à execução de trabalhos e manutenções da rede.

A extensão mínima de um trecho foi de 50,93 m e a extensão máxima de 134,15 m. As extensões que excederam os 100,0 m devem-se a projeção arquitetônica da cidade, pois foi definido a instalação de pontos de inspeção em inícios de trechos e a cada fim de quadra. Foi definido que a profundidade padrão da rede seria a mínima permitida pela NBR 9649, que é de $0,90 \mathrm{~m}$, visando a questão econômica para a instalação.

O diâmetro adotado para a maior parte da rede foi de $150 \mathrm{~mm}$, correspondendo à $96,3 \%$ dos pontos, e a partir do trecho 1-24, o diâmetro necessitou ser aumentado para $200 \mathrm{~mm}$, correspondente a 3,7\% dos trechos, para que desta maneira atendesse as vazões de esgoto e que a lâmina líquida, que está associada a manutenção do sistema como conduto livre, não ultrapassasse os 75\%, garantindo a autolimpeza das tubulações. Já a taxa de contribuição linear calculada para a rede é de 0,001139 L/s.m.

\subsection{Análise dos trechos}

O trecho 1 é o um dos três principais da rede, onde inicia na cota 485,10 m e termina na cota 419,20 m, sendo o maior trecho totalizando uma extensão de 2.953,75 m. Ao analisar o trecho 1-1, verifica-se que ao multiplicar a taxa de contribuição linear de esgoto pela distância é possível obter a contribuição de esgoto para o trecho no 
valor de $0,0615 \mathrm{~L} / \mathrm{s}$. A vazão inicial do trecho à montante é igual a zero, por se tratar de início de rede. Já a vazão jusante do trecho é a soma da vazão montante com a contribuição do trecho, que resulta no valor de $0,0615 \mathrm{~L} / \mathrm{s}$, por se tratar de início de trecho, este valor se iguala a contribuição dele.

Por ser o principal trecho da rede que destina o esgoto até os interceptores, o trecho 1 recebe a contribuição de vazão de todos os pontos seja diretamente ou por contribuição dos outros trechos, chegando a uma vazão de 19,37 L/s ao final da rede, como pode ser visto na Tabela 6. No trecho 1-24 o diâmetro necessitou ser aumentado para $200 \mathrm{~mm}$, para atender a vazão de esgoto, e para que a lâmina líquida não ultrapassasse os $75 \%$, desta forma garantindo a autolimpeza das tubulações.

A declividade do terreno calculada ficou em alguns pontos do trecho com valores negativos, como pode ser visto na Tabela 6 , devido as condições do terreno serem irregulares, o que é bastante comum em cidades de serra. Por causa desse fator necessita-se aprofundar mais os coletores da rede para atender a declividade mínima de 0,005 m/m estabelecido pela NBR 9649, garantindo assim a o escoamento da vazão. Sendo necessário aprofundar mais do que $5,0 \mathrm{~m}$ em seis pontos do trecho 1 , em que a profundidade mais crítica foi de $7,20 \mathrm{~m}$ nos entroncamentos dos trechos 1- 16, 32-4 e 1-17, como pode ser visto na Figura 11. 
Tabela 6 - Levantamento dos principais dados dos trechos 1

\begin{tabular}{|c|c|c|c|c|c|c|}
\hline TRECHO & $\begin{array}{l}\text { VAZÃO A } \\
\text { JUSANTE }\end{array}$ & DIÂMETRO & $\begin{array}{c}\text { DECLIVIDADE } \\
\text { TERRENO } \\
\text { CALCULADA }\end{array}$ & $\begin{array}{l}\text { COTA DO } \\
\text { TERRENO }\end{array}$ & $\begin{array}{l}\text { PROF. DO } \\
\text { COLETOR }\end{array}$ & $\begin{array}{l}\text { DECLIVIDADE } \\
\text { TUBULAÇÃO } \\
\text { USADA }\end{array}$ \\
\hline N. & (L/s) & $(\mathrm{mm})$ & $(\mathrm{m} / \mathrm{m})$ & $\begin{array}{c}\text { JUSANTE } \\
(\mathrm{m})\end{array}$ & $\begin{array}{c}\text { JUSANTE } \\
(\mathrm{m})\end{array}$ & $(\mathrm{m} / \mathrm{m})$ \\
\hline $1-1$ & 0,0615 & 150 & 0,1019 & 479,60 & 0,90 & 0,1019 \\
\hline $1-2$ & 0,1893 & 150 & 0,0080 & 478,70 & 1,20 & 0,0107 \\
\hline $1-3$ & 0,2906 & 150 & 0,0821 & 471,40 & 0,90 & 0,0787 \\
\hline $1-4$ & 0,4201 & 150 & $-0,0282$ & 474,60 & 5,10 & 0,0088 \\
\hline $1-5$ & 0,7132 & 150 & 0,0476 & 469,50 & 0,90 & 0,0084 \\
\hline $1-6$ & 0,8483 & 150 & 0,1399 & 452,90 & 0,90 & 0,1399 \\
\hline $1-7$ & 1,4789 & 150 & 0,0020 & 452,70 & 1,20 & 0,0050 \\
\hline $1-8$ & 1,6317 & 150 & $-0,0201$ & 455,40 & 4,60 & 0,0052 \\
\hline $1-9$ & 1,7461 & 150 & 0,0120 & 454,20 & 3,90 & 0,0050 \\
\hline $1-10$ & 1,8585 & 150 & 0,0466 & 449,60 & 0,90 & 0,0162 \\
\hline $1-11$ & 1,9485 & 150 & 0,0835 & 443,00 & 0,90 & 0,0835 \\
\hline $1-12$ & 2,0384 & 150 & $-0,0621$ & 447,90 & 6,20 & 0,0051 \\
\hline $1-13$ & 2,9347 & 150 & 0,0292 & 444,60 & 3,50 & 0,0053 \\
\hline $1-14$ & 3,1620 & 150 & $-0,0182$ & 446,60 & 6,10 & 0,0055 \\
\hline $1-15$ & 3,3900 & 150 & 0,0481 & 441,30 & 1,35 & 0,0050 \\
\hline $1-16$ & 6,9835 & 150 & $-0,0464$ & 446,60 & 7,25 & 0,0053 \\
\hline $1-17$ & 7,7396 & 150 & 0,0138 & 445,00 & 6,25 & 0,0052 \\
\hline $1-18$ & 8,0114 & 150 & 0,0220 & 442,50 & 4,35 & 0,0053 \\
\hline $1-19$ & 8,1943 & 150 & $-0,0029$ & 442,80 & 5,20 & 0,0053 \\
\hline $1-20$ & 8,3864 & 150 & 0,0471 & 437,60 & 0,90 & 0,0082 \\
\hline $1-21$ & 8,5040 & 150 & $-0,0078$ & 438,40 & 2,3 & 0,0058 \\
\hline $1-22$ & 18,5592 & 150 & 0,1013 & 432,00 & 0,90 & 0,0791 \\
\hline $1-23$ & 18,6336 & 150 & 0,0551 & 428,40 & 0,90 & 0,0551 \\
\hline $1-24$ & 18,7057 & 200 & $-0,0076$ & 429,10 & 1,95 & 0,0055 \\
\hline $1-25$ & 18,8400 & 200 & 0,0383 & 425,30 & 0,90 & 0,0233 \\
\hline $1-26$ & 18,9634 & 200 & $-0,0245$ & 427,70 & 3,85 & 0,0051 \\
\hline $1-27$ & 19,0676 & 200 & 0,0186 & 428,20 & 4,85 & 0,0055 \\
\hline $1-28$ & 19,1657 & 200 & 0,0295 & 425,50 & 2,60 & 0,0052 \\
\hline $1-29$ & 19,2639 & 200 & 0,0035 & 420,40 & 0,90 & 0,0394 \\
\hline $1-30$ & 19,3697 & 200 & 0,0453 & 419,50 & 0,90 & 0,0129 \\
\hline
\end{tabular}

Fonte: Autor, (2019). 
Figura 10 - Detalhamento de alguns pontos do trecho 1, 4, 5, 26 e 19 da rede de esgoto

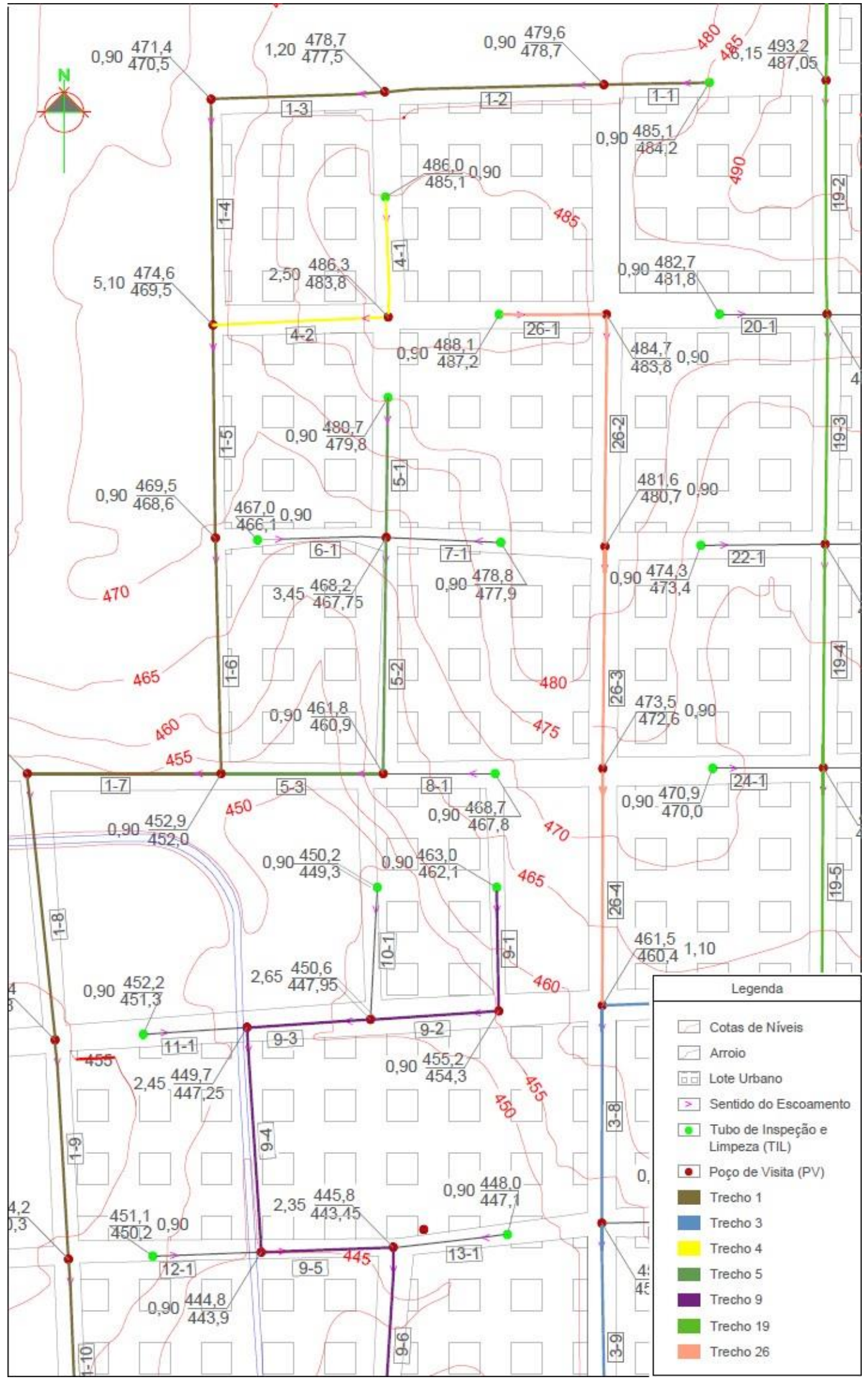

Fonte: Autor, (2019). 
Já o trecho 2 inicia na cota 517,40 m e termina na 438,40 m, onde percorre uma extensão de $1.767 \mathrm{~m}$, sendo o segundo maior em extensão. A maior vazão é ao final do trecho 2-16, com valor de 9,98 L/s. Em toda sua extensão o diâmetro utilizado foi o de $150 \mathrm{~mm}$.

Nesse trecho a declividade do terreno calculada ficou negativa em quatro pontos, como pode ser analisado na Tabela 7. Sendo necessário ao ponto 2-13 aprofundar mais que 5,0 m, o qual faz entroncamento com o trecho $82-5$, chegando a uma profundidade de 5,60 m. Nos demais trechos com declividade negativa 0 aprofundamento não ultrapassou os 3,25 m, como pode ser visto na Figura 12.

Figura 11 - Detalhamento de alguns pontos do trecho 2, 68, 77 e 82 da rede de esgoto

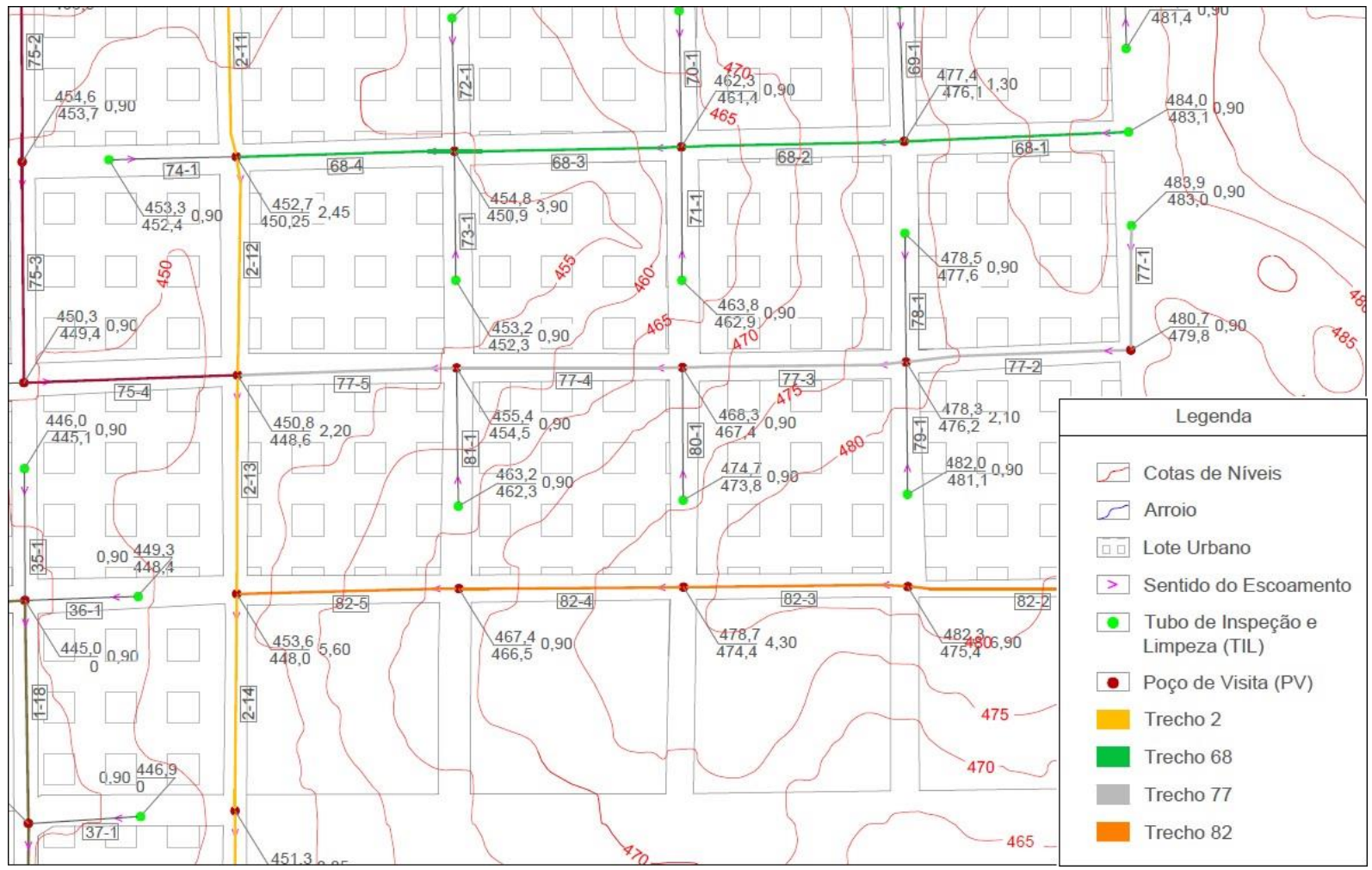

Fonte: Autor, (2019). 
Tabela 7 - Levantamento dos principais dados dos trechos 2

\begin{tabular}{c|c|c|c|c|c|c}
\hline TRECHO & $\begin{array}{c}\text { VAZÃO A } \\
\text { JUSANTE }\end{array}$ & DIÂMETRO & $\begin{array}{c}\text { DECLIVIDADE } \\
\text { TERRENO } \\
\text { CALCULADA }\end{array}$ & $\begin{array}{c}\text { COTA DO } \\
\text { TERRENO }\end{array}$ & $\begin{array}{c}\text { PROF. DO } \\
\text { COLETOR }\end{array}$ & $\begin{array}{c}\text { DECLIVIDADE } \\
\text { TUBULAÇAिO } \\
\text { USADA }\end{array}$ \\
\hline $\mathbf{N}$. & $(\mathrm{L} / \mathrm{s})$ & $(\mathrm{mm})$ & $(\mathrm{m} / \mathrm{m})$ & $\begin{array}{c}\text { JUSANTE } \\
(\mathrm{m})\end{array}$ & $\begin{array}{c}\text { JUSANTE } \\
(\mathrm{m})\end{array}$ & $(\mathrm{m} / \mathrm{m})$ \\
\hline $\mathbf{2 - 1}$ & 0,1148 & 150 & 0,0952 & 507,80 & 0,90 & 0,0952 \\
\hline $\mathbf{2 - 2}$ & 0,2422 & 150 & 0,1100 & 495,50 & 1,40 & 0,1145 \\
\hline $\mathbf{2 - 3}$ & 0,5088 & 150 & $-0,0091$ & 496,50 & 3,25 & 0,0077 \\
\hline $\mathbf{2 - 4}$ & 0,6357 & 150 & 0,1455 & 480,30 & 0,90 & 0,1244 \\
\hline $\mathbf{2 - 5}$ & 0,7493 & 150 & $-0,0030$ & 480,60 & 1,75 & 0,0055 \\
\hline $\mathbf{2 - 6}$ & 0,8783 & 150 & 0,0345 & 476,70 & 0,90 & 0,0269 \\
\hline $\mathbf{2 - 7}$ & 1,9433 & 150 & 0,0466 & 471,50 & 0,90 & 0,0466 \\
\hline $\mathbf{2 - 8}$ & 2,9431 & 150 & 0,0164 & 469,60 & 0,90 & 0,0164 \\
\hline $\mathbf{2 - 9}$ & 4,1005 & 150 & $-0,0080$ & 470,50 & 2,40 & 0,0053 \\
\hline $\mathbf{2 - 1 0}$ & 5,3005 & 150 & 0,0965 & 459,70 & 1,85 & 0,0916 \\
\hline $\mathbf{2 - 1 1}$ & 6,4136 & 150 & 0,0612 & 452,70 & 2,45 & 0,0665 \\
\hline $\mathbf{2 - 1 2}$ & 7,4443 & 150 & 0,0171 & 450,80 & 2,20 & 0,0148 \\
\hline $\mathbf{2 - 1 3}$ & 9,0078 & 150 & $-0,0251$ & 453,60 & 5,60 & 0,0054 \\
\hline $\mathbf{2 - 1 4}$ & 9,7329 & 150 & 0,0208 & 451,30 & 3,85 & 0,0050 \\
\hline $\mathbf{2 - 1 5}$ & 9,8572 & 150 & 0,0178 & 449,36 & 2,50 & 0,0054 \\
\hline $\mathbf{2 - 1 6}$ & 9,9832 & 150 & 0,1013 & 438,40 & 2,30 & 0,0995 \\
\hline
\end{tabular}

Fonte: Autor, (2019).

O terceiro trecho principal da rede pode ser visto na Figura 13, e possui extensão total de 1.230,25 m, e sua cota inicia em 500,80 m e finaliza em 441,30 m. A maior vazão desse trecho é no ponto $3-11$, com $3,46 \mathrm{~L} / \mathrm{s}$, podendo ser visto na Tabela 8. No trecho 3 a declividade do terreno colaborou, sem a necessidade da realização de aprofundamentos excessivos, e em quase sua totalidade ficou com profundidade padrão de $0,90 \mathrm{~m}$, e seu ponto com maior profundidade foi a $4,35 \mathrm{~m}$ no trecho 3-10 com entroncamento com os trechos 30-1 e 31-1. 
Figura 12 - Detalhamento de alguns pontos do trecho 3, 19, 26 e 55 da rede de esgoto

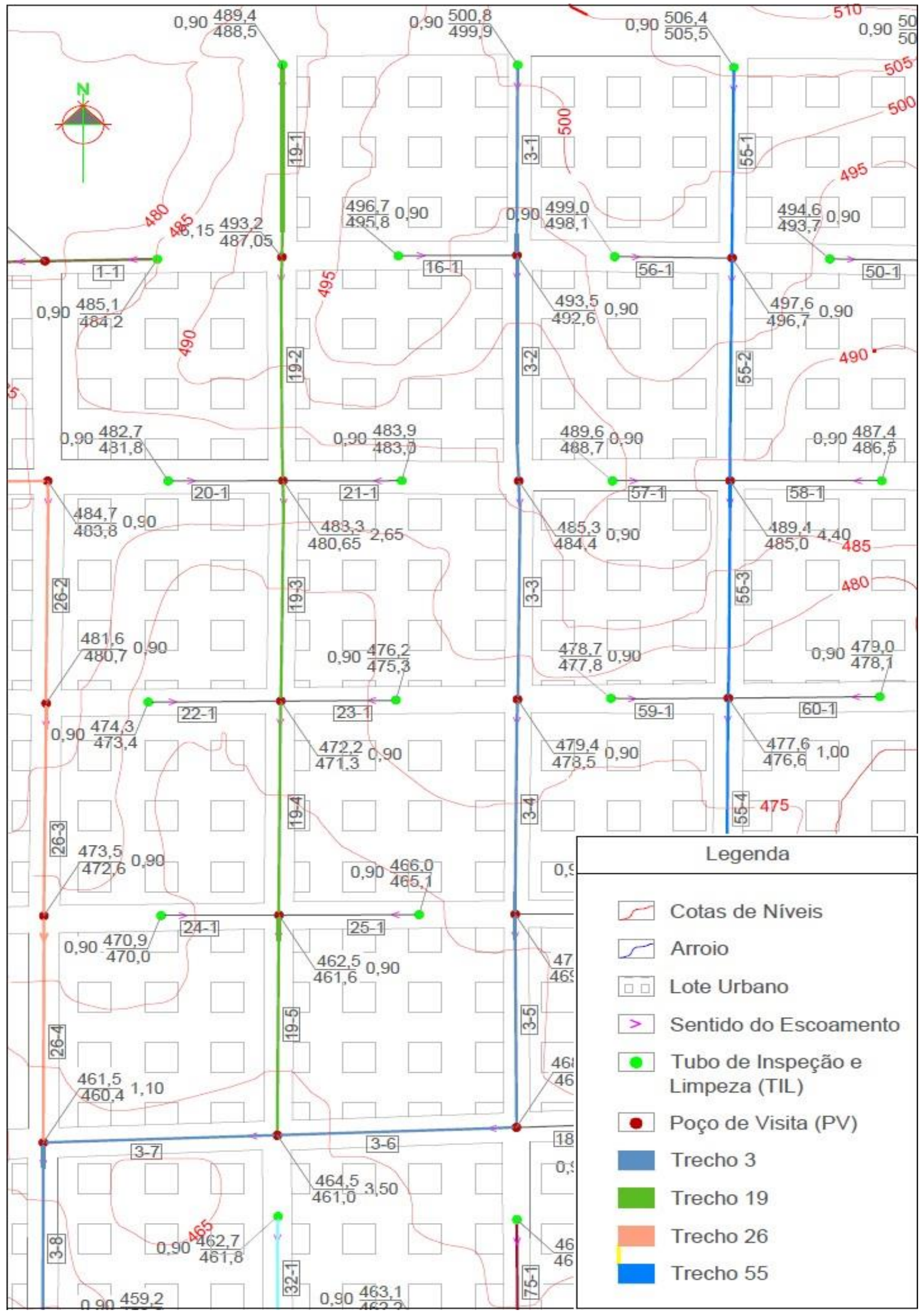

Fonte: Autor, (2019). 
Tabela 8 - Levantamento dos principais dados dos trechos 3

\begin{tabular}{|c|c|c|c|c|c|c|}
\hline TRECHO & $\begin{array}{l}\text { VAZÃO A } \\
\text { JUSANTE }\end{array}$ & DIÂMETRO & $\begin{array}{c}\text { DECLIVIDADE } \\
\text { TERRENO } \\
\text { CALCULADA }\end{array}$ & $\begin{array}{l}\text { COTA DO } \\
\text { TERRENO }\end{array}$ & $\begin{array}{l}\text { PROF. DO } \\
\text { COLETOR }\end{array}$ & $\begin{array}{c}\text { DECLIVIDADE } \\
\text { TUBULAÇÃO } \\
\text { USADA }\end{array}$ \\
\hline N. & $(\mathrm{L} / \mathrm{s})$ & $(\mathrm{mm})$ & $(\mathrm{m} / \mathrm{m})$ & $\begin{array}{l}\text { JUSANTE } \\
(\mathrm{m})\end{array}$ & $\begin{array}{l}\text { JUSANTE } \\
(\mathrm{m})\end{array}$ & $(\mathrm{m} / \mathrm{m})$ \\
\hline $3-1$ & 0,1140 & 150 & 0,0729 & 493,50 & 0,90 & 0,0729 \\
\hline $3-2$ & 0,3141 & 150 & 0,0691 & 485,30 & 0,90 & 0,0691 \\
\hline $3-3$ & 0,4450 & 150 & 0,0513 & 479,40 & 0,90 & 0,0513 \\
\hline $3-4$ & 0,5737 & 150 & 0,0779 & 470,60 & 0,90 & 0,0779 \\
\hline $3-5$ & 0,7630 & 150 & 0,0178 & 468,60 & 0,90 & 0,0178 \\
\hline $3-6$ & 0,9555 & 150 & 0,0357 & 464,50 & 3,50 & 0,0583 \\
\hline $3-7$ & 2,1294 & 150 & 0,0267 & 461,50 & 1,10 & 0,0053 \\
\hline $3-8$ & 2,7132 & 150 & 0,0749 & 453,30 & 0,90 & 0,0730 \\
\hline $3-9$ & 2,9205 & 150 & 0,0152 & 451,60 & 3,60 & 0,0394 \\
\hline $3-10$ & 3,2009 & 150 & 0,0284 & 448,40 & 4,35 & 0,0350 \\
\hline $3-11$ & 3,4634 & 150 & 0,0644 & 441,30 & 1,35 & 0,0372 \\
\hline
\end{tabular}

Fonte: Autor, (2019).

No trecho 9, que tem início na cota 463,00 $\mathrm{m}$ e termino na 447,90 m, percorrendo uma extensão de 439,75 m, podendo ser visualizado na Figura 11. Há dois pontos onde a declividade do terreno ficou negativa, sendo eles os trechos 9-5 e 9-6, com valor de $-0,0148 \mathrm{~m} / \mathrm{m}$ e $-0,0209 \mathrm{~m} / \mathrm{m}$ respectivamente, e o trecho que ficou mais negativo teve que ser aprofundado em $6,20 \mathrm{~m}$, podendo ser verificado na Tabela 9.

Tabela 9 - Levantamento dos principais dados dos trechos 9

\begin{tabular}{|c|c|c|c|c|c|c}
\hline TRECHO & $\begin{array}{c}\text { VAZÃO A } \\
\text { JUSANTE }\end{array}$ & DIÂMETRO & $\begin{array}{c}\text { DECLIVIDADE } \\
\text { TERRENO } \\
\text { CALCULADA }\end{array}$ & $\begin{array}{c}\text { COTA DO } \\
\text { TERRENO }\end{array}$ & $\begin{array}{c}\text { PROF. DO } \\
\text { COLETOR }\end{array}$ & $\begin{array}{c}\text { DECLIVIDADE } \\
\text { TUBULAÇÃO } \\
\text { USADA }\end{array}$ \\
\hline $\mathbf{N}$. & $(\mathrm{L} / \mathrm{s})$ & $(\mathrm{mm})$ & $(\mathrm{m} / \mathrm{m})$ & $\begin{array}{c}\text { JUSANTE } \\
(\mathrm{m})\end{array}$ & $\begin{array}{c}\text { JUSANTE } \\
(\mathrm{m})\end{array}$ & $(\mathrm{m} / \mathrm{m})$ \\
\hline $\mathbf{9 - 1}$ & 0,0710 & 150 & 0,1252 & 455,20 & 0,90 & 0,1252 \\
\hline $\mathbf{9 - 2}$ & 0,1458 & 150 & 0,0701 & 450,60 & 2,65 & 0,0967 \\
\hline $9-3$ & 0,2937 & 150 & 0,0142 & 449,70 & 2,45 & 0,0110 \\
\hline $9-4$ & 0,4459 & 150 & 0,0609 & 444,80 & 0,90 & 0,0417 \\
\hline $9-5$ & 0,5862 & 150 & $-0,0148$ & 445,80 & 2,35 & 0,0066 \\
\hline $9-6$ & 0,7674 & 150 & $-0,0209$ & 447,90 & 6,20 & 0,0174 \\
\hline
\end{tabular}

Fonte: Autor, (2019).

O trecho 19, que pode ser visto na Figura 13, inicia na cota 489,40 m e termina na 464,50 m, e sua extensão é de 563,05 m. A declividade da tubulação usada ficou com a mínima em dois pontos, para atender as condições de escoamento da rede, 
podendo ser observado na Tabela 10. No trecho 19-1 foi necessário a realização do aprofundamento da rede em 6,15 m, por conta das condições do terreno.

Tabela 10 - Levantamento dos principais dados dos trechos 19

\begin{tabular}{|c|c|c|c|c|c|c|}
\hline TRECHO & $\begin{array}{l}\text { VAZÃO A } \\
\text { JUSANTE }\end{array}$ & DIÂMETRO & $\begin{array}{l}\text { DECLIVIDADE } \\
\text { TERRENO } \\
\text { CALCULADA }\end{array}$ & $\begin{array}{l}\text { COTA DO } \\
\text { TERRENO }\end{array}$ & $\begin{array}{l}\text { PROF. DO } \\
\text { COLETOR }\end{array}$ & $\begin{array}{c}\text { DECLIVIDADE } \\
\text { TUBULAÇÃO } \\
\text { USADA }\end{array}$ \\
\hline N. & $(\mathrm{L} / \mathrm{s})$ & $(\mathrm{mm})$ & $(\mathrm{m} / \mathrm{m})$ & $\begin{array}{c}\text { JUSANTE } \\
(\mathrm{m})\end{array}$ & $\begin{array}{l}\text { JUSANTE } \\
(\mathrm{m})\end{array}$ & $(\mathrm{m} / \mathrm{m})$ \\
\hline $19-1$ & 0,1152 & 150 & $-0,0376$ & 493,20 & 6,15 & 0,0143 \\
\hline $19-2$ & 0,2492 & 150 & 0,0841 & 483,30 & 2,65 & 0,0544 \\
\hline $19-3$ & 0,5090 & 150 & 0,0958 & 472,20 & 0,90 & 0,0807 \\
\hline $19-4$ & 0,7729 & 150 & 0,0861 & 462,50 & 0,90 & 0,0861 \\
\hline $19-5$ & 1,0459 & 150 & $-0,0173$ & 464,50 & 3,50 & 0,0052 \\
\hline
\end{tabular}

Fonte: Autor, (2019).

O trecho 32 não teve declividade negativa, porém teve dois pontos que excederam os 5,00 m de profundidade, podendo ser visto na Tabela 11, para atender a tensão trativa mínima estipulada pela NBR 9649 que é de 1,0 Pa. Este trecho pode ser visualizado na Figura 14.

Tabela 11 - Levantamento dos principais dados dos trechos 32

\begin{tabular}{c|c|c|c|c|c|c}
\hline TRECHO & $\begin{array}{c}\text { VAZÃO A } \\
\text { JUSANTE }\end{array}$ & DIÂMETRO & $\begin{array}{c}\text { DECLIVIDADE } \\
\text { TERRENO } \\
\text { CALCULADA }\end{array}$ & $\begin{array}{c}\text { COTA DO } \\
\text { TERRENO }\end{array}$ & $\begin{array}{c}\text { PROF. DO } \\
\text { COLETOR }\end{array}$ & $\begin{array}{c}\text { DECLIVIDADE } \\
\text { TUBULAÇÃO } \\
\text { USADA }\end{array}$ \\
\hline $\mathbf{N}$. & $(\mathrm{L} / \mathrm{s})$ & $(\mathrm{mm})$ & $(\mathrm{m} / \mathrm{m})$ & $\begin{array}{c}\text { JUSANTE } \\
(\mathrm{m})\end{array}$ & $\begin{array}{c}\text { JUSANTE } \\
(\mathrm{m})\end{array}$ & $(\mathrm{m} / \mathrm{m})$ \\
\hline $\mathbf{3 2 - 1}$ & 0,0778 & 150 & 0,0424 & 459,80 & 0,90 & 0,0424 \\
\hline $\mathbf{3 2 - 2}$ & 0,2887 & 150 & 0,0124 & 458,40 & 5,15 & 0,0501 \\
\hline $\mathbf{3 2 - 3}$ & 0,4973 & 150 & 0,0107 & 457,20 & 4,80 & 0,0076 \\
\hline $\mathbf{3 2 - 4}$ & 0,6237 & 150 & 0,0955 & 446,60 & 7,25 & 0,1176 \\
\hline
\end{tabular}

Fonte: Autor, (2019). 
Figura 13 - Detalhamento de alguns pontos do trecho 2, 3, 32 e 75 da rede de esgoto

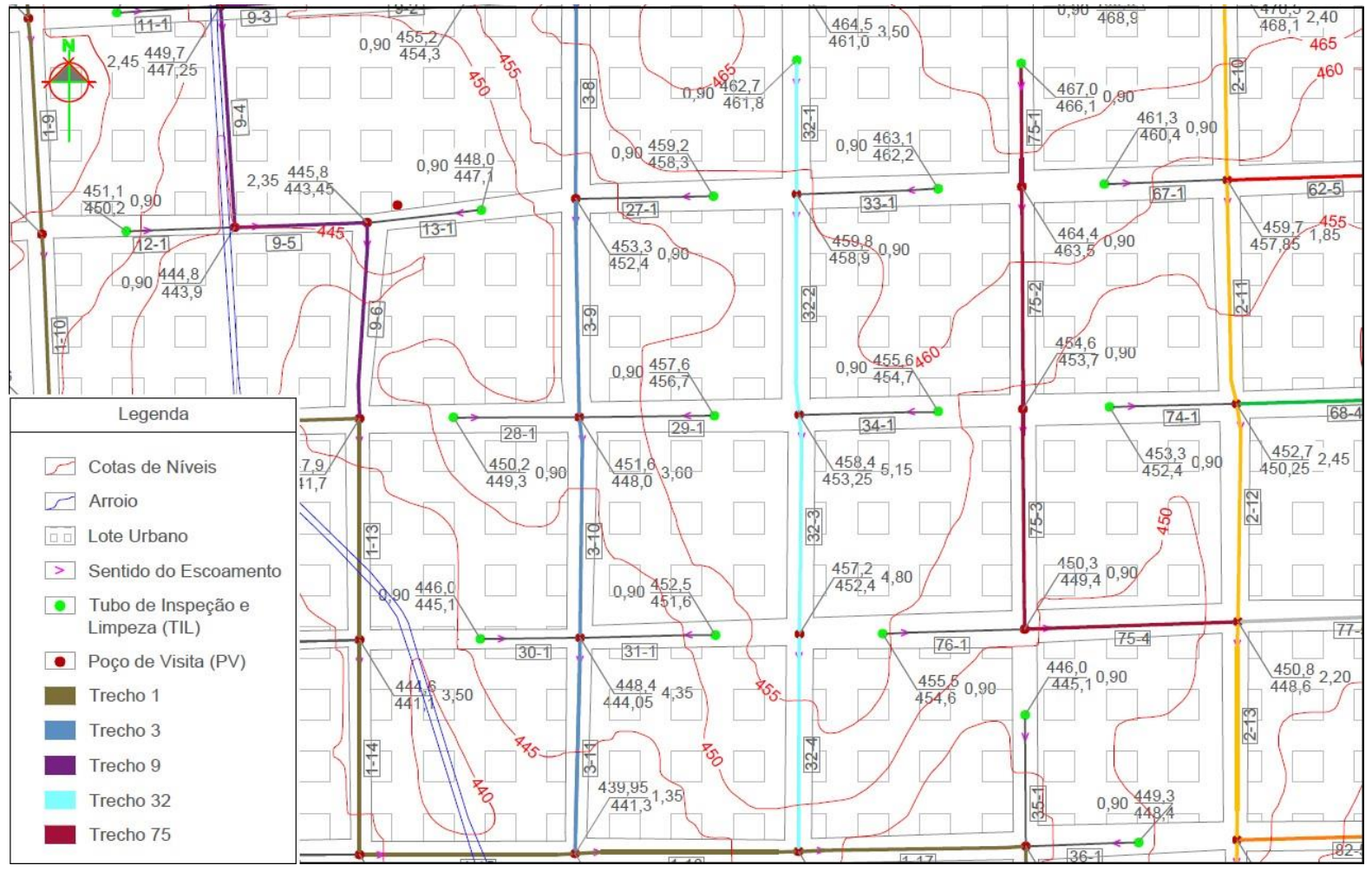

Fonte: Autor, (2019).

O trecho 45 possui cinco pontos, em que quatro deles tem a profundidade do coletor à 0,90 m, e o 45-4 precisou ser aprofundado a 2,85 m, ficando com uma declividade da tubulação usada de 0,0066, sendo esta um pouco acima da mínima para atender a tensão trativa neste ponto, podendo ser visto na Tabela 12.

Tabela 12 - Levantamento dos principais dados dos trechos 45

\begin{tabular}{|c|c|c|c|c|c|c|}
\hline TRECHO & $\begin{array}{l}\text { VAZÃO A } \\
\text { JUSANTE }\end{array}$ & DIÂMETRO & $\begin{array}{l}\text { DECLIVIDADE } \\
\text { TERRENO } \\
\text { CALCULADA }\end{array}$ & $\begin{array}{l}\text { COTA DO } \\
\text { TERRENO }\end{array}$ & $\begin{array}{l}\text { PROF. DO } \\
\text { COLETOR }\end{array}$ & $\begin{array}{c}\text { DECLIVIDADE } \\
\text { TUBULAÇÃO } \\
\text { USADA }\end{array}$ \\
\hline N. & $(\mathrm{L} / \mathrm{s})$ & $(\mathrm{mm})$ & $(\mathrm{m} / \mathrm{m})$ & $\begin{array}{l}\text { JUSANTE } \\
(\mathrm{m})\end{array}$ & $\begin{array}{c}\text { JUSANTE } \\
(\mathrm{m})\end{array}$ & $(\mathrm{m} / \mathrm{m})$ \\
\hline $45-1$ & 0,1144 & 150 & 0,0466 & 500,50 & 0,90 & 0,0468 \\
\hline $45-2$ & 0,3271 & 150 & 0,0774 & 491,70 & 0,90 & 0,0774 \\
\hline $45-3$ & 0,5374 & 150 & 0,0744 & 483,40 & 0,90 & 0,0744 \\
\hline $45-4$ & 0,7502 & 150 & $-0,0105$ & 484,60 & 2,85 & 0,0066 \\
\hline $45-5$ & 0,8677 & 150 & 0,1270 & 471,50 & 0,90 & 0,1081 \\
\hline
\end{tabular}

Fonte: Autor, (2019). 
$\mathrm{Na}$ Tabela 13 pode ser visto que os trechos 26 e 49 foram os que menos necessitaram de aprofundamento do coletor, sendo que o ponto com maior aprofundamento do trecho 26 foi a $1,10 \mathrm{~m}$, e no trecho 49 foi a $1,00 \mathrm{~m}$, e os demais pontos ficaram com a profundidade mínima de $0,90 \mathrm{~m}$, tornando sua execução mais fácil.

Tabela 13 - Levantamento dos principais dados dos trechos 26 e 49

\begin{tabular}{|c|c|c|c|c|c|c|}
\hline TRECHO & $\begin{array}{l}\text { VAZÃO A } \\
\text { JUSANTE }\end{array}$ & DIÂMETRO & $\begin{array}{c}\text { DECLIVIDADE } \\
\text { TERRENO } \\
\text { CALCULADA }\end{array}$ & $\begin{array}{l}\text { COTA DO } \\
\text { TERRENO }\end{array}$ & $\begin{array}{l}\text { PROF. DO } \\
\text { COLETOR }\end{array}$ & $\begin{array}{c}\text { DECLIVIDADE } \\
\text { TUBULAÇÃO } \\
\text { USADA }\end{array}$ \\
\hline N. & $(\mathrm{L} / \mathrm{s})$ & $(\mathrm{mm})$ & $(\mathrm{m} / \mathrm{m})$ & $\begin{array}{c}\text { JUSANTE } \\
(\mathrm{m})\end{array}$ & $\begin{array}{l}\text { JUSANTE } \\
(\mathrm{m})\end{array}$ & $(\mathrm{m} / \mathrm{m})$ \\
\hline 26-1 & 0,0626 & 150 & 0,0619 & 484,70 & 0,90 & 0,0619 \\
\hline $26-2$ & 0,1958 & 150 & 0,0265 & 481,60 & 0,90 & 0,0265 \\
\hline $26-3$ & 0,3231 & 150 & 0,0725 & 473,50 & 0,90 & 0,0725 \\
\hline $26-4$ & 0,4590 & 150 & 0,1006 & 461,50 & 1,10 & 0,1023 \\
\hline $49-1$ & 0,1137 & 150 & 0,1132 & 492,30 & 0,90 & 0,1132 \\
\hline $49-2$ & 0,4026 & 150 & 0,0346 & 488,30 & 0,90 & 0,0346 \\
\hline $49-3$ & 0,6140 & 150 & 0,0718 & 480,20 & 0,90 & 0,0718 \\
\hline $49-4$ & 0,8268 & 150 & 0,0053 & 479,60 & 1,00 & 0,0061 \\
\hline $49-5$ & 1,0286 & 150 & 0,0957 & 469,60 & 0,90 & 0,0947 \\
\hline
\end{tabular}

Fonte: Autor, (2019).

O trecho 55 teve algumas variações na profundidade do coletor, chegando a $4,40 \mathrm{~m}$ no entroncamento do trecho 55-2 com o 56-1, mas ficou abaixo da profundidade máxima, tornando possível sua execução, podendo ser verificado na Tabela 14.

Tabela 14 - Levantamento dos principais dados dos trechos 55

\begin{tabular}{|c|c|c|c|c|c|c|}
\hline TRECHO & $\begin{array}{l}\text { VAZÃO A } \\
\text { JUSANTE }\end{array}$ & DIÂMETRO & $\begin{array}{c}\text { DECLIVIDADE } \\
\text { TERRENO } \\
\text { CALCULADA }\end{array}$ & $\begin{array}{l}\text { COTA DO } \\
\text { TERRENO }\end{array}$ & $\begin{array}{l}\text { PROF. DO } \\
\text { COLETOR }\end{array}$ & $\begin{array}{c}\text { DECLIVIDADE } \\
\text { TUBULAÇÃO } \\
\text { USADA }\end{array}$ \\
\hline N. & $(\mathrm{L} / \mathrm{s})$ & $(\mathrm{mm})$ & $(\mathrm{m} / \mathrm{m})$ & $\begin{array}{l}\text { JUSANTE } \\
(\mathrm{m})\end{array}$ & $\begin{array}{l}\text { JUSANTE } \\
(\mathrm{m})\end{array}$ & $(\mathrm{m} / \mathrm{m})$ \\
\hline $55-1$ & 0,1142 & 150 & 0,0878 & 497,60 & 0,90 & 0,0878 \\
\hline $55-2$ & 0,3120 & 150 & 0,0699 & 489,40 & 4,40 & 0,0998 \\
\hline $55-3$ & 0,5894 & 150 & 0,1033 & 477,60 & 1,00 & 0,0735 \\
\hline $55-4$ & 0,8666 & 150 & 0,0377 & 473,30 & 0,90 & 0,0368 \\
\hline $55-5$ & 1,0726 & 150 & 0,0259 & 470,50 & 2,40 & 0,0398 \\
\hline
\end{tabular}

Fonte: Autor, (2019). 
O trecho 62, é o que possui apenas um ponto em que a profundidade do coletor ficou a $0,90 \mathrm{~m}$ sendo ele o ponto $62-4$, e os demais com profundidade variando de 1,85 $\mathrm{m}$ até 2,95 m, podendo ser visto na Tabela 15. A declividade do terreno calculada ficou negativa em dois pontos, sendo o trecho em que a declividade da tubulação ficou a $0,0057 \mathrm{~m} / \mathrm{m}$ e a profundidade do coletor ficou a $1,85 \mathrm{~m}$.

Tabela 15 - Levantamento dos principais dados dos trechos 62

\begin{tabular}{|c|c|c|c|c|c|c|}
\hline TRECHO & $\begin{array}{l}\text { VAZÃO A } \\
\text { JUSANTE }\end{array}$ & DIÂMETRO & $\begin{array}{l}\text { DECLIVIDADE } \\
\text { TERRENO } \\
\text { CALCULADA }\end{array}$ & $\begin{array}{l}\text { COTA DO } \\
\text { TERRENO }\end{array}$ & $\begin{array}{l}\text { PROF. DO } \\
\text { COLETOR }\end{array}$ & $\begin{array}{c}\text { DECLIVIDADE } \\
\text { TUBULAÇÃO } \\
\text { USADA }\end{array}$ \\
\hline N. & (L/s) & $(\mathrm{mm})$ & $(\mathrm{m} / \mathrm{m})$ & $\begin{array}{l}\text { JUSANTE } \\
(\mathrm{m})\end{array}$ & $\begin{array}{l}\text { JUSANTE } \\
(\mathrm{m})\end{array}$ & \\
\hline $62-1$ & 0,0734 & 150 & $-0,0109$ & 480,40 & 2,95 & 0,0210 \\
\hline $62-2$ & 0,2899 & 150 & 0,0159 & 478,60 & 2,40 & 0,0110 \\
\hline $62-3$ & 0,4947 & 150 & 0,0787 & & 2,50 & 0,0796 \\
\hline $62-4$ & 0,7043 & 150 & 0,0890 & 459,40 & 0,90 & 0,0752 \\
\hline $62-5$ & 0,9113 & 150 & $-0,0026$ & 459,70 & 1,85 & 0,0057 \\
\hline
\end{tabular}

Fonte: Autor, (2019).

O trecho 82 inicia na cota 479,80 m e termina na 453,60 m, onde percorre uma extensão de 525,95 m, como pode ser visto na Figura 12. Este trecho resulta numa vazão de 0,599 L/s, sendo o trecho com maior variação de cota do coletor, iniciando com a mínima de 0,90 m e passando os 5,00 $\mathrm{m}$ em dois pontos, sendo eles os pontos $82-2$ e 82-5, com a profundidade de 6,90 e 5,60 respectivamente, podendo ser visto na Tabela 16.

Tabela 16 - Levantamento dos principais dados dos trechos 82

\begin{tabular}{c|c|c|c|c|c|c} 
TRECHO & $\begin{array}{c}\text { VAZÃO A } \\
\text { JUSANTE }\end{array}$ & DIÂMETRO & $\begin{array}{c}\text { DECLIVIDADE } \\
\text { TERRENO } \\
\text { CALCULADA }\end{array}$ & $\begin{array}{c}\text { COTA DO } \\
\text { TERRENO }\end{array}$ & $\begin{array}{c}\text { PROF. DO } \\
\text { COLETOR }\end{array}$ & $\begin{array}{c}\text { DECLIVIDADE } \\
\text { TUBULAÇÃO } \\
\text { USADA }\end{array}$ \\
\hline $\mathbf{N}$. & $(\mathrm{L} / \mathrm{s})$ & $(\mathrm{mm})$ & $(\mathrm{m} / \mathrm{m})$ & $\begin{array}{c}\text { JUSANTE } \\
(\mathrm{m})\end{array}$ & $\begin{array}{c}\text { JUSANTE } \\
(\mathrm{m})\end{array}$ & $(\mathrm{m} / \mathrm{m})$ \\
\hline $\mathbf{8 2 - 1}$ & 0,0756 & 150 & 0,0332 & 477,60 & 0,90 & 0,0332 \\
\hline $\mathbf{8 2 - 2}$ & 0,2093 & 150 & $-0,0401$ & 482,30 & 6,90 & 0,0111 \\
\hline $\mathbf{8 2 - 3}$ & 0,3396 & 150 & 0,0315 & 478,70 & 4,30 & 0,0087 \\
\hline $\mathbf{8 2 - 4}$ & 0,4701 & 150 & 0,0986 & 467,40 & 0,90 & 0,0690 \\
\hline $\mathbf{8 2 - 5}$ & 0,5991 & 150 & 0,1218 & 453,60 & 5,60 & 0,1633 \\
\hline
\end{tabular}

Fonte: Autor, (2019). 


\subsection{Análise geral da declividade do terreno}

Para o cálculo da declividade do terreno, foi possível verificar que em 33 pontos a declividade ficou negativa por conta da irregularidade do terreno, condição comum principalmente em cidades da serra, sendo necessário que a rede seja aprofundada um pouco mais do que o padrão, e o ponto mais crítico de declividade foi o 1-12, atingindo $-0,0621 \mathrm{~m} / \mathrm{m}$.

Em nove pontos, por conta da declividade, a profundidade ultrapassou os 5,00 $\mathrm{m}$, carecendo nesses casos uma análise detalhada para verificar a necessidade de instalação de estações de bombeamento.

\subsection{Análise geral das profundidades}

Foi estabelecida a profundidade padrão como sendo de 0,90m, que é a mínima estipulada pela NBR 9649, para evitar gastos excessivos com escavações e escoramentos. Para os pontos em que a declividade da tubulação ficou abaixo da mínima foi necessário realizar um aprofundamento maior da rede, como pode ser visto na Tabela 17, onde em 19 entroncamentos a profundidade da rede coletora ultrapassou 5,00 m, sendo seis desses pontos para atender a declividade mínima de $0,005 \mathrm{~m} / \mathrm{m}$. O ponto com maior profundidade foi entre os trechos $32-4$ e $1-17$, em que a profundidade máxima foi de $7,25 \mathrm{~m}$.

Nesses trechos será necessário uma análise detalhada para a instalação de estações de bombeamento ou procurar alguma outra forma de traçado, de forma a manobrar essas profundidades maiores, tornando-se necessário a avaliação por parte de técnicos da área juntamente com o poder público do município, para encontrar alguma solução de transporte de efluentes que não necessitem de tanto aprofundamento de rede, para viabilizar a obra. 
Tabela 17 - Coletores com excesso de profundidade

\begin{tabular}{|c|c|c|c|}
\hline Trecho & $\begin{array}{l}\text { Profundidade } \\
\text { do coletor } \\
\text { (Montante) } \\
\text { (m) }\end{array}$ & $\begin{array}{l}\text { Profundidade } \\
\text { do coletor } \\
\text { (Jusante) } \\
\text { (m) }\end{array}$ & $\begin{array}{l}\text { Declividade } \\
\text { Tubulação } \\
\text { Usada } \\
(\mathrm{m} / \mathrm{m})\end{array}$ \\
\hline $1-4$ & 0,90 & 5,10 & 0,0088 \\
\hline $4-2$ & 2,50 & 5,10 & 0,1596 \\
\hline $1-5$ & 5,10 & 0,90 & 0,0084 \\
\hline $1-12$ & 0,90 & 6,20 & 0,0051 \\
\hline $9-6$ & 2,35 & 6,20 & 0,0174 \\
\hline $1-13$ & 6,20 & 3,50 & 0,0053 \\
\hline $1-14$ & 3,50 & 6,10 & 0,0055 \\
\hline $15-1$ & 0,90 & 6,10 & 0,2261 \\
\hline $1-15$ & 6,10 & 1,35 & 0,0050 \\
\hline 19-1 & 0,90 & 6,15 & 0,0143 \\
\hline $19-2$ & 6,15 & 2,65 & 0,0544 \\
\hline $1-16$ & 1,35 & 7,25 & 0,0053 \\
\hline $32-2$ & 0,90 & 5,15 & 0,0501 \\
\hline $34-1$ & 0,90 & 5,15 & 0,0204 \\
\hline $32-3$ & 5,15 & 4,80 & 0,0076 \\
\hline $32-4$ & 4,80 & 7,25 & 0,1176 \\
\hline $1-17$ & 7,25 & 6,25 & 0,0052 \\
\hline $35-1$ & 0,90 & 6,25 & 0,0946 \\
\hline $36-1$ & 0,90 & 6,25 & 0,1670 \\
\hline $1-18$ & 6,25 & 4,35 & 0,0053 \\
\hline $1-19$ & 4,35 & 5,20 & 0,0053 \\
\hline $38-1$ & 0,90 & 5,20 & 0,1525 \\
\hline $1-20$ & 5,20 & 0,90 & 0,0082 \\
\hline $2-13$ & 2,20 & 5,60 & 0,0054 \\
\hline $82-2$ & 0,90 & 6,90 & 0,0111 \\
\hline $82-3$ & 6,90 & 4,30 & 0,0087 \\
\hline $82-5$ & 0,90 & 5,60 & 0,1633 \\
\hline $2-14$ & 5,60 & 3,85 & 0,0050 \\
\hline
\end{tabular}

Fonte: Autor (2019).

\subsection{Comparação entre velocidade final e critica para atender a tensão trativa}

Em 66 trechos a velocidade final ficou maior que a crítica, sendo necessário verificar quais pontos não atendiam a tensão trativa de 1,0 Pa. Após a verificação, constatou-se que em 31 trechos a tensão trativa estava abaixo do estipulado pela NBR 9649 e pelas diretrizes da CORSAN, necessitando de uma análise da tensão trativa, para que esta não ultrapassasse 0,50 da lâmina líquida, desta forma garantindo a autolimpeza das tubulações, em que os pontos que necessitaram de ajustes na tensão trativa podem ser visualizados na Tabela 18. 
A maior velocidade final encontrada na rede foi de $2,87 \mathrm{~m} / \mathrm{s}$ no trecho $15-1$, portanto todas as velocidades atenderam as diretrizes da CORSAN e da NBR 9649, não ultrapassando o máximo de $5,00 \mathrm{~m} / \mathrm{s}$, em que a velocidade estando dentro dos limites estipulados diminui o problema com manutenções da rede, por conta de danificações de tubulações.

Tabela 18 - Trechos com tensão trativa ajustada para atender 1,0 Pa

\begin{tabular}{ccccc}
\hline Trecho & $\begin{array}{c}\text { Lâmina } \\
\text { Líquida (Y/D) }\end{array}$ & $\begin{array}{c}\text { Velocidade } \\
\text { Final (Vf) }\end{array}$ & $\begin{array}{c}\text { Tensão } \\
\text { Trativa }\end{array}$ & $\begin{array}{c}\text { Velocidade } \\
\text { Crítica (Vc) }\end{array}$ \\
\hline $\mathbf{1 - 2}$ & 0,100 & 0,625 & 1,0267 & 1,841 \\
$\mathbf{1 - 4}$ & 0,125 & 0,567 & 1,0427 & 2,046 \\
$\mathbf{4 - 1}$ & 0,050 & 0,886 & 1,0645 & 1,322 \\
$\mathbf{6 - 1}$ & 0,050 & 0,865 & 1,0142 & 1,322 \\
$\mathbf{1 0 - 1}$ & 0,050 & 0,861 & 1,0047 & 1,322 \\
$\mathbf{9 - 3}$ & 0,100 & 0,635 & 1,0599 & 1,841 \\
$\mathbf{9 - 5}$ & 0,150 & 0,492 & 9,2725 & 7,019 \\
$\mathbf{1 9 - 1}$ & 0,075 & 0,723 & 1,0326 & 1,595 \\
$\mathbf{2 0 - 1}$ & 0,050 & 0,873 & 1,0341 & 1,322 \\
$\mathbf{3 4 - 1}$ & 0,050 & 0,863 & 1,0101 & 1,322 \\
$\mathbf{3 2 - 3}$ & 0,150 & 0,526 & 1,0578 & 2,220 \\
$\mathbf{3 9 - 2}$ & 0,075 & 0,724 & 1,0350 & 1,595 \\
$\mathbf{2 - 3}$ & 0,150 & 0,531 & 1,0799 & 2,220 \\
$\mathbf{2 - 5}$ & 0,200 & 0,448 & 1,0003 & 2,532 \\
$\mathbf{4 1 - 1}$ & 0,050 & 0,866 & 1,0164 & 1,322 \\
$\mathbf{4 4 - 1}$ & 0,050 & 0,866 & 1,0171 & 1,322 \\
$\mathbf{4 5 - 4}$ & 0,175 & 0,490 & 1,0582 & 2,381 \\
$\mathbf{4 9 - 4}$ & 0,200 & 0,473 & 1,1130 & 2,532 \\
$\mathbf{5 8 - 1}$ & 0,050 & 0,867 & 1,0192 & 1,322 \\
$\mathbf{5 9 - 1}$ & 0,050 & 0,879 & 1,0495 & 1,322 \\
$\mathbf{6 0 - 1}$ & 0,050 & 0,867 & 1,0206 & 1,322 \\
$\mathbf{6 2 - 1}$ & 0,050 & 0,875 & 1,0377 & 1,322 \\
$\mathbf{6 5 - 1}$ & 0,050 & 0,865 & 1,0146 & 1,322 \\
$\mathbf{6 2 - 5}$ & 0,200 & 0,456 & 1,0362 & 2,532 \\
$\mathbf{7 3 - 1}$ & 0,050 & 0,881 & 1,0522 & 1,322 \\
$\mathbf{6 8 - 4}$ & 0,200 & 0,462 & 1,0604 & 2,532 \\
$\mathbf{7 4 - 1}$ & 0,050 & 1,099 & 1,6393 & 1,322 \\
$\mathbf{7 5 - 4}$ & 0,150 & 0,518 & 1,0243 & 2,220 \\
$\mathbf{7 8 - 1}$ & 0,050 & 0,882 & 1,0556 & 1,322 \\
$\mathbf{8 2 - 2}$ & 0,100 & 0,636 & 1,0635 & 1,841 \\
$\mathbf{8 2 - 3}$ & 0,125 & 0,565 & 1,0358 & 2,046 \\
\hline $\mathbf{F} 05 \mathbf{A}$ & $\mathbf{2 0 1 9 ) .}$ & & & \\
\hline
\end{tabular}

Fonte: Autor (2019). 


\subsection{Critérios da tensão trativa}

Nos 31 trechos mencionados acima, em que a tensão trativa ficou abaixo do valor mínimo estipulado pela NBR 9649 (ABNT, 1986) de 1,0 Pa, foi necessário o aprofundamento do coletor, para atender o valor mínimo para tensão trativa, acarretando em maiores custos de implantação, mas garantindo a operação do sistema.

Para metade dos pontos foi necessário o aprofundamento de até $50 \mathrm{~cm}$. Em outros dois pontos o aprofundamento chegou a $90 \mathrm{~cm}$, e os demais necessitaram de aprofundamento de $1,00 \mathrm{~m}$ ou mais do determinado pela declividade. $O$ ponto que precisou de maior aprofundamento foi o 9-3, chegando a 1,35 $\mathrm{m}$ a mais do estipulado pela declividade.

\subsection{Determinação da ETE}

O local definido para a implantação da Estação de Tratamento de Esgoto foi pensando por questão topográfica, situando-se em um ponto baixo da cidade para facilitar o escoamento dos efluentes, e também por ser próximo ao Arroio Barracão possibilitando o descarte da água tratada em seu leito, sendo em um local retirado da área com maior densidade populacional, para evitar problemas com odores, podendo analisar sua disposição na Figura 15. 
Figura 14 - Localização da estação de tratamento

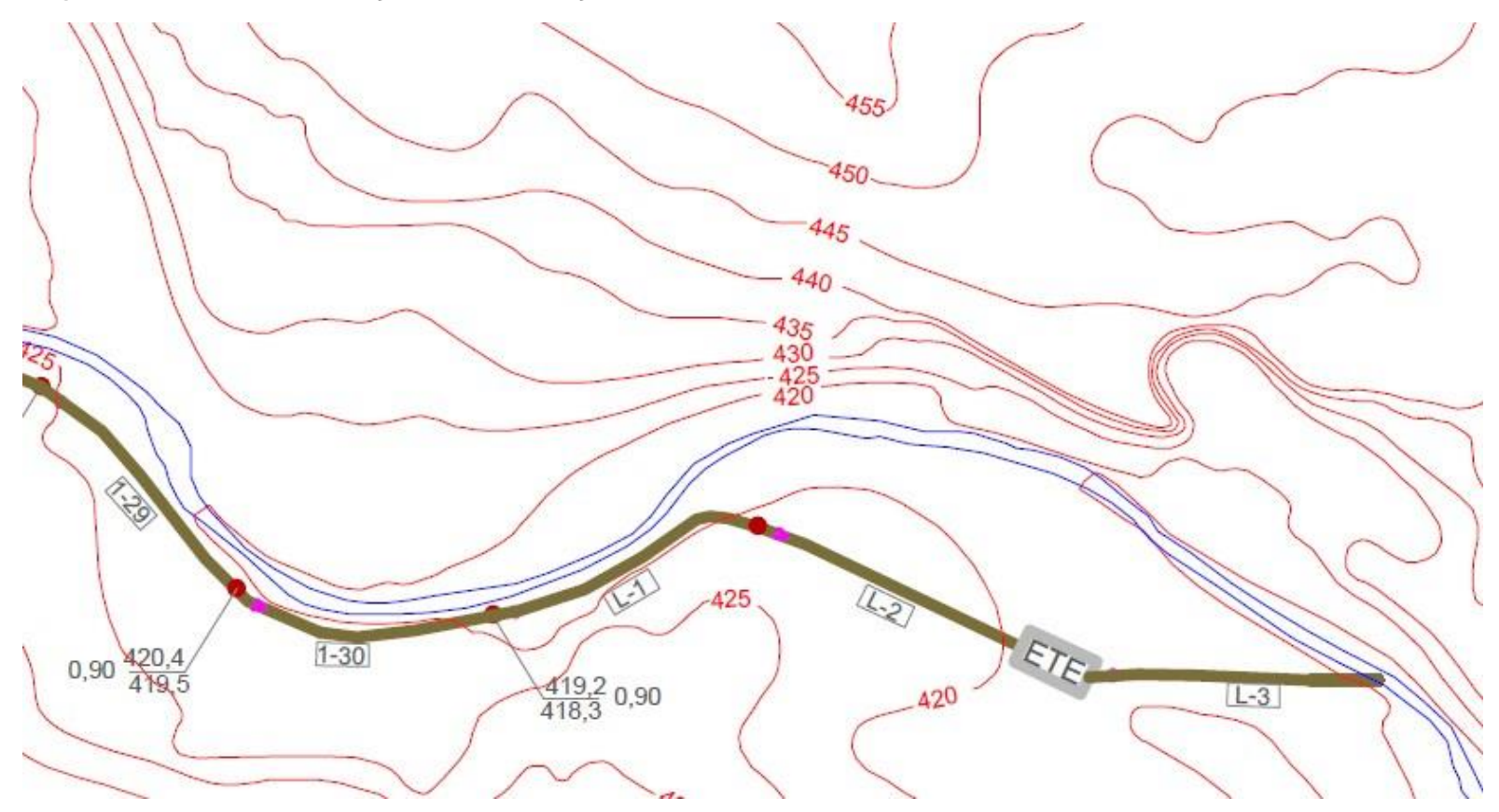

Fonte: Autor (2019).

A estação de tratamento é composta por três interceptores de 100 m cada, em que dois são do percurso até a chegada à ETE e um até despejar a água no arroio, e sua vazão final é de $21,38 \mathrm{~L} / \mathrm{s}$, podendo ser verificado no Anexo $\mathrm{F}$.

\subsection{Custos da rede coletora}

Tendo para o diâmetro de $150 \mathrm{~mm}$ o equivalente a 16.426 metros, e sendo seu custo ao metro linear de $R \$ 307,03$, o valor para a rede coletora de esgoto neste diâmetro é de $\mathrm{R} \$ 5.043 .274,78$ Já para o diâmetro de $200 \mathrm{~mm}$ tem-se o equivalente a 646 metros, e o seu custo de $R \$ 336,39$ ao metro linear, gerando um custo de $R$ \$ 217.307,94 para este diâmetro. Portanto, o custo de implantação da rede coletora de esgoto é de $R \$ 5.260 .582,72$, mas vale ressaltar que a estimativa deste valor é apenas para a rede, não contabilizando custos dos demais setores para esta obra. 


\section{CONSIDERAÇÕES FINAIS}

A realização deste estudo foi para apontar uma alternativa viável de uma rede coletora para sistema de esgotamento sanitário na cidade de Guaporé/RS. A escolha para realizar este estudo se deu devido ao fato que o município não possui um sistema de esgotamento sanitário, em que o esgoto é disposto em corpo receptor sem nenhum tratamento, deixando a população exposta a contaminações, prejudicando a qualidade de vida e danificando as condições ambientais locais.

Tendo por base as revisões bibliográficas, bem como materiais e informações coletadas nos órgãos públicos do município, foi possível realizar o diagnóstico da situação de Guaporé em várias maneiras para a formulação de um estudo de concepção.

O projeto de um sistema de saneamento demanda tempo e ponderações em diversos quesitos, tais como: local em estudo, recursos financeiros, população, necessidades da localidade, etc. Deste modo, este estudo elencou os passos iniciais para uma possível execução do mesmo, tendo por base a bibliografia e a normativa, juntamente ao Plano de Saneamento da cidade.

Para atender a demanda de onde localiza-se a bacia do Arroio Barracão foram traçados 17.072 metros de trechos a serem construídos para a coleta do esgoto gerado pela população do bairro centro em que o sistema abrange, com diâmetro igual ao mínimo exigido pela CORSAN na maior parte de sua extensão e disposta em rede simples à, no mínimo $0,90 \mathrm{~m}$ de profundidade da cota estabelecida em levantamento altimétrico. Percebe-se que em uma possível execução das obras propostas haverá 
diversas dificuldades, visto que em alguns pontos da rede houve um aprofundamento muito alto, sendo necessário a instalação de sistema de bombeamento, gerando acréscimo de encargos financeiros para a execução dos mesmos. Foi realizada a projeção de uma ETE, num ponto retirado da área com maior densidade populacional, avaliando as cotas altimétricas e principalmente pensando em um local de possível aquisição e que não gere odores para a área urbana da cidade, e ficando próxima a margem do Arroio Barracão, facilitando o descarte da água tratada em seu próprio leito.

Após chegar aos resultados finais do processo de cálculos do dimensionamento da rede coletora de esgoto para a cidade de Guaporé, e após a realização de uma avaliação de custos de implantação desta rede num valor estimado em $\mathrm{R} \$ 5.260 .582,72$ pode-se dizer que o presente trabalho serve de base para a posterior realização do projeto executivo e implantação do sistema de esgotamento no município, colaborando para o progresso da infraestrutura de saneamento básico em Guaporé e, por conseguinte, para garantir a recuperação do meio ambiente e qualidade de vida dos habitantes. 


\section{REFERÊNCIAS BIBLIOGRÁFICAS}

ABES: Associação Brasileira de Engenharia Sanitária e Ambiental/SC. Saneamento em Santa Catarina X Investimento Pac, 2008.

ASSOCIAÇÃO BRASILEIRA DE NORMAS TÉCNICAS. NBR 9648: Estudo de concepção de sistemas de esgoto sanitário. Rio de Janeiro - RJ, 1986.5 p.

ASSOCIAÇÃO BRASILEIRA DE NORMAS TÉCNICAS. NBR 9649: Projeto de redes coletoras de esgoto sanitário. Rio de Janeiro - RJ, 1986. 7 p.

ASSOCIAÇÃO BRASILEIRA DE NORMAS TÉCNICAS. NBR 13133: Execução de levantamento topográfico. Rio de Janeiro - RJ, 1994. 35 p.

ABNT: ASSOCIAÇÃO BRASILEIRA DE NORMAS TÉCNICAS. NBR 14486: Sistemas enterrados para condução de esgoto sanitário - Projeto de redes coletoras com tubos de PVC. Rio de Janeiro - RJ, 2000.19 p.

ARRETCHE, M. T. S. Saneamento Básico. Disponível em:

<http://www.tecsi.fea.usp.br/eventos/Contecsi2004/>. Acesso em 2019.

AZEVEDO NETTO, J. M.; FERNANDEZ, M. F.; ARAÚJO, R.; ITO, A. E. Manual de Hidráulica. 8.ed. São Paulo: Editora Edgard Blücher, 1998.

BARATTA, Cleto Augusto Monteiro. Caracterização do Esgotamento Sanitário de Teresina: Eficiência, Restrições e Aspectos Condicionantes. 2004. 215 f. Dissertação (Mestrado em Desenvolvimento e Meio Ambiente) - Núcleo de Referência 
em Ciências Ambientais do Trópico Ecotonal do Nordeste, Universidade Federal do Piauí, Teresina, 2004.

BARROS, R. T. V. et al. Saneamento - Manual de saneamento e proteção ambiental para os municípios. Belo Horizonte: Escola de Engenharia da UFMG, 1995. v. II.

BARROSO, Luis Roberto. Saneamento básico, competências constitucionais da União, Estados e Municípios. Revista Diálogo Jurídico, Salvador, CAJ - Centro de Atualização Jurídica, n. 13, abr./ maio de 2002.

BELLI FILHO, B.; SOARES, H. M.; MATIAS, W. G.; PINTO; R. O.; CHARGAS, A.; CASTILHO JR, A. B. Digestão Anaeróbia de Resíduos Sólidos Orgânicos e Lodo de Tanque Séptico. Universidade Federal de Santa Catarina, Brasil, 2002.

BORGES, A. C. Topografia. São Paulo: Blucher, 1977.

BRASIL. Decreto no 7.217, de 21 de junho de 2010. Regulamenta A Lei no 11.445, de 5 de Janeiro de 2007, Que Estabelece Diretrizes Nacionais Para O Saneamento Básico, e Dá Outras Providências. Brasília, DF, 2010.

BRASIL. Lei no 11.445, de 05 de janeiro de 2007. Estabelece Diretrizes Nacionais Para O Saneamento Básico; Altera As Leis nos 6.766, de 19 de Dezembro de 1979, 8.036, de 11 de Maio de 1990, 8.666, de 21 de Junho de 1993, 8.987, de 13 de Fevereiro de 1995; Revoga A Lei no 6.528, de 11 de Maio de 1978; e Dá Outras Providências. Brasília, DF, 2007.

BRASIL. Ministério das Cidades. Secretaria Nacional de Saneamento Ambiental. Diagnóstico de Serviços de Água e Esgoto - 2012. Disponível em:<http://www.snis.gov.br. Acesso em: abril de 2019.

BRASIL. Ministério da Saúde. Sistema de Informações da atenção Básica 2013. Disponível em: <www2.datasus.gov.br/SIAB> Acesso em: agosto de 2019.

CORSAN. Companhia Riograndense de Saneamento. OS 601/05 - Estudo de Concepção do Sistema de Esgotos Sanitários de Bento Gonçalves. Porto Alegre, RS, jul. 2009, fotocópia p. 132. 
CORSAN. Companhia Riograndense de Saneamento. Informações primárias e secundárias: Unidade de Guaporé. Brasil. Estado do Rio Grande do Sul, 2016.

FARIA, Caroline, 19 de julho de 2007. Tratamento de esgoto. Disponível em: $<$ http://www.infoescola.com/geografia/tratamento-de-esgoto>.

FEE. Porto Alegre: FEE, 2017. Disponível em: <http://atlas.fee.tche.br/rio-grande-dosul/socioambiental/saneamento/ >. Acesso em: 4 de maio de 2019.

FERREIRA, P. MARTINS, J. "Crescimento econômico e consumo de água - uma abordagem para planejamento de sistemas." In: 23ํㅡㄹ Congresso Brasileiro de Engenharia Sanitária e Ambiental. Anais... ABES, Campo Grande/MS, 2005.

FUNASA, Fundação Nacional de Saúde. Manual de saneamento. Brasília, $3^{a}$ edição, 2006.

FUNASA, Fundação Nacional de Saúde. Manual de saneamento. Brasília, 4를 edição, 2015.

HANAI, F. Y.; CAMPOS, J.R. Avaliação da Infiltração na Rede Coletora de Esgotos na Bacia do Ribeirão do Ouro da Cidade de Araraquara-SP. In: $19^{\circ}$ Congresso Brasileiro de Engenharia Sanitária e Ambiental. Foz do Iguaçú, set. 1997, 14p.

GUAPORÉ (2017). Plano Municipal de Saneamento de Saneamento Básico. Relatório Contento a Versão Final do Plano de Saneamento Básico. 2017. 645 f. Prefeitura Municipal de Guaporé - RS, 2017.

IBGE. Pesquisa Nacional por Amostra de Domicílios (PNAD), 2010; Disponível em: http://censo2010.ibge.gov.br/. Acesso em: 23/02/2019.

IBGE - INSTITUTO BRASILEIRO DE GEOGRAFIA E ESTATÍSTICA. Censo Demográfico de 2010. 2013. Disponível em http://censo2010.ibge.gov.br/. Acesso em 15 mar. 2019.

IBGE - INSTITUTO BRASILEIRO DE GEOGRAFIA E ESTATÍSTICA. Atlas de Saneamento 2011. Rio de Janeiro: IBGE, 2011a. Disponível em http://www.ibge.gov.br/. Acesso em 02/05/2019 
IBGE - INSTITUTO BRASILEIRO DE GEOGRAFIA E ESTATÍSTICA. Pesquisa de Informações Básicas Municipais 2012. Disponível em http://www.ibge.gov.br/. Acesso em: 02/05/2019.

IBGE - Instituto Brasileiro de Geografia e Estatística. Território e Ambiente 2017. Rio Grande do Sul: IBGE 2017. Disponível em: <http://www.ibge.gov.br/>.

KOBIYAMA, M. et al. Recursos hídricos e saneamento. Curitiba: Organic Trading, 2008.

KNAPIK, H. G.; CUBAS, S. Coleta e Tratamento de Esgotos. Qualidade e Conservação ambiental - TH041. Engenharia Civil e Ambiental. Universidade Federal do Paraná. Paraná, 2016.

LEONETI, A. B.; PRADO, E. L.; OLIVEIRA, S. V. W. B. Saneamento Básico no Brasil: Considerações sobre Investimentos e Sustentabilidade para o Século XXI. Revista de Administração Pública, Rio de Janeiro, 2011.

METCALF \& EDDY. Wastewater engineering, treatment, disposal and reuse. $3^{a}$.ed. Nova lorque: McGraw - Hill, International Editions. 1991.

MONTEIRO JUNIOR, Adriano Pires; RENDEIRO NETO, Henrique Fernandes. Sistema Individual de Tratamento de Esgoto. 2011. 97 f. TCC (Graduação) - Curso de Engenharia Civil, Universidade da Amazônia - UNAMA, Belém - PA, 2011.

NETTO, Azevedo; FERNÁNDEZ, Miguel Fernández y. Manual de Hidráulica. 9. ed. São Paulo: Blucher, 2015.

NUVOLARI, A. Esgoto Sanitário, Coleta Transporte, Tratamento e Reuso Agrícola. Editora Edgard Blücher, São Paulo, Brasil, 2ª edição, 2011.

NUVOLARI, Ariovaldo. Esgoto Sanitário: Coleta, transporte, tratamento e reuso agrícola. 2. ed. São Paulo, Blücher, 2014.

OLIVEIRA, M. V. C. de. CARVALHO, A. R. Princípios Básicos de Saneamento do meio. São Paulo. Editora Senac, 2003. 
PACHECO, R. P. Custos para implantação de sistemas de esgotamento sanitário. 2011. 149p. Dissertação (Engenharia de Recursos Hídricos), Universidade Federal do Paraná, Curitiba, 2011.

PEREIRA, José Almir Rodrigues (Org.). Saneamento Ambiental em Áreas Urbanas: esgotamento Sanitário na Região Metropolitana de Belém. Belém: NUMA/UFPA/EDUFPA, 2003.

PEREIRA, José Almir Rodrigues. Rede Coletora de Esgoto Sanitário: Projeto, Construção e Operação. 2. Ed. rev. e ampliada. Universidade Federal do Pará, 2006.

PEREIRA, H. S.; SILVA, S. S. F.; SOUZA, V. C. Saneamento Básico e seus Impactos na Saúde Pública no Brasil. In: Bruno Soares de Abreu; Ireneide Gomes de Abreu; Pollyana de Abreu Morais. (Org.). Meio Ambiente, Sociedade e Desenvolvimento: Uma Abordagem Sistêmica do Comportamento Humano. 1ed. Campina Grande: EDUFCG, 2010.

RECESA. Esgotamento sanitário: Projetos e construção de sistemas de esgotamento sanitário: guia do profissional em treinamento: nível 2. Salvador, 2008.

REZENDE, S. C; HELLER. L. O saneamento no Brasil: políticas e interfaces. Universidade Federal de Minas Gerais, Belo Horizonte, 2002.

SAKER, João Paulo Pellegrini. Saneamento Básico e Desenvolvimento. Dissertação (mestrado em Direito Político e Econômico) - Universidade Presbiteriana Mackenzie, São Paulo, 2007.

SANTANA, Henrique Batista de. A Importância do Saneamento Básico na Área Urbana do Município de São João do Rio do Peixe, com um Enfoque no Esgotamento Sanitário. 2014. 67 f. TCC (Graduação) - Curso de Licenciatura em Geografia, Universidade Federal da Campina Grande, Cajazeiras - PB, 2014.

SANTOS, André Bezerra dos. Avaliação Técnica dos Sistemas de Tratamento de Esgotos. Fortaleza: Banco do Nordeste do Brasil. 2007. 
SOUZA, Maria Salete de. Meio Ambiente Urbano e Saneamento Básico. Departamento de Geografia da Universidade Federal do Ceará. Mercator. Revista de Geografia, ano 01, n. 01, 2002.

SNIS - Sistema Nacional De Informações Sobre Saneamento. Diagnóstico dos Serviços de Água e Esgotos. Ministério das Cidades, 2010.

TAKAHASHI, A. Sulfetos em interceptores de esgotos: ocorrência, medidas preventivas e corretivas. São Paulo, 1983. Dissertação (Mestrado em Engenharia) - Escola Politécnica, Universidade de São Paulo.

TELLES, JAMILLA REGINA. Dimensionamento de Rede de Esgoto Sanitário Considerando o Uso de Diâmetros não Progressivos Calculados com o Programa SANCAD. Palhoça, 2014. Universidade do Sul de Santa Catarina UNISUL, 2014.

TISCOSKI, C.L.; Brasil. Ministério das Cidades. Secretaria Nacional de Sanemanto Ambiental Programa de Educação Ambiental e Mobilização Social em Saneamento. Caderno metodológico para ações de educação ambiental e mobilização social em saneamento. Brasília, 2009.

TSUTIYA, M. T., \& SOBRINHO, P. A. Coleta e Transporte de Esgoto Sanitário. São Paulo: Departamento de Engenharia Hidráulica e Sanitária da Escola Politécnica da Universidade de São Paulo, 2000.

TSUTIYA, Milton Tomoyuki; SOBRINHO, Pedro Além. Coleta e Transporte de Esgoto Sanitário. 3. Ed. Rio de Janeiro: Abes, 2011.

VON SPERLING, M. Introdução à Qualidade das Águas e ao Tratamento dos Esgotos Vol.1. Belo Horizonte, UFMG, 1995.

VON SPERLING, Marcos. Princípios do Tratamento Biológico de Águas Residuárias. 1996. 2 v. Departamento de Engenharia Sanitária - UFMG. Belo Horizonte - MG, 1996.

VON SPERLING, Marcos. Princípios do tratamento biológico de águas residuárias. 2005. Volume 1. Introdução à Qualidade das Águas e ao Tratamento de 
Esgotos. 3를 Edição. Departamento de Engenharia Sanitária e Ambiental - UFMG. Belo horizonte - MG, 2005.

Wagner, V.R.; Balsan, L.A.G.; Moura, G.L. Saneamento básico: gestão de serviços de esgoto em um município. Contribuciones a las Ciencias Sociales, Espanha, s.n, 2013. 


\section{ANEXOS}




\section{ANEXO - A}

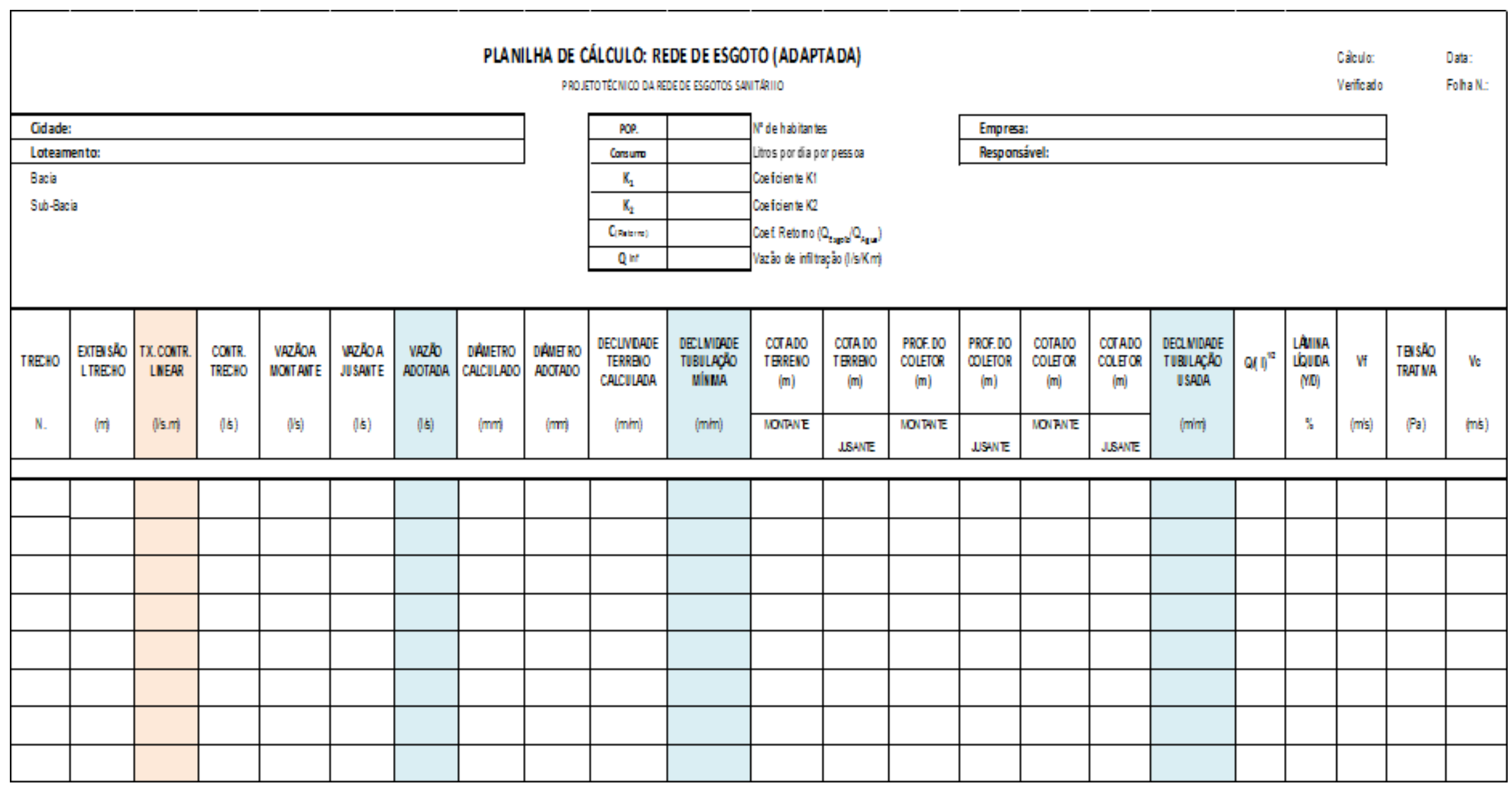

Fonte: Adaptada da CORSAN (2019). 
ANEXO - B

n 0,01

\begin{tabular}{|c|c|c|c|c|c|c|c|c|c|c|c|c|c|c|c|c|c|c|c|c|c|}
\hline met ro & $1 / 10$ & 0,050 & 200 & 0.150 & 200 & 250 &, 300 & 0,350 & 0,400 & 0,450 & 0,500 & 0,550 & 0,600 & 0,650 & 0,700 & 0,750 & 0,800 & , 500 & 0,900 & 0.950 & 2,000 \\
\hline \multirow{2}{*}{100} & $v /(1)^{\wedge 1}$ & 2,196 & 3,430 & 4,418 & 5,259 & 5,991 & 6,686 & 7,207 & 7,713 & 8,160 & 8,550 & 8,856 & 9,169 & 9,399 & 9,574 & 9,691 & 9,745 & 9,725 & 9,613 & 9,362 & 8,550 \\
\hline & $Q /(1)^{11}$ & .00032 & 0,00140 & 0,00326 & 00588 & .00920 & 0,01315 & 2,01766 & 0,02263 & 02797 & 0,03358 & 0,03933 & 04511 & 0,0507 & 0,05622 & 0,06123 & 0,06564 & 06919 & 0,07157 & 0,07215 & 0,06715 \\
\hline \multirow[t]{2}{*}{150} & & 2,878 & 4,494 & 5,790 & 6,891 & 7,850 & 8,695 & 9,444 & 10,107 & 10,692 & 11,204 & 11,644 & 12,015 & 12,316 & 12,545 & 12,699 & 12,769 & 12,743 & 12,596 & 12,268 & 11,204 \\
\hline & $a /(1)$ & 0,0010 & 0,0041 & 0,0096 & 1173 & 0,0271 & 0388 & 1521 & 0,0667 & 825 & 0,0990 & 0,1160 & 330 & 2495 & 0,1658 & .805 & 0,1935 & 2040 & 2110 & 127 & 80 \\
\hline \multirow{2}{*}{200} & & & 5,445 & 7,014 & 8,348 & 9,510 & 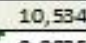 & & $2,2$. & & & & & & & & & & & & \\
\hline & & & 0,0089 & & & 0,0584 & 0,0835 & & 0,14 & 0,1776 & & 97 & & & Q: & 8 & 0,4168 & & & 0,4582 & $0,4=$ \\
\hline \multirow[t]{2}{*}{250} & & 4,046 & 6,318 & 8,139 & $\begin{array}{l}9,6677 \\
977\end{array}$ & 035 & 12,223 & 13,276 & 14,208 & 15,030 & 15,749 & 68 & 50 & & 17,6 & 851 & 17,950 & 17,913 & & 245 & 15,749 \\
\hline & & & 0,0161 & & & & & & & 0,3220 & 0,3365 & 528 & 194 & & & 050 & 7557 & & & & 0,7731 \\
\hline \multirow{2}{*}{300} & & & 7,134 & 9,191 & 10,939 & 151 & 13,503 & 14,992 & 15,045 & 16,973 & 784 & 15,454 & & 550 & 19,915 & 158] & 270 & & 19,995 & 19,474 & 17,784 \\
\hline & & & 0,0262 & & & & 0,2452 & & 0.4236 & & & & & & 1,0525 & 463? & 2285 & & & & \\
\hline 350 & & $\begin{array}{r}5,063 \\
0,0091\end{array}$ & $\begin{array}{r}7,907 \\
0,0396\end{array}$ & $\frac{10,186}{0,0922}$ & $\frac{12,122}{0,1651}$ & $\frac{13,510}{0,2598}$ & $\frac{15,297}{0,3713}$ & $\frac{15,624}{0,4956}$ & $\frac{17,781}{0,6390}$ & \begin{tabular}{|c|c|}
18,810 \\
0,7898
\end{tabular} & $\frac{19,709}{0,9451}$ & $\frac{0,454}{1107}$ & & .656 & $\frac{22,070}{15876}$ & $\frac{22,340}{1,7292}$ & $\frac{22,464}{1.2535}$ & $\frac{22,418}{1,9540}$ & $\frac{22,159}{2,0210}$ & $\frac{21,581}{2,0376}$ & $\begin{array}{ll}19,709 \\
1,8963\end{array}$ \\
\hline \multirow{2}{*}{400} & & & 8,643 & 1,134 & 251 & 0.95 & 6,721 & 18,169 & & & & 2,391 & 105 & & & & & & & & \\
\hline & & 0,0130 & 565 & 311. & $\sqrt{37}$ & 3709 & 79 & 0,71 & ל123 & 1277 & 35: & 58 & & & & & & & & & 073 \\
\hline \multirow{2}{*}{450} & & 5,987 & 9,349 & 12,04 & 14,3 & 16,329 & 8,087 & 19,6 & & 2,241 & 3,3 & 8,2 & & & & & & & & & \\
\hline & $\bar{a}$ & 0,0178 & 0,0774 & 0,1802 & 0,324 & 0,5077 & $\frac{0,7258}{10}$ & 0,974 & 1,2490 & 5435 & 1,853 & 1709 &, 4901 & $\infty$ & 1,103 &, 3796 & 5 & & & & 7054 \\
\hline \multirow{2}{*}{500} & $\mathrm{~V}_{1}$ & 6,422 & 10,02 & 12,920 & 15,3 & 7,51 & 9,40 & & & & $5,0,0$ & 25,9 & & & & & & & & & \\
\hline & $a /(1)^{n}$ & 0,0236 & 0,1025 & 0,2356 & 0,429 & 62 & 0,9613 & 1,290 & 1,6542 & 2,0446 & 2,4544 & 2,87 & 2.2979 & 7130 & 4,109 & 4,4762 & 4,796 & 5058 & & 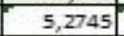 & 9087 \\
\hline \multirow{2}{*}{600} & $v /(1)^{n} 1 / 2$ & 7,252 & 11,325 & 14,59 & 17,36 & 19,781 & 21,911 & 23,78 & 25,46 & 26,943 & 28,231 & 29,3 & 30,276 & 1,0 & 31,6 & 31,999 & {$[, 17$} & 3 & 31. & 0,913 & 8,231 \\
\hline & & & & & & & & & & & & & & & & & & & & & \\
\hline \multirow{2}{*}{700} & $\mathrm{v} / \mathrm{d}$ & 8,037 & 12,551 & 15,169 & 24 & 21,92 & 24,283 & 26,39 & 28,22 & 29,559 & & 2,5 & 33,4 & & 35,0 & & & & & & 1,287 \\
\hline & & & 251. & & & & & & & & & & & & & & & & & & \\
\hline \multirow{2}{*}{800} & & 8,786 & 13,719 & $17,674 \mid$ & .03 & 1,96 & 6,543 & 28,$82 ;$ & 2,55 & 32. & 34,20 & 5,5 & & & 88,2 & 38,764 & & & & & , \\
\hline & & & 15899] & & 0.5 & & & & & & 8,5 & 06 & & & & & & $x, 1$ & & & \\
\hline \multirow{2}{*}{900} & & 9,503 & 1,540] & 19,113 & .75 &, 92 & 28,712 & 1,15 & 3,37 & 35,305 & 36,993 & 8,445 & 9,672 & & .42 & $1,93$. & $12,16:$ & & & & 36,993 \\
\hline & & 130 & 913] & & & 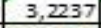 & 6008 & & & 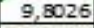 & 2 & & & & $\pi$ & & & & & & \\
\hline \multirow{2}{*}{1000} & & & 9200 & 509 & & & 00,501 & & & 7,874 & $9,68: 5$ & & & & & & & & & & \\
\hline & & 497 & 5507 & 151] & 29 & 6595 & & & & & & & & & & & & & & & \\
\hline \multirow{2}{*}{1200} & & & , & 159 & 563 & $\Delta 00$ & 1,782 & & 0,43 & 2,769 & 44,514 & 5,575 & 8,060 & 9,264 & $0,18:$ & 2,796 & & & & & \\
\hline & & 2434 & 5832 & 637) & 384 & & 125 & & 799 & 12 & $5,3$. & 56 & & & & & & 226. & & & 50,6335 \\
\hline \multirow{2}{*}{1400} & & 5.8 & . & & 34 & 79.5 & 546 & & & $7,39.9$ & 664 & & & & & 6,293 & & & & & \\
\hline & & 71 & 5962 & 71636 & & 1726 & 718 & & & , 84477 & 262 & 90 & & & & 7153] & & & & & \\
\hline \multirow[t]{2}{*}{1600} & & 1,946 & $\frac{2}{7}$ & 23,056 & & 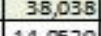 & $\frac{42,135}{3756}$ & 764 & & & 54 & 23 & 20 & 79 & $\begin{array}{l}0,791 \\
3, \sqrt[0]{3}\end{array}$ & 1,534 & $\begin{array}{r}61,875 \\
1006933\end{array}$ & $\frac{61,749}{2,475}$ & 037 & 59,445 & \\
\hline & & 15086 & 23,557 & 30,347 & & .14 & 45,577 & 49,502 & & 5,06 & & 61,032 & - & & 65,757 & 56,561 & (3) & 66,7 & & t & $\begin{array}{c}09,1552 \\
58,723\end{array}$ \\
\hline \multirow{4}{*}{$\begin{array}{l}1800 \\
20000\end{array}$} & & 0,7 & 3,1 & & & 2 & 29 & & 50,3 & & & & & & & 36 & & & & & \\
\hline & & 16,183 & 25,2 & 32,5 & 38,7 & 44,139 & 48,899 & 53,1 & 56,833 & 60 & & 65, & $67,55 \mathrm{~B}$ & & 70,541 & 71,404 & 71,799 & 71,653 & 827] & 68 & \\
\hline & $\alpha /\left(\|^{n} 1 / 2\right.$ & 0,990 & 4,132 & 9,620 & 17,331 & 27,110 & 35,757 & 52,038 & 66,693 & 82,435 & 98,954 & 17 & 132,963 & 149,699 & 165,695 & \begin{tabular}{|l|l|}
150,466 \\
\end{tabular} & 193,448 & 203,932 & 210,930 & 212,655 & 197 \\
\hline & & 0,033 & 0,064 & 0,093 & 0,121 & 0,147 & 0,171 & 0,193 & 0,214 & 0,233 & 0,250 & 0,265 & 0,278 & 0,288 & 0,296 & 0,302 & 0,304 & 0,303 & 0,298 & 0,286 & 0,250 \\
\hline & & & & & & & & & & & & & & & & 189 & & & & & \\
\hline$a$ & & & & & & & & & & & & & & & & & & & & & \\
\hline
\end{tabular}
Fonte: Tsutiya (2000). 


\section{ANEXO - C}

\begin{tabular}{|c|c|c|c|c|c|c|c|c|c|c|c|c|c|c|c|c|c|c|c|c|c|}
\hline & 0,013 & & & & & & & & & & & & & & & & & & & & \\
\hline Diâmetro & $y / D$ & 250 & 100 & 0,150 & 0,200 & 250 & 0,300 & 0,350 & $a_{1}$ & 0,450 & 0,500 & 0,550 & 0,600 & 0,650 & 0,700 & 0,750 & 0,800 & 250 & 0,900 & 95 & ( \\
\hline \multirow{2}{*}{100} & $v /(1)^{\wedge 1 / 2}$ & 1,690 & 2,638 & 3,399 & 4,045 & 4,608 & 5,105 & 5,544 & 5,933 & 6,277 & 6,577 & 6,835 & 7,053 & 7,230 & 7,365 & 7,455 & $\begin{array}{ll}7,496 \\
\end{array}$ & 7,481 & 7,394 & 7,202 & 6,577 \\
\hline & $Q /(1)^{\wedge 1 / 2}$ & , 00025 & 0,00108 & 0,00251 & 0,00452 & 2,00708 & 0,01012 & 0,01358 & 2,01741 & 0,02152 & 2,02583 & 0,03025 & 0,03470 & 0,03907 & 0,04325 & 0,04710 & 05049 & 05323 & 0,05505 & 0.05550 & 2,05165 \\
\hline \multirow{2}{*}{150} & $1 / 2$ & 2,214 & 3,457 & 4,454 & 5,301 & 6,038 & 6,609 & 7,265 & 7,775 & 8,225 & 8,618 & 8,957 & 9,242 & 9,474 & 9,650 & 9,768 & 9,822 & 9,802 & 9,689 & 9,437 & 8,618 \\
\hline & $Q /(1)^{\wedge 1 / 2}$ & 0,0007 & 0,0032 & 0,0074 & 0,0133 & 0,0209 & 0,0298 & 0,0400 & 0,0513 & 0,0634 & 0,0761 & 0,0692 & 0,1023 & 0,1152 & 0,1275 & 0,1389 & 0,1489 & 0,1569 & 2,1623 & 0,1636 & 0,1523 \\
\hline \multirow{2}{*}{200} & $v /(1)^{\wedge 1 / 2}$ & 2,682 & $4,18 \mathrm{~B}$ & 5,395 & 6,421 & 7,315 & 8,103 & 8,801 & 9,419 & 9,964 & 10,440 & 0,851 & 11,196 & 11,477 & 11,691 & 11,834 & 11,899 & 11,875 & 1,738 & 1,432 & 10,440 \\
\hline & $Q /(1)^{\wedge 1 / 2}$ & 0,0016 & 0,0068 & 0,0159 & 0,0287 & 0,0449 & 0,0642 & 0,0862 & 0,1105 & 0,1366 & 0,1640 & ,1921 & 0,2204 & 0,2481 & 0,2746 & 2991 & 0,3206 & 0,3380 & 3496 &, 3524 & 3280 \\
\hline \multirow{2}{*}{250} & $v /(1)^{\wedge 1 / 2}$ & 3,112 & 4,860 & 6,261 & 7,451 & $\mathrm{~B}, 4 \mathrm{BB}$ & 9,403 & 10,212 & 10,929 & 11,562 & 12,115 & 12,591 & 12,992 & 13,318 & 13,566 & 13,732 & 13,808 & 13,780 & 3,621 & 13,265 & 2,115 \\
\hline & $Q /(1)^{\wedge 1 / 2}$ & 0,0029 & 0,0124 & 0,0289 & 0,0521 & 0,0815 & 0,1165 & 0,1564 & 0,2004 & 0,2477 & 0,2973 & 0,3483 & 0,3995 & 0,4498 & 0,4979 & 0,5423 & 0,5813 & 0,6128 & $0,633$. & 0,6390 &, 5947 \\
\hline \multirow{2}{*}{300} & $v /(1)^{\wedge 1 / 2}$ & 3,514 & $5,48 B$ & 7,070 & B,414 & 9,585 & 10,618 & 11,532 & 12,342 & 13,056 & 13,680 & 14,218 & 14,671 & 15,039 & 15,319 & 15,506 & 15,592 & 15,560 & 15,381 & 14,960 &, 6500 \\
\hline & $Q /(1)^{\wedge 1 / 2}$ & 0,0046 & 0,0202 & 0,0470 & 0,0847 & 0,1325 & 0,1894 & 0,2543 & 0,3259 & 0,4028 & 0,4335 & 0,5664 & 0,6497 & 0,7315 & 0,8096 & $0,8 \mathrm{~B} 18$ & 0,9452 & 0,9964 & 1,0306 & 1,0391 & 0,9670 \\
\hline \multirow{2}{*}{350} & $v /(1)^{\wedge 1 / 2}$ & 3,895 & 6,082 & 7,835 & 9,325 & 10,623 & 11,767 & 12,780 & 13,678 & 14,469 & 15,161 & 15,757 & 16,259 & 16,667 & 16,977 & 17,185 & $17,2 \mathrm{BO}$ & 17,245 & 17,046 & 16,601 & 5,161 \\
\hline & $Q /(1)^{\wedge 1 / 2}$ & 0,0070 & 0,0305 & 0,0709 & 0,1277 & 0,1998 & 0,2857 & 0,3835 & 0,4916 & 0,6076 & 0,7293 & 0,8544 & 0,9500 & 1,1033 & 1,2212 & 1,3301 & 1,4258 & 1,5031 & 1,5546 & 1,5674 & 4587 \\
\hline \multirow{2}{*}{400} & $v /(1)^{\wedge 1 / 2}$ & 4,257 & 6,648 & 8,565 & 0,193 & 1,612 & 12,863 & 13,970 & 14,951 & 15,816 & 16,573 & 17,224 & 17,773 & 18,218 & 18,558 & 18,785 & $18,8 \mathrm{~B}$ & 18,850 & 18,633 & 18,147 & $5,573 \mid$ \\
\hline & $Q /(1)^{\wedge 1 / 2}$ & 0,0100 & 0,0435 & 0,1012 & 1824 & 2853 & 0,4078 & 0,5476 & 0,7018 & 0,8675 & 1,0413 & 1,2198 & 1,3992 & 1,5753 & 1,7436 & 1,8991 & 2,0356 & 2,1460 & 2,2196 & 2,2378 & 0826 \\
\hline \multirow{2}{*}{450} & $v /(1)^{\wedge} 1 / 2$ & 4,605 & 7,191 & 9,264 & , 026 & 2,560 & 13,913 & 15,111 & 16,173 & 17,108 & 17,926 & 18,631 & 19,225 & 19,706 & 20,073 & 20,319 & 20,431 & 20,390 & 0,155 & 19,629 &, 926 \\
\hline & $Q /(1)^{\wedge 1 / 2}$ & 0,0137 & 0,0595 & 0,1336 & 2497 & 0,3905 & 0,5583 & 0,7497 & 0,9608 & 1,1876 & 1,4255 & 1,6699 & 1,9155 & 2,1566 & 2,3670 & 2,5998 & 2,7668 & 2,9378 & 0387 & 0635 & 8511 \\
\hline \multirow{2}{*}{500} & $v /(1)^{\wedge} 1 / 2$ & 4,940 & 7,715 & 9,938 & 828 & 3,474 & 14,926 & 16,211 & 17,349 & 18,353 & 19,231 & 9,987 & 20,624 & 21,140 & 21,534 & 21,798 & 21,918 & 21,874 & 1,621 & 1,057 &, 231 \\
\hline & $Q /(1)^{\wedge 1 / 2}$ & 0,0181 & 0,078 & 1835 & 307 & 5172 & 0,7394 & 0,9928 & 1,2724 & 1,5728 & 1,8380 & 2116 & 2,5368 & 2,8562 & 3,1614 & 3,4432 & 3,6909 & 3,8909 & 0244 & 0573 & 7760 \\
\hline \multirow{2}{*}{600} & $v /(1)^{\wedge 1 / 2}$ & 5,579 & 8,712 & 223 & 3,357 & 15,216 & 16,855 & 18,306 & 19,592 & 20,725 & 21,716 & $22,5 \pi 0$ & 23,289 & 23,873 & 24,317 & 24,615 & 24,751 & 24,701 & 24,416 & 23,779 & 1,716 \\
\hline & $Q /(1)^{\wedge 1 / 2}$ & 0,0295 & 0,1282 & 1925 & 377 & 3411 & 1,2024 & 1,6145 & 0691 & 5575 & 3,0701 & 5963 & 4,1252 & 4,6444 & 5,1407 & 5,5990 & $6, \infty 18$ & 6,3270 & 5441 & 6,5976 & 1401 \\
\hline \multirow{2}{*}{700} & $v /(1)^{\wedge 1 / 2}$ & 6,183 & 9,654 & 2,437 & 4,802 & 16,863 & 18,679 & 20,288 & 21,712 & 22,968 & 24,067 & 25,013 & 25,810 & 26,456 & 26,949 & 27,279 & 27,430 & 27,374 & 27,05, & 26,353 & 4,057 \\
\hline & $Q /(1)$ & 0,0445 & 0,1934 & & 8111 & 2687 & 1,8138 & 2,4353 & 1212 & 8579 & s.510 & 243 & 6,2225 & 7,0058 & 7,7544 & 4457 & 0532 &, 5439 & , & 521 & 201 \\
\hline 800 & $Q /(1)^{\wedge 1 / 2}$ & 0,0635 & 2761 & 5428 & 580 & 1114 & 1896 & 3,4770 & 4562 & 5050 & {$[, 6118$} & 451 & 8,8541 & 10,0024 & 11,0712 & 12,0582 & 12,9255 & 260 & 14,0936 & 14,2088 & 13,2235 \\
\hline \multirow{2}{*}{900} & $1 / 2$ & 7,310 & 1,415 & 14,706 & 17,502 & 19,938 & 22,086 & 23,958 & 25,672 & 27,158 & 28,456 & 29,575 & 30,517 & 31,282 & 31,365 & 32,254 & 32,433 & 32,367 & 31,994 & \begin{tabular}{|l|l|}
31,159 \\
\end{tabular} & 28,456 \\
\hline & af & $0,0869 \mid$ & 8730 & & , & & 5452 & 4,7600 & 1005 & 5405 & 0516 & , & 2,1624 & 13,6933 & 15,1566 & 16,5078 & 17,6952 & 18,6542 & 19,2942 & 19,4521 & 8,1031 \\
\hline \multirow{2}{*}{1000} & $\mathrm{v} / \mathrm{l}$ & 7,842 & 12,246 & 15,776 & 18,776 & $1,3.89$ & 23,693 & 25,733 & 27,541 & 29,134 & 30,527 & 31,727 & 32,738 & 33,558 & 34,183 & 34,601 & 34,793 & 34,722 & 34,322 & 33,426 & 30,527 \\
\hline & $a /(1$ & 0,1151 & 5006 & 1654 & 996 & 842 & 6952 & 3042 & 0796 & 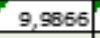 & 11,9679 & 14,0429 & 16,1079 & 18,1355 & 20,0734 & 21,8630 & 23,4356 & 24,7056 & 25,5533 & 25,7624 & 23,9758 \\
\hline \multirow{2}{*}{1200} & $v /(1)^{\wedge 1 / 2}$ & 8,856 & 3,829 & 815 &, 203 & 154 & 26,755 & 29,059 & 1,100 & 2,899 & 34,472 & 35,828 & 36,969 & 37,895 & 38,601 & 39,073 & 39,290 & 39,210 & 38,758 & 37,747 & 34,472 \\
\hline & $Q /(1)^{1 / 1 / 2}$ & 0,1872 & 0,8140 & 1,8951 & 3,4142 & 5,3406 & 7,6349 & 10,2513 & 13,1382 & 6,2394 & 19,4937 & 22,8353 & 26,1932 & 29,4903 & 32,6416 & 35,5517 & $38,108 \mathrm{~B}$ & 40,1741 & 41,5526 & 41,8924 & 38,9873 \\
\hline \multirow{2}{*}{1400} & & 9,814 & 5,326 & & & 768 & 29,651 & 32,205 & & 36,460 & 38,203 & &, 970 & 41,997 & $42, \pi 79$ & & & & & & \\
\hline & $a /(1)$ & 2824 & 1,2278 & 8587 & 1500 & 0558 & 1,5167 & 15,4634 & 19,8181 & 4,4959 & 29,4048 & 4454 & 39,5106 & 44,4840 & 49,2376 & 53,6271 & 57,4844 & 0,5998 & 62,6791 & 63,1917 & 58,8096 \\
\hline \multirow{2}{*}{1600} & & 728 & 757 & & & & & 208 & & & & & & 907 & & & & & & & \\
\hline & $Q$ & 0,4032 & 1,7530 & 0814 & 7,3528 & 1,5015 & 16,4428 & 22,0775 & 28,2948 & 34,9735 & 11,9620 & 49,1786 & 56,4104 & 63,5111 & 70,2978 & 76,5649 & 82,0720 & 86,5199 & $89,48 B 6$ & 90,2205 & 83,9640 \\
\hline & & & (171) & & & & & & & & & & & & & & & & & & \\
\hline & $Q /(1)^{1 / 2}$ & 0,552 & 2,400 & 5,568 & 10,066 & 15,746 & 22,510 & 30,224 & 38,736 & 47,879 & 57,474 & 67,326 & 77,226 & 86,947 & 96,238 & 104,818 & 112,357 & 118,447 & 122,511 & 123,513 & 114,948 \\
\hline & & 12,449 & 43.9] & & & & & & & & & & & 270 & 263 & & & & & & \\
\hline & $Q /(1)^{1 / 2}$ & 0,731 & 3,178 & 7,400 & 13,332 & 20,854 & 29,813 & 40,029 & 51,302 & 63,411 & 76,118 & 89,167 & 102,279 & 115,153 & 127,458 & 138,821 & \begin{tabular}{|l|}
148,807 \\
\end{tabular} & 156,871 & 162,254 & 163,581 & 152,237 \\
\hline & $\beta$ & 0,033 & 0,064 & 0,093 & 0,121 & 0,147 & 0,171 & 0,193 & 0,214 & 0,233 & 0,250 & 0,265 & 0,278 & $0,28 \mathrm{~B}$ & 0,296 & 0,302 & 0,304 & 0,303 & 0,298 & 0,286 & 0,250 \\
\hline & & 0,902 & 287 & 1,591 & & & 19 & 32 & 2,739 & & 3,142 & 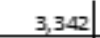 & 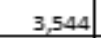 & 751 & $3 \propto 9=$ & & $\approx$ & 92 & & 381 & 283 \\
\hline$a$ & $G 0^{\circ} 0$ & 51,7 & 73,7 & ( & 66,3 & 20,0 & 2,8 & 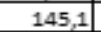 & 6,9 & 168.5 & 90,0 & I & 3.1 & 4,9 & 7,2 & 0,0 & 33,7 & 8,9 & 6,3 & 8,3 & \\
\hline
\end{tabular}
Fonte: Tsutiya (2000). 
ANEXO - D

\begin{tabular}{|c|c|c|c|c|c|c|c|c|c|c|c|c|c|c|c|c|c|c|c|c|c|c|c|}
\hline ECH & EXTENSĀ & \begin{tabular}{|c} 
TX. \\
CONTR \\
LNEAAR
\end{tabular} & $\begin{array}{c}\text { CONTR, } \\
\text { TRECH } \\
\text { O }\end{array}$ & $\begin{array}{l}\text { VAZÄO A } \\
\text { MONTANT } \\
\text { E }\end{array}$ & \begin{tabular}{|l|} 
VAZZ̄AOA A \\
JUSANTEE
\end{tabular} & $\begin{array}{l}\text { DIÂMETRO } \\
\text { CALCULA } \\
\text { DO }\end{array}$ & $\begin{array}{l}\text { DIÂMET } \\
\text { RO } \\
\text { USADO }\end{array}$ & $\begin{array}{l}\text { DECLLIDIDAD } \\
\text { TERRENO } \\
\text { CALCULADA }\end{array}$ & $\begin{array}{l}\text { DECLIVIDAD } \\
\text { E AD } \\
\text { TUBULAC̄Ã } \\
\text { LÁ } \\
\text { MAXIMA } \\
\text { ADM. }\end{array}$ & $\begin{array}{l}\text { COTADO } \\
\text { TERRENO } \\
\text { (m) }\end{array}$ & $\begin{array}{l}\text { COTADO } \\
\text { TERREN } \\
\text { T } \\
\text { (m) }\end{array}$ & $\begin{array}{l}\text { PROF. DO } \\
\text { COLETOR } \\
\text { (m) }\end{array}$ & \begin{tabular}{|c|} 
PROF. \\
DO \\
COLETO \\
R \\
(m) \\
\end{tabular} & $\begin{array}{c}\text { COTA DO } \\
\text { COLETOR } \\
\text { (m) }\end{array}$ & \begin{tabular}{|c|} 
COTA DO \\
COLETO \\
R \\
$(\mathrm{m})$
\end{tabular} & \begin{tabular}{|c|} 
DECLIVIDA \\
DE \\
TUBuLAC \\
AO \\
USADA \\
\end{tabular} & $Q /(1)^{1 / 2}$ & $\begin{array}{c}\text { LAMINA } \\
\text { LíUIDA } \\
\text { (YID) }\end{array}$ & RH/D & $\begin{array}{l}\text { RAO } \\
\text { HIDRAULI } \\
\text { CRABID } \\
\text { XD }\end{array}$ & & \begin{tabular}{|l} 
TENSĀO \\
TRATIVA
\end{tabular} & Vc \\
\hline N. & (m) & (Ls.m) & (L/s) & (L/s) & (L/s) & $(\mathrm{mm})$ & $(\mathrm{mm})$ & $(\mathrm{m} / \mathrm{m})$ & $(\mathrm{m} / \mathrm{m})$ & MONTANTE & JUSANTE & NTA & JUSANTE & ONTANT & JUSANTE & $(\mathrm{m} / \mathrm{m})$ & & & & & & (Pa) & $(\mathrm{m} / \mathrm{s})$ \\
\hline 1-1 & 53,96 & \begin{tabular}{|l|l|}
0,001139 \\
\end{tabular} & \begin{tabular}{|l|}
0,0615 \\
\end{tabular} & 0 & 0,0615 & 10,62 & 150 & 0,1019 & 30,134 & 485,10 & 479,60 & 0,90 & 0,90 & 484,20 & 478,70 & 0,1019 & 0,00019 & \begin{tabular}{|l|}
0,025 \\
\end{tabular} & 0,016 & 0,0024 & 1,928 & 2,4463 & 0,921 \\
\hline $1-2$ & 112,20 & \begin{tabular}{|l|l|}
0,001139 \\
\end{tabular} & \begin{tabular}{|l|l|}
0,1278 \\
\end{tabular} & 0,0615 & 0,1893 & 24,71 & 150 & 0,0080 & 14,184 & 479,60 & 478,70 & 0,90 & 1,20 & 478,70 & 477,50 & 0,0107 & \begin{tabular}{|l|l|}
0,00183 \\
\end{tabular} & \begin{tabular}{|l|}
0,100 \\
\end{tabular} & \begin{tabular}{|l|}
0,064 \\
\end{tabular} & 0,0096 & $0,0,625$ & 1,0267 & 1,841 \\
\hline \begin{tabular}{|l|}
$1-3$ \\
\end{tabular} & 88,95 & 001139 & 0,1013 & 0,1893 & 0,2906 & 19,96 & 150 & 0,0821 & 10,642 & 478,70 & 471,40 & 1,2 & 0,90 & 477,50 & 470,50 & 0,0787 & \begin{tabular}{|l|l|}
0,00104 \\
\end{tabular} & \begin{tabular}{|l|l}
0,075 \\
\end{tabular} & \begin{tabular}{|l|l|}
0,048 \\
\end{tabular} & 0,0072 & \begin{tabular}{|l|}
1,694 \\
\end{tabular} & 5,6661 & 1,595 \\
\hline 1-4 & 113,65 & 0,001139 & 0,1295 & 0,2906 & 0,4201 & 34,56 & 150 & $-0,0282$ & 8,314 & 471,40 & 474,60 & 0,90 & 5,10 & 470,50 & 469,50 & 0,0088 & 0,00448 & \begin{tabular}{|l|}
0,125 \\
\end{tabular} & \begin{tabular}{|l|l|}
0,079 \\
\end{tabular} & 0,01185 & \begin{tabular}{|c|}
0,567 \\
\end{tabular} & 1,0427 & 2,046 \\
\hline 4-1 & 60,45 & \begin{tabular}{|l|l|}
0,001139 \\
\end{tabular} & 0,0689 & - & 0,0689 & 14,84 & 150 & $-0,0050$ & 27,926 & 486,00 & 486,30 & 09 & 2,50 & 485,10 & 483,80 & 0,0215 & \begin{tabular}{|l|l|}
0,00047 \\
\end{tabular} & 0,050 & \begin{tabular}{|l|l|}
0,033 \\
\end{tabular} & 0,00495 & 0,886 & 1,0645 & 1,322 \\
\hline $4-2$ & 89,60 & 001139 & 0,1021 & 0,0689 & 0,1709 & 14,33 & 150 & 0,1306 & 15,187 & 486,30 & 474,60 & 2, & 5,10 & 483 & 469,50 & 0,1596 & \begin{tabular}{|l|l|}
0,00043 \\
\end{tabular} & \begin{tabular}{ll|}
0,050 \\
\end{tabular} & \begin{tabular}{|l|}
0,033 \\
\end{tabular} & \begin{tabular}{|l|}
0,00495 \\
\end{tabular} & \begin{tabular}{|l|}
2,413 \\
\end{tabular} & 7,9001 & 1,322 \\
\hline $1-5$ & 107,25 & 0,001139 & \begin{tabular}{|l|l|}
0,1222 \\
\end{tabular} & 0,5910 & 0,7132 & 42,53 & 150 & 0,0476 & 5,832 & 474,60 & 469,50 & 5,1 & 0,90 & 469,50 & 468,60 & 0,0084 & \begin{tabular}{|l|l|}
0,00779 \\
\end{tabular} & \begin{tabular}{|l|}
0,175 \\
\end{tabular} & \begin{tabular}{|l|l|}
0,107 \\
\end{tabular} & \begin{tabular}{|l|l|}
0,01605 \\
\end{tabular} & \begin{tabular}{|c|}
0,553 \\
\end{tabular} & 1,3469 & 2,381 \\
\hline 1-6 & 118,65 & \begin{tabular}{|l|l|}
0,001139 \\
\end{tabular} & \begin{tabular}{|l|}
0,1352 \\
\end{tabular} & 0,7132 & 0,8483 & 26,78 & 150 & 0,1399 & 5,192 & 469,50 & 452,90 & 0,9 & 0,90 & 468,60 & 452,00 & 0,1399 & \begin{tabular}{|l|}
0,00227 \\
\end{tabular} & \begin{tabular}{|l|}
0,100 \\
\end{tabular} & \begin{tabular}{|l|}
0,064 \\
\end{tabular} & \begin{tabular}{|l}
0,0096 \\
\end{tabular} & \begin{tabular}{|l|}
2,259 \\
\end{tabular} & 13,4311 & 1,841 \\
\hline 5-1 & 70,50 & 001139 & 0,0803 & 0 & 0,0803 & 10,22 & 150 & 0,1773 & 25,192 & 480,70 & 468,20 & $\overline{0,9}$ & 3,45 & 479 & 464,75 & 0,2135 & \begin{tabular}{|l|l}
0,00017 \\
\end{tabular} & \begin{tabular}{|l|l}
0,025 \\
\end{tabular} & 0,0 & 0,0024 & 2,791 & 5,1234 & 0,921 \\
\hline 6-1 & 65,89 & \begin{tabular}{|l|l|}
0,001139 \\
\end{tabular} & \begin{tabular}{|l|l|}
0,0751 \\
\end{tabular} & 0 & 0,0751 & 15,46 & 150 & $-0,0182$ & 26,360 & 7,00 & 468,20 & 0, & 3,45 & 466,10 & 464,75 & 0,0205 & \begin{tabular}{|l|}
0,00052 \\
\end{tabular} & \begin{tabular}{|l|}
0,050 \\
\end{tabular} & \begin{tabular}{|l|}
0,033 \\
\end{tabular} & \begin{tabular}{|l|l|}
0,00495 \\
\end{tabular} & \begin{tabular}{|l|}
0,865 \\
\end{tabular} & 1,0142 & 1,322 \\
\hline $7-1$ & 58,74 & 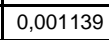 & \begin{tabular}{|l|l|}
0,0669 \\
\end{tabular} & 0 & 0,0669 & 9,46 & 150 & 0,1805 & 28,468 & 478,80 & 468,20 & 0,90 & 3,45 & 477,90 & 464,75 & 0,2239 & \begin{tabular}{|l|l|}
0,00014 \\
\end{tabular} & \begin{tabular}{|l|}
0,025 \\
\end{tabular} & \begin{tabular}{|l|l|}
0,016 \\
\end{tabular} & $\begin{array}{l}0,0024 \\
\end{array}$ & \begin{tabular}{|l|}
2,858 \\
\end{tabular} & 5,3728 & 0,921 \\
\hline 5-2 & 118,85 & 0,001139 & 0,1354 & 0,2223 & 0,3577 & 25,48 & 150 & 0,0538 & 9,260 & 468,20 & 461,80 & 3,4 & 0,90 & 464,75 & 460,90 & 0,0324 & \begin{tabular}{|l|l|}
0,00199 \\
\end{tabular} & \begin{tabular}{|l|}
0,100 \\
\end{tabular} & \begin{tabular}{|l|l|}
0,064 \\
\end{tabular} & 0,0096 & \begin{tabular}{|l|}
1,087 \\
\end{tabular} & 3,1098 & 1,841 \\
\hline $8-1$ & 57,25 & 001139 & \begin{tabular}{|l|l|}
0,0652 \\
\end{tabular} & 0 & 0,0652 & 10,52 & 150 & 0,1205 & 28,963 & 468,7 & 461,8 & 0,9 & 0,90 & 467 & 460,90 & 0,1205 & \begin{tabular}{|l|}
0,00019 \\
\end{tabular} & \begin{tabular}{|l|}
0,025 \\
\end{tabular} & 0,0 & 0,0024 & 2,097 & 2,8 & 0,921 \\
\hline 5-3 & 83,15 & \begin{tabular}{|l|l|}
0,001139 \\
\end{tabular} & \begin{tabular}{|l|}
0,0947 \\
\end{tabular} & 0,4229 & 0,5176 & 23,40 & 150 & 0,1070 & 7,229 & 461,80 & 452,90 & 0,9 & 0,90 & 460 & 452,00 & 0,1070 & \begin{tabular}{|l|}
0,00158 \\
\end{tabular} & \begin{tabular}{|l|}
0,075 \\
\end{tabular} & \begin{tabular}{|l|}
0,048 \\
\end{tabular} & 0,0072 & \begin{tabular}{|l|}
1,976 \\
\end{tabular} & 7,7066 & 1,595 \\
\hline \begin{tabular}{|l|}
$1-7$ \\
\end{tabular} & 99,15 & 0,001139 & \begin{tabular}{|l|l|}
0,1129 \\
\end{tabular} & 1,3659 & 1,4789 & 61,50 & 150 & 0,0020 & 3,578 & 452,90 & 452,70 & 0, & 1,20 & 452 & 451,50 & 0,0050 & \begin{tabular}{|l|l|}
0,02083 \\
\end{tabular} & \begin{tabular}{|l|}
0,250 \\
\end{tabular} & \begin{tabular}{|l|l|}
0,147 \\
\end{tabular} & \begin{tabular}{|l|}
0,02205 \\
\end{tabular} & \begin{tabular}{|l|}
0,429 \\
\end{tabular} & 1,1120 & 2,791 \\
\hline \begin{tabular}{|l|}
$1-8$ \\
\end{tabular} & 134,15 & 0,001139 & \begin{tabular}{|l|l|}
0,1528 \\
\end{tabular} & 1,4789 & 1,6317 & 63,41 & 150 & $-0,0201$ & 3,350 & 452,70 & 455,40 & 1,4 & 4,60 & 451,50 & 450,80 & 0,0052 & \begin{tabular}{|l|l|}
0,02259 \\
\end{tabular} & \begin{tabular}{|l|}
0,275 \\
\end{tabular} & \begin{tabular}{|l|}
0,171 \\
\end{tabular} & \begin{tabular}{|l|}
0,02565 \\
\end{tabular} & \begin{tabular}{|l|}
0,436 \\
\end{tabular} & 1,3384 & 3,010 \\
\hline 1-9 & 100,40 & 001139 & 1144 & & 1,74 & & 150 & & 3,2 & & 454, & & & & 450, & 0,0050 & \begin{tabular}{|l|l|}
0,02474 \\
\end{tabular} & 0,2 & $\mid$ & 0,02565 & $\overline{0,4}$ & & 3,010 \\
\hline 1-10 & 98,70 & \begin{tabular}{|l|l|}
0,001139 \\
\end{tabular} & 0,1124 & 1,7461 & 1,8585 & 53,83 & 150 & 0,0466 & 3,070 & 454,20 & 449,60 & 3 & 0,9 & 450 & 448,70 & 0,0162 & \begin{tabular}{|l}
0,0146 \\
\end{tabular} & \begin{tabular}{|l|}
0,225 \\
\end{tabular} & \begin{tabular}{|l|}
0,134 \\
\end{tabular} & 0,0201 & \begin{tabular}{|l|}
0,769 \\
\end{tabular} & 3,2584 & 2,664 \\
\hline 1-11 & 79,00 & 0,001139 & \begin{tabular}{|l|l|}
0,0900 \\
\end{tabular} & 1,8585 & 1,9485 & 40,29 & 150 & 835 & 2,974 & 449, & 443,0 & , & 0,90 & 448, & 442,10 & 0,0835 & \begin{tabular}{|l|l|}
0,00674 \\
\end{tabular} & \begin{tabular}{|l||}
0,150 \\
\end{tabular} & \begin{tabular}{|l|l|}
0,093 \\
\end{tabular} & \begin{tabular}{|l|}
0,01395 \\
\end{tabular} & \begin{tabular}{|l|}
1,746 \\
\end{tabular} & 1,6544 & 2,220 \\
\hline 1-12 & 78,95 & \begin{tabular}{|l|l|}
0,001139 \\
\end{tabular} & \begin{tabular}{|l|l|} 
\\
\end{tabular} & 1,9485 & 2,0384 & 69 & 150 & $-0,0621$ & 2,886 & 443 & 447, & 0 & 6,20 & & 441,70 & 0,0051 & \begin{tabular}{|l|l|}
0,02864 \\
\end{tabular} & \begin{tabular}{|l|}
0,300 \\
\end{tabular} & \begin{tabular}{|l|}
0,171 \\
\end{tabular} & \begin{tabular}{|l|}
0,02565 \\
\end{tabular} & \begin{tabular}{|l|}
0,430 \\
\end{tabular} & 1,2996 & 3,010 \\
\hline 9-1 & 62,30 & & 0,071 & 0 & 0,071 & 10, & 150 & & 27,36 & & 455 & & 0,9 & & 454 & 0,1252 & $\mid 0,0$ & 0,0 & 0,0 & 0,0 & 2,15 & & 0,921 \\
\hline $9-2$ & 65,65 & \begin{tabular}{|l|l|}
0,001139 \\
\end{tabular} & 0,0748 & 0,0710 & 0,1458 & 14,82 & 150 & 0,0701 & 16,898 & 455,20 & 450,6 & 0,8 & 2,65 & 454,30 & 447,95 & 0,0967 & \begin{tabular}{|l}
0,00047 \\
\end{tabular} & 0,050 & \begin{tabular}{|l|}
0,033 \\
\end{tabular} & 0,00495 & \begin{tabular}{|l|}
1,878 \\
\end{tabular} & 4,7879 & 1,322 \\
\hline $10-1$ & 66,51 & \begin{tabular}{|l|l|}
0,001139 \\
\end{tabular} & \begin{tabular}{|l|l|}
0,0758 \\
\end{tabular} & 0 & 0,0758 & 15,54 & 150 & $-0,0060$ & 26,195 & 450,20 & 450,6 & 0,9 & 2,65 & 449,3 & 447,95 & 0,0203 & 0,00053 & \begin{tabular}{|l|l|}
0,050 \\
\end{tabular} & \begin{tabular}{|l|l|}
0,033 \\
\end{tabular} & \begin{tabular}{|l}
0,00495 \\
\end{tabular} & \begin{tabular}{|l|}
0,861 \\
\end{tabular} & 1,0047 & 1,322 \\
\hline 9-3 & 63, & & & & & & & & & & & & & & & & & 100 & & & & & 841 \\
\hline 11-1 & 53,15 & 0,001139 & 0,0605 & 0 & 0,0605 & 11,15 & 150 & 0,0470 & 30,441 & 452,20 & 449,70 & 0,9 & 2,45 & 451, & 447,25 & 0,0762 & $0,0002$. & \begin{tabular}{|l|}
0,050 \\
\end{tabular} & \begin{tabular}{|l|}
0,033 \\
\end{tabular} & 0,00495 & 1,667 & 3,7719 & 1,322 \\
\hline $9-4$ & 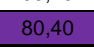 & & & & & & & & & & 444,80 & & 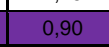 & 117 & 443,90 & & & 0,100 & & & 1,233 & & 1,841 \\
\hline 12-1 & 55,50 & 0,001139 & \begin{tabular}{|l|l|}
0,0632 \\
\end{tabular} & 0 & 0,0632 & 10,5 & 150 & & 29,571 & 451,10 & & 0, & 0,90 & & 443 & 0,1135 & 000 & \begin{tabular}{|l|l|}
0,025 \\
\end{tabular} & $0,0,016$ & \begin{tabular}{|l|l|} 
& 0,0024 \\
\end{tabular} & \begin{tabular}{|l|}
2,035 \\
\end{tabular} & 2,7243 & 0,921 \\
\hline $9-5$ & & & & & & & & & & & & & & & & & & & & & & 9,2725 & \\
\hline 13-1 & 58,78 & 0,001139 & 0,0670 & 0 & 0,0670 & 12,03 & 150 & 0,0374 & 28,455 & 448,00 & 445,80 & 0,9 & 2,35 & 447,10 & 443,45 & 0,0621 & \begin{tabular}{|l|}
0,00027 \\
\end{tabular} & \begin{tabular}{|l|}
0,050 \\
\end{tabular} & \begin{tabular}{|l|}
0,033 \\
\end{tabular} & \begin{tabular}{|l|l} 
& 0,00495 \\
\end{tabular} & \begin{tabular}{|l|l|}
1,505 \\
\end{tabular} & 3,0737 & 1,322 \\
\hline $9-6$ & & & & & & & & $-0,0209$ & & & & & & & & & & 0,150 & & & & & \\
\hline 1-13 & 113,10 & 0,001139 & \begin{tabular}{|l|l|}
0,1288 \\
\end{tabular} & 2,8058 & 2,934 & 787 & 150 & & 2,260 & & 444, & 6, & 3,50 & & 44 & 0,0053 & \begin{tabular}{|l|l|}
0,04029 \\
\end{tabular} & \begin{tabular}{|l|}
0,375 \\
\end{tabular} & \begin{tabular}{|l|l|}
0,215 \\
\end{tabular} & \begin{tabular}{|l|}
0,03225 \\
\end{tabular} & \begin{tabular}{|l|}
0,440 \\
\end{tabular} & 1,7109 & 3,375 \\
\hline 14-1 & 89,80 & \begin{tabular}{|l|l|}
0,001139 \\
\end{tabular} & \begin{tabular}{|l|l|}
0,1023 \\
\end{tabular} & 0 & 0,1023 & 11,65 & 150 & 0,1437 & 21,422 & 457,50 & $444,6 \mathrm{C}$ & 0, & $3,5 \mathrm{C}$ & 456 & 441,10 & 0,1726 & \begin{tabular}{|l|}
0,00025 \\
\end{tabular} & \begin{tabular}{|l|}
0,050 \\
\end{tabular} & \begin{tabular}{|l|}
0,033 \\
\end{tabular} & \begin{tabular}{|l|l|}
0,00495 \\
\end{tabular} & \begin{tabular}{|l|}
2,509 \\
\end{tabular} & 8,5440 & 1,322 \\
\hline $1-14$ & 109.80 & \begin{tabular}{|l|l|}
0.001139 \\
\end{tabular} & \begin{tabular}{|l|} 
\\
\end{tabular} & 3.0370 & 3.1620 & 80.56 & 150 & -0.01 & 2.150 & 444.60 & 446.60 & 3.5 & 6.11 & 441 & 440.50 & 0.0055 & \begin{tabular}{|l|}
0.04278 \\
\end{tabular} & \begin{tabular}{|l|}
0.375 \\
\end{tabular} & 0.215 & 0.03225 & \begin{tabular}{|l|}
0.446 \\
\end{tabular} & 1,7623 & 3.375 \\
\hline 15-1 & 89,80 & \begin{tabular}{|l|l|}
0,001139 \\
\end{tabular} & \begin{tabular}{|l|}
0,1023 \\
\end{tabular} & 0 & 0,1023 & 11,07 & 150 & & 21,422 & 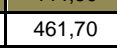 & 446,60 & 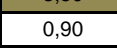 & 6,10 & 460,80 & 440,50 & 0,2261 & \begin{tabular}{|l|}
0,00022 \\
\end{tabular} & \begin{tabular}{|l|}
0,050 \\
\end{tabular} & \begin{tabular}{|l|}
0,033 \\
\end{tabular} & \begin{tabular}{|l|l|l}
0,00495 \\
\end{tabular} & \begin{tabular}{|l|}
2,872 \\
\end{tabular} & 11,1899 & 1,322 \\
\hline \begin{tabular}{|l|l|}
$1-15$ \\
\end{tabular} & 110,30 & & & 3,264 & & 84 & 150 & & & & & 0, & 1,34 & 446 & 439,95 & 0,0050 & \begin{tabular}{|l|l|}
0,04801 \\
\end{tabular} & \begin{tabular}{|l|}
0,400 \\
\end{tabular} & \begin{tabular}{|l|l|}
0,215 \\
\end{tabular} & & \begin{tabular}{|l|}
0,427 \\
\end{tabular} & 1,6081 & 3,375 \\
\hline 3-1 & 100,10 & \begin{tabular}{|l}
0,001139 \\
\end{tabular} & 0,1140 & 0 & 0,1140 & 14,26 & 150 & 29 & 19,918 & 500,80 & 493,50 & 0 & 0,90 & 499,90 & 492,60 & 0,0729 & \begin{tabular}{|l|l|}
0,00042 \\
\end{tabular} & \begin{tabular}{|l|}
0,050 \\
\end{tabular} & \begin{tabular}{|l|}
0,033 \\
\end{tabular} & \begin{tabular}{|l|}
0,00495 \\
\end{tabular} & \begin{tabular}{|l|}
1,631 \\
\end{tabular} & 3,6099 & 1,322 \\
\hline 16-1 & 56,90 & 001139 & 0,0648 & - & 0,0648 & 121 & 150 & & 29,082 & & 493, & & & 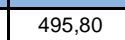 & 492,60 & 0,0562 & \begin{tabular}{|l|l|}
0,00027 \\
\end{tabular} & \begin{tabular}{l|l|}
0,050 \\
\end{tabular} & \begin{tabular}{|l|}
0,033 \\
\end{tabular} & 0,00495 & \begin{tabular}{ll|}
1,432 \\
\end{tabular} & 2703 & 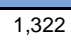 \\
\hline 3-2 & 118,70 & & & & & & 150 & & 10, & & & & & 49 & 48 & 0,0 & & \begin{tabular}{|l|}
0,075 \\
\end{tabular} & & 0,0072 & \begin{tabular}{|l|}
1,588 \\
\end{tabular} & 4,9739 & 1,595 \\
\hline 3-3 & 114,95 & 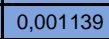 & \begin{tabular}{|l|l|}
0,1309 \\
\end{tabular} & 0,3 & 0,4 & 25,37 & 150 & & 7,999 & 485,30 & 479 & 0,4 & 0,96 & 484 & 478,50 & 0,0513 & \begin{tabular}{|l|l|}
0,00196 \\
\end{tabular} & \begin{tabular}{|l|}
0,100 \\
\end{tabular} & \begin{tabular}{|l|}
0,064 \\
\end{tabular} & \begin{tabular}{|l|}
0,0096 \\
\end{tabular} & \begin{tabular}{|l|}
1,368 \\
\end{tabular} & 4,9274 & 1,841 \\
\hline 3-4 & 113,00 & \begin{tabular}{|l|l|}
0,001139 \\
\end{tabular} & \begin{tabular}{|l|}
0,1287 \\
\end{tabular} & 0,4450 & 0,5737 & 25,81 & 150 & 0,0779 & 6,747 & 479,40 & 470,60 & 0,90 & 0,90 & 478,50 & 469,70 & 0,0779 & \begin{tabular}{|l|l}
0,00206 \\
\end{tabular} & \begin{tabular}{|l|}
0,100 \\
\end{tabular} & \begin{tabular}{|l|}
0,064 \\
\end{tabular} & 0,0096 & \begin{tabular}{|l|}
1,686 \\
\end{tabular} & 7,4761 & 1,841 \\
\hline 17-1 & 54,07 & 0,001139 & 0,0616 & 0 & 0,0616 & 13,7 & 150 & 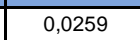 & 30,05 & 770 & 470 & & & & 487 & 0020 & \begin{tabular}{|l|}
0,00038 \\
\end{tabular} & \begin{tabular}{l|l|}
0,050 \\
\end{tabular} & \begin{tabular}{|l|}
0,033 \\
\end{tabular} & 0,00495 & \begin{tabular}{l|l|}
0,972 \\
\end{tabular} & 1,2817 & 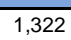 \\
\hline 3-5 & 112,10 & & & 0, & 0,7630 & 37,86 & 150 & & 5,574 & & & & & & 467,70 & 0,0178 & 00571 & 0,150 & 0,093 & 0,01395 & 0,807 & 2,4888 & 2,220 \\
\hline
\end{tabular}




\begin{tabular}{|c|c|c|c|c|c|c|c|c|c|c|c|c|c|c|c|c|c|c|c|c|c|c|c|}
\hline 18-1 & 54,13 & 0,001139 & 0,0617 & 0 & 0,0617 & 14,15 & 150 & 0,0222 & 30,071 & 469,80 & 468,60 & 0,90 & 0,90 & 468,90 & 467,70 & 0,0222 & \begin{tabular}{|l|}
0,00041 \\
\end{tabular} & 0,050 & 0,033 & \begin{tabular}{|l|l|}
0,00495 \\
\end{tabular} & \begin{tabular}{|l|l|}
0,899 \\
\end{tabular} & 1,0974 & 1,322 \\
\hline 3-6 & 114,85 & \begin{tabular}{|l}
0,001139 \\
\end{tabular} & 0,1308 & 0,8247 & 0,9555 & 32,99 & 150 & 0,0357 & 4,794 & 468,60 & 464,50 & 0,90 & 3,50 & 467,70 & 461,00 & 0,0583 & \begin{tabular}{|l|}
0,00396 \\
\end{tabular} & 0,125 & 0,079 & \begin{tabular}{|l|l|}
0,01185 \\
\end{tabular} & \begin{tabular}{|l|l|}
1,459 \\
\end{tabular} & 6,9129 & 2,046 \\
\hline 19-1 & 101,10 & 001139 & 0,1152 & 0 & 0,1152 & 19,41 & 150 & $-0,0376$ & 19,786 & 489,40 & 493,20 & 0,90 & 6,15 & 488,50 & 487,05 & 0,0143 & 0,00096 & 0,075 & 0,048 & \begin{tabular}{|c|}
0,0072 \\
\end{tabular} & \begin{tabular}{|l|l|}
0,723 \\
\end{tabular} & 1,0326 & 1,595 \\
\hline \begin{tabular}{l|l|}
$19-2$ \\
\end{tabular} & 117,70 & 001139 & \begin{tabular}{|l|l|}
0,1341 \\
\end{tabular} & 0,1152 & 0,2492 & 20,20 & 150 & 0,0841 & 11,795 & 493,20 & 483,30 & 6,15 & 2,65 & 487,05 & 480,65 & 0,0544 & \begin{tabular}{|l|l|}
0,00107 \\
\end{tabular} & 0,075 & 0,048 & \begin{tabular}{|c|}
0,0072 \\
\end{tabular} & \begin{tabular}{|l|l|}
1,408 \\
\end{tabular} & 3,9150 & 1,595 \\
\hline $20-1$ & 55,05 & \begin{tabular}{|c|}
0.001139 \\
\end{tabular} & 0.0627 & - & 0,0627 & 14,40 & 150 & -0.0109 & 29,733 & 482,70 & 483,30 & 0.90 & 2.65 & 481.80 & 480,65 & 0.0209 & 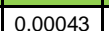 & 0.050 & \begin{tabular}{|l|l|}
0,033 \\
\end{tabular} & \begin{tabular}{|l|l|}
0.00495 \\
\end{tabular} & \begin{tabular}{|l|l|}
0.873 \\
\end{tabular} & 1.0341 & 1.322 \\
\hline 21-1 & 57,10 & 001139 & $\begin{array}{l}0,0650 \\
\end{array}$ & 0 & 0,0650 & 12,86 & 150 & 0,0105 & 29,014 & 483,90 & 483,30 & 0,9 & 2,65 & 483,00 & 480,65 & 0,0412 & 0,00032 & 0,050 & 0,033 & \begin{tabular}{|l|l|}
0,00495 \\
\end{tabular} & 1,225 & 2,0372 & 1,322 \\
\hline \begin{tabular}{|l|}
$19-3$ \\
\end{tabular} & 115,85 & 001139 & 0,1320 & 0,3770 & 0,5090 & 24,51 & 150 & 0,0958 & 7,311 & 483,30 & 472,20 & 2,65 & 0,90 & 480,65 & 471,30 & 0,0807 & \begin{tabular}{|l|l|}
0,00179 \\
\end{tabular} & 0,100 & \begin{tabular}{|l|}
0,064 \\
\end{tabular} & \begin{tabular}{|l|l|}
0,0096 \\
\end{tabular} & 1,716 & 7,7479 & 1,841 \\
\hline $22-1$ & 63,70 & \begin{tabular}{|l}
0,001139 \\
\end{tabular} & \begin{tabular}{|l|l|}
0,0726 \\
\end{tabular} & 0 & 0,0726 & 13,97 & 150 & 0,0330 & 26,963 & 474,30 & 472,20 & 0,90 & 0,90 & 473,40 & 471,30 & 0,0330 & \begin{tabular}{|l|l|}
0,00040 \\
\end{tabular} & 0,050 & 0,033 & \begin{tabular}{|l|l|}
0,00495 \\
\end{tabular} & \begin{tabular}{|l|l|}
1,097 \\
\end{tabular} & 1,6319 & 1,322 \\
\hline 23-1 & 55,30 & 0.001139 & 0.0630 & 0 & 0.0630 & 111.43 & 150 & 0.0723 & 29.643 & 476,20 & 472,20 & 0.90 & 0.90 & 475,30 & 471,30 & 0.0723 & \begin{tabular}{|l|l|l|l}
0.00023 \\
\end{tabular} & 0,050 & \begin{tabular}{l|l}
0.033 \\
\end{tabular} & \begin{tabular}{|l|}
0.00495 \\
\end{tabular} & \begin{tabular}{|l|l|}
1.624 \\
\end{tabular} & 3.5805 & 1.322 \\
\hline \begin{tabular}{|l|}
$19-4$ \\
\end{tabular} & 112,70 & 0,001139 & \begin{tabular}{|c|}
0,1284 \\
\end{tabular} & 0,644 & 0,7729 & 28,33 & 150 & 0,0861 & 5,526 & 472,20 & 462,50 & 0,9 & 0,90 & 471,30 & 461,60 & 0,0861 & 0,00263 & 0,100 & 0,064 & 0,0096 & \begin{tabular}{|l|l}
1,772 \\
\end{tabular} & 8,2626 & 1,841 \\
\hline 24-1 & 56,55 & 001139 & 0,0644 & 0 & 0,0644 & 10,07 & 150 & 0,1485 & 29,202 & 470,90 & 462,50 & 0,9 & 0,90 & 470,00 & 461,60 & 0,1485 & \begin{tabular}{|l|}
0,00017 \\
\end{tabular} & 0,025 & 0,016 & \begin{tabular}{|c|c|}
0,0024 \\
\end{tabular} & \begin{tabular}{|l|}
2,328 \\
\end{tabular} & 3,5650 & 0,921 \\
\hline \begin{tabular}{|l|}
$25-1$ \\
\end{tabular} & 67,40 & \begin{tabular}{|l|l}
0,001139 \\
\end{tabular} & \begin{tabular}{|l|l|l}
0,0768 \\
\end{tabular} & 0 & 0,0768 & 13,10 & 150 & 0,0519 & 25,962 & 466,00 & 462,50 & 0,9 & 0,90 & 465,10 & 461,60 & 0,0519 & \begin{tabular}{|l|l|}
0,00034 \\
\end{tabular} & 0,050 & \begin{tabular}{|l|}
0,033 \\
\end{tabular} & \begin{tabular}{|l|l|}
0,00495 \\
\end{tabular} & \begin{tabular}{|l|l|}
1,376 \\
\end{tabular} & 2,5705 & 1,322 \\
\hline $\begin{array}{ll}19-5 \\
\end{array}$ & 115,70 & $\mid 0.001139$ & $\begin{array}{ll}0,1318 \\
\end{array}$ & 0.9141 & 1.0459 & 53,73 & 150 & -0.0173 & 4.512 & 462.50 & 464.50 & 0.9 & 3.50 & 461,60 & 461,00 & 0.0052 & $\mid$\begin{tabular}{|l|l|l|l|l|l|}
012 \\
\end{tabular} & 0.225 & \begin{tabular}{|l|l|l|l|l|l|}
044 \\
\end{tabular} & \begin{tabular}{|l|}
0.0201 \\
\end{tabular} & \begin{tabular}{|l}
0.435 \\
\end{tabular} & $\begin{array}{ll}1.0424 \\
\end{array}$ & \begin{tabular}{|l|l|}
2.664 \\
\end{tabular} \\
\hline 3-7 & 112,40 & 001139 & $\begin{array}{l}0,1280 \\
\end{array}$ & 2,0014 & 2,12 & 69,76 & 150 & 0,026 & 2,802 & 464,5 & 461 & 3,5 & $\mathrm{I}, \mathrm{I}$ & 461 & 466 & 0,0053 & \begin{tabular}{|l|}
0,02915 \\
\end{tabular} & 0,300 & \begin{tabular}{|l|l|}
0,171 \\
\end{tabular} & 0,02 & \begin{tabular}{|l|l|}
0,441 \\
\end{tabular} & 1,3692 & 3,010 \\
\hline 26-1 & 54,95 & \begin{tabular}{|l|l|}
0,001139 \\
\end{tabular} & 0,0626 & 0 & 0,0626 & 11,74 & 150 & 0,0619 & 29,769 & 488,10 & 484,70 & 0,9 & 0,90 & 487,20 & 483,80 & 0,0619 & \begin{tabular}{|l|}
0,00025 \\
\end{tabular} & 0,050 & \begin{tabular}{|l|}
0,033 \\
\end{tabular} & 0,00495 & \begin{tabular}{|l|}
1,502 \\
\end{tabular} & 3,0628 & \begin{tabular}{|l|l|}
1,322 \\
\end{tabular} \\
\hline $26-2$ & 116,90 & \begin{tabular}{|l}
0,001139 \\
\end{tabular} & \begin{tabular}{|l|l|l}
0,132 \\
\end{tabular} & 0,0626 & 0,1958 & 21,11 & 150 & 0,0265 & 13,867 & 484,70 & 481,60 & 0,9 & 0,90 & 483,80 & 480,70 & 0,0265 & \begin{tabular}{|l|}
0,00120 \\
\end{tabular} & 0,075 & \begin{tabular}{|l|}
0,048 \\
\end{tabular} & \begin{tabular}{|c|}
0,0072 \\
\end{tabular} & \begin{tabular}{|l|l|}
0,984 \\
\end{tabular} & 1,9093 & \begin{tabular}{|l|l|}
1,595 \\
\end{tabular} \\
\hline $26-3$ & 1111,80 & 001139 & $\begin{array}{ll}0,1274 \\
\end{array}$ & 0,1958 & 0.3231 & 21.09 & 150 & $\begin{array}{ll}0.0725 \\
\end{array}$ & 9.912 & 481,60 & 473.50 & 0.9 & 0.90 & 480,70 & 472,60 & $\begin{array}{l}0.0725 \\
\end{array}$ & 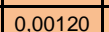 & 0.075 & \begin{tabular}{|l|l|}
0.048 \\
\end{tabular} & \begin{tabular}{|l|}
0.0072 \\
\end{tabular} & \begin{tabular}{|l|l|}
1.626 \\
\end{tabular} & 5,2165 & $\begin{array}{ll}1.595 \\
\end{array}$ \\
\hline $26-4$ & 119,25 & 001 & $\begin{array}{ll}0,1358 \\
\end{array}$ & 0,3231 & 0,4 & 22,5 & 15 & 0,10 & 7,8 & & 461 & & & & & 0,10 & \begin{tabular}{|l|}
0,00143 \\
\end{tabular} & 0,075 & \begin{tabular}{|l|}
0,048 \\
\end{tabular} & \begin{tabular}{|l|l}
0,0 \\
\end{tabular} & $\mid 1,932$ & 7,3660 & \begin{tabular}{|l|l|}
1,595 \\
\end{tabular} \\
\hline 3-8 & 109,55 & \begin{tabular}{|l|l}
0,001139 \\
\end{tabular} & 0,1248 & 2,5884 & 2,7132 & 46,78 & 150 & 0,0749 & 2,382 & 461,50 & 453,30 & 1,1 & 0,90 & 460,40 & 452,40 & 0,0730 & 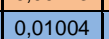 & 0,175 & \begin{tabular}{|l|}
0,107 \\
\end{tabular} & \begin{tabular}{|l|}
0,01605 \\
\end{tabular} & \begin{tabular}{|l|}
1,632 \\
\end{tabular} & 11,7207 & \begin{tabular}{|l|}
2,381 \\
\end{tabular} \\
\hline 27-1 & 70,37 & \begin{tabular}{|l}
0,001139 \\
\end{tabular} & 0,0802 & 0 & 0,0802 & 12,17 & 150 & 0,0838 & 25,223 & 459,20 & 453,30 & 0,90 & 0,90 & 458,30 & 452,40 & 0,0838 & \begin{tabular}{|l|}
0,00028 \\
\end{tabular} & 0,050 & \begin{tabular}{|l|}
0,033 \\
\end{tabular} & \begin{tabular}{|l|l|}
0,00495 \\
\end{tabular} & \begin{tabular}{|l|l|}
1,749 \\
\end{tabular} & 4,1502 & \begin{tabular}{|l|l|}
1,322 \\
\end{tabular} \\
\hline 3-9 & 1111,65 & $\mid 0.001139$ & $\begin{array}{ll}0.1272 \\
\end{array}$ & 2.7934 & 2.9205 & 53.99 & 150 & 0.0152 & 2,268 & 453.30 & 451,60 & 0.9 & 3.60 & 452.40 & 448.00 & 0.0394 & 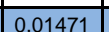 & 0.225 & \begin{tabular}{|l|l|l|l|l|l|}
044 \\
\end{tabular} & \begin{tabular}{|l|}
0.0201 \\
\end{tabular} & \begin{tabular}{|l|l|l}
1,199 \\
\end{tabular} & 7.9212 & \begin{tabular}{|l|l|}
2.664 \\
\end{tabular} \\
\hline $28-1$ & 64,35 & 001139 & \begin{tabular}{|l}
0,0733 \\
\end{tabular} & 0 & 0,07 & 15,37 & 15 & $-0,02$ & 26,78 & 450,2 & 451,60 & & 3, & 449 & 448 & 0,02 & \begin{tabular}{|l|}
0,00052 \\
\end{tabular} & 0,050 & \begin{tabular}{|l|}
0,033 \\
\end{tabular} & \begin{tabular}{|l|l|}
0,00495 \\
\end{tabular} & \begin{tabular}{|l|l|}
0,858 \\
\end{tabular} & 1,0000 & \begin{tabular}{|l|l|}
1,322 \\
\end{tabular} \\
\hline 29-1 & 69,00 & 001139 & 0,0786 & 0 & 0,0786 & 11,19 & 150 & 0,0870 & 25,558 & 457,60 & 451,60 & 0,9 & 3,60 & 456,70 & 448,00 & 0,1261 & \begin{tabular}{|l|}
0,00022 \\
\end{tabular} & 0,050 & \begin{tabular}{|l|}
0,033 \\
\end{tabular} & \begin{tabular}{|l|}
0,00495 \\
\end{tabular} & \begin{tabular}{|l|}
2,145 \\
\end{tabular} & 6,2413 & $\begin{array}{ll}1,322 \\
\end{array}$ \\
\hline 3-10 & 112,75 & 001139 & $\begin{array}{ll}0,1284 \\
\end{array}$ & 3,0724 & 3,2009 & 57,12 & 150 & 0,0284 & 2,133 & 451,60 & 448,40 & 3,6 & 4,35 & 448,00 & 444,05 & 0,0350 & 0,0171 & 0,250 & \begin{tabular}{|l|}
0,147 \\
\end{tabular} & 0,02205 & 1,131 & 7,7248 & 2,791 \\
\hline $30-1$ & 50,93 & 001139 & 0.0580 & 0 & 0.0580 & 14,02 & 150 & -0.0471 & 31.324 & 446,00 & 448.40 & 0,0 & 4.35 & 445,10 & 444,05 & 0.0206 & $\mid$\begin{tabular}{|l|l|l|l}
0.00040 \\
\end{tabular} & 0,050 & \begin{tabular}{|l|l|}
0.033 \\
\end{tabular} & \begin{tabular}{|l|l|}
0.00495 \\
\end{tabular} & \begin{tabular}{|l|}
0.867 \\
\end{tabular} & 1.0205 & \begin{tabular}{|l|}
1.322 \\
\end{tabular} \\
\hline 31-1 & 69,30 & \begin{tabular}{|l|l}
0,001139 \\
\end{tabular} & 0,0789 & 0 & 0,078 & 11,5 & 15 & 0,05 & 25,4 & 452 & 448 & & 4, & 451 & 444 & 0,10 & \begin{tabular}{|l|l|}
0,00024 \\
\end{tabular} & 0,050 & \begin{tabular}{|l|}
0,033 \\
\end{tabular} & \begin{tabular}{|l|}
0,00495 \\
\end{tabular} & \begin{tabular}{|l|}
1,994 \\
\end{tabular} & 5,3929 & \begin{tabular}{|l}
1,322 \\
\end{tabular} \\
\hline 3-11 & 110,20 & 001139 & 0,1255 & 3,3378 & 3,4634 & 58,18 & 150 & 0,0644 & 2,023 & 448,40 & 441,30 & 4,3 & 1,35 & 444,05 & 439,95 & 0,0372 & \begin{tabular}{|l|}
0,01796 \\
\end{tabular} & 0,250 & \begin{tabular}{|l|}
0,147 \\
\end{tabular} & \begin{tabular}{|l|l|}
0,02205 \\
\end{tabular} & $\begin{array}{l}1,165 \\
\end{array}$ & 8,2037 & \begin{tabular}{|l|}
2,791 \\
\end{tabular} \\
\hline $1-16$ & 114,25 & 001139 & \begin{tabular}{|l|l|}
0,1301 \\
\end{tabular} & 6,8534 & 6,9835 & 109,24 & 150 & $-0,0464$ & 1,265 & 441,30 & 446,60 & 1,3 & 7,25 & 439,95 & 439,35 & 0,0053 & $\mid$\begin{tabular}{|l|}
0,09637 \\
\end{tabular} & 0,600 & \begin{tabular}{|l|}
0,278 \\
\end{tabular} & \begin{tabular}{|l|l|l}
0,0417 \\
\end{tabular} & \begin{tabular}{|l|l|}
0,438 \\
\end{tabular} & 2,1899 & \begin{tabular}{|l|l}
3,838 \\
\end{tabular} \\
\hline $32-1$ & 68.32 & D01139 & $\begin{array}{ll}0.0778 \\
\end{array}$ & 0 & 0.0778 & 13.67 & 150 & \begin{tabular}{l|l|}
0.0424 \\
\end{tabular} & 25,728 & 462,70 & 459.80 & 0,0 & 0.90 & 46 & 458.90 & \begin{tabular}{l|}
0.0424 \\
\end{tabular} & $\mid$\begin{tabular}{|l}
0.00038 \\
\end{tabular} & 0.050 & \begin{tabular}{|l|l|}
0.033 \\
\end{tabular} & \begin{tabular}{|l|l|}
0.00495 \\
\end{tabular} & \begin{tabular}{|l|}
1,244 \\
\end{tabular} & 2.1011 & \begin{tabular}{|l|l|}
1.322 \\
\end{tabular} \\
\hline 33-1 & 72,33 & 001139 & 0,0824 & 0 & 0,0 & 13,78 & 15 & 0,04 & 24,7 & 463 & 459 & & 0, & 462 & 458 & 0,04 & \begin{tabular}{|l|}
0,00039 \\
\end{tabular} & 0,050 & \begin{tabular}{|l|l|}
0,033 \\
\end{tabular} & \begin{tabular}{|l|l|}
0,00495 \\
\end{tabular} & \begin{tabular}{|l|l|}
1,290 \\
\end{tabular} & 2,2584 & \begin{tabular}{|l|}
1,322 \\
\end{tabular} \\
\hline $32-2$ & 112,75 & 001139 & 0,1284 & 0,1602 & 0,2887 & 21,67 & 150 & 0,0124 & 10,690 & 459,80 & 458,40 & $0, \varepsilon$ & 5,15 & 458 & 453,25 & 0,0501 & \begin{tabular}{|l|}
0,00129 \\
0
\end{tabular} & 0,075 & \begin{tabular}{|l|}
0,048 \\
\end{tabular} & \begin{tabular}{|l|}
0,0072 \\
\end{tabular} & \begin{tabular}{|l|}
1,352 \\
\end{tabular} & 3,6080 & \begin{tabular}{|l}
1,595 \\
\end{tabular} \\
\hline 34-1 & 71,06 & 001139 & 0,08 & 0 & 0,08 & 15,92 & 150 & $-0,03$ & 25,059 & 455,60 & 458,40 & 0, & 5,15 & 45 & 453,25 & 0,0204 & $\mid$\begin{tabular}{|l|}
0,00057 \\
\end{tabular} & 0,050 & \begin{tabular}{|l|}
0,033 \\
\end{tabular} & \begin{tabular}{|l|l|}
0,00495 \\
\end{tabular} & \begin{tabular}{|l|l|}
0,863 \\
\end{tabular} & 1,0101 & \begin{tabular}{|l|l|}
1,322 \\
\end{tabular} \\
\hline 32-3 & 112,10 & 001139 & 0,1277 & 0,3696 & 0,4973 & 37,86 & 150 & 0,0 & 7,4 & 458 & 457,20 & 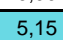 & $4, \varepsilon$ & 45 & 452,40 & 0,0076 & \begin{tabular}{|l|}
0,00571 \\
\end{tabular} & 0,150 & \begin{tabular}{|l|}
0,093 \\
\end{tabular} & \begin{tabular}{|l|}
0,01395 \\
\end{tabular} & \begin{tabular}{|l|}
0,526 \\
\end{tabular} & 1.0578 & \begin{tabular}{|l|}
2.220 \\
\end{tabular} \\
\hline $32-4$ & 111,00 & 001139 & 0,1264 & 0,4973 & 0,6237 & 24,65 & 15 & $0,09 !$ & 6,3 & 457,2 & 446 & 4, & $7, z^{2}$ & 452 & 439 & 0,11 & \begin{tabular}{|l|}
0,00182 \\
\end{tabular} & 0,100 & \begin{tabular}{|l|l|}
0,0 \\
\end{tabular} & \begin{tabular}{|l|l|}
0,0096 \\
\end{tabular} & \begin{tabular}{|l|}
2,071 \\
\end{tabular} & 11,2865 & \begin{tabular}{|l|}
1,841 \\
\end{tabular} \\
\hline $1-17$ & 116,15 & 01139 & 0,1323 & 7,6073 & 7,7396 & 113,89 & 150 & 0,01 & 1,18 & 446,6 & 445 & 7,2 & 6,2 & 439 & 438 & 0,0052 & \begin{tabular}{|l|}
0,10768 \\
\end{tabular} & 0,625 & 0,2 & \begin{tabular}{|l|}
0,0432 \\
\end{tabular} & 0,434 & 2,2316 & 3,906 \\
\hline $35-1$ & 67,14 & 39 & 0,07 & 0 & 0,0765 & 11,69 & 150 & 0,01 & 26,0 & 446,00 & 445,00 & 0, & 6,25 & 445 & 438,75 & 0,0946 & \begin{tabular}{|l|}
0,00025 \\
\end{tabular} & 0,050 & \begin{tabular}{|l|}
0,033 \\
\end{tabular} & \begin{tabular}{|l|l|}
0,00495 \\
\end{tabular} & \begin{tabular}{|l|l|}
1,858 \\
\end{tabular} & 4,6816 & \begin{tabular}{|l}
1,322 \\
\end{tabular} \\
\hline \begin{tabular}{|l|}
$36-1$ \\
\end{tabular} & 57,80 & \begin{tabular}{|l|l}
0,001139 \\
\end{tabular} & 0,0658 & 0 & 0,0658 & 9,93 & 150 & 0,0744 & 28,778 & 449,30 & 445,00 & 0, & 6.25 & 448.40 & 438.75 & 0.1670 & \begin{tabular}{|l|}
0.00016 \\
\end{tabular} & 0.025 & \begin{tabular}{|l|}
0.016 \\
\end{tabular} & \begin{tabular}{|l|}
0.0024 \\
\end{tabular} & \begin{tabular}{|l|l|}
2.468 \\
\end{tabular} & $\begin{array}{l}4.0069 \\
\end{array}$ & \begin{tabular}{|l|}
0.921 \\
\end{tabular} \\
\hline \begin{tabular}{|l|}
$1-18$ \\
\end{tabular} & 113,70 & \begin{tabular}{|l|l|} 
& 0,01139 \\
\end{tabular} & 0,1295 & 7,881 & 8,0114 & 114,91 & 150 & 0,02 & 1,153 & 445,00 & 442,50 & 6,2 & $4,3 !$ & 438,75 & 438,15 & 0,0053 & \begin{tabular}{|l|}
0,11028 \\
\end{tabular} & 0,650 & \begin{tabular}{|l|}
0,288 \\
\end{tabular} & \begin{tabular}{|l|}
0,0432 \\
\end{tabular} & 0,439 & 2,2797 & 3 \\
\hline \begin{tabular}{|l|}
$37-1$ \\
\end{tabular} & 57,37 & 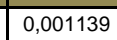 & 0,0654 & 0 & 0,0654 & 10,28 & 150 & 0,07 & 28,922 & 446,90 & 442,50 & 0, & 4,35 & 446, & 438,15 & 0,1368 & \begin{tabular}{|l|}
0,00018 \\
\end{tabular} & 0,025 & \begin{tabular}{|l|}
0,016 \\
\end{tabular} & \begin{tabular}{|l|l|}
0,0024 \\
\end{tabular} & 2,234 & 3,2839 & \begin{tabular}{|l|l|}
0,921 \\
\end{tabular} \\
\hline \begin{tabular}{|l|l|}
$1-19$ \\
\end{tabular} & 103,20 & \begin{tabular}{|l|l}
0,001139 \\
\end{tabular} & 0,117 & 8,076 & 8,1943 & 115,67 & 150 & $-0,00$ & 1,136 & 442,50 & 442 & 4,3 & 5,21 & 438,15 & 437,60 & 0,0053 & \begin{tabular}{|l|}
0,11225 \\
\end{tabular} & 0,675 & \begin{tabular}{|l|l|}
0,297 \\
\end{tabular} & 0,04455 & 0,441 & 2,3743 & \begin{tabular}{|l}
3,967 \\
\end{tabular} \\
\hline \begin{tabular}{|l|}
$38-1$ \\
\end{tabular} & 58,35 & \begin{tabular}{|l|l|l}
0,001139 \\
\end{tabular} & 0,0665 & 0 & 0,0665 & 10,14 & 150 & 0,0788 & 28,596 & 447,40 & 442,80 & 0,9 & 5,20 & 446,50 & 437,60 & 0,1525 & $\mid$\begin{tabular}{|l|}
0,00017 \\
\end{tabular} & 0,025 & \begin{tabular}{|l|}
0.016 \\
\end{tabular} & \begin{tabular}{|l|}
0.0024 \\
\end{tabular} & \begin{tabular}{|l|}
2.359 \\
\end{tabular} & 3.6607 & \begin{tabular}{|l|}
0.921 \\
\end{tabular} \\
\hline \begin{tabular}{|l|}
$1-20$ \\
\end{tabular} & 110,30 & 0,001139 & 0,1256 & . & 8,3864 & 107,73 & 150 & 0,047 & 1,11 & 442,80 & 437,60 & 5, & 0,6 & 437,60 & 436,70 & 0,0082 & \begin{tabular}{|l|}
0,09284 \\
\end{tabular} & 0,575 & \begin{tabular}{|l|}
0,278 \\
\end{tabular} & \begin{tabular}{|l|}
0,0417 \\
\end{tabular} & \begin{tabular}{|l|l|}
0,546 \\
\end{tabular} & 3,4025 & \begin{tabular}{|l|}
3,838 \\
\end{tabular} \\
\hline \begin{tabular}{|l|}
$1-21$ \\
\end{tabular} & 103,20 & & $\overline{0,1}$ & 8,3864 & 8,5 & 115 & 150 & $-0,0$ & 1, & 437 & 438 & 0 & 2,3 & $\overline{43}$ & 436 & 0,0058 & \begin{tabular}{|l|l|}
0,11153 \\
\end{tabular} & 0,650 & \begin{tabular}{|l|}
0,288 \\
\end{tabular} & \begin{tabular}{|l|l|}
0,0432 \\
\end{tabular} & \begin{tabular}{|l|}
0,461 \\
\end{tabular} & 2,5116 & \begin{tabular}{|l|}
3,906 \\
\end{tabular} \\
\hline \begin{tabular}{|l|}
$2-1$ \\
\end{tabular} & 100,80 & \begin{tabular}{|l}
0,001139 \\
\end{tabular} & 0,1148 & 0 & 0,1148 & 13,60 & 150 & 0,0952 & 19,826 & 517,40 & 507,80 & 0,9 & 0,9 & 516 & 506,90 & 0,0952 & \begin{tabular}{|l|}
0,00037 \\
\end{tabular} & 0,050 & \begin{tabular}{|l|}
0,033 \\
\end{tabular} & \begin{tabular}{|l|l|}
0,00495 \\
\end{tabular} & \begin{tabular}{|l|l|}
1,864 \\
\end{tabular} & 4,7143 & \begin{tabular}{|l|l}
1,322 \\
\end{tabular} \\
\hline \begin{tabular}{|l|}
$2-2$ \\
\end{tabular} & 111.80 & \begin{tabular}{|l|l} 
& 0.001139 \\
\end{tabular} & 0.1274 & 0.1148 & 0,2422 & 17,38 & 150 & 0,1100 & 12.025 & 507.80 & 495.50 & 0,90 & 1.40 & 506,90 & 494,10 & 0,1145 & \begin{tabular}{|l|l|}
0.00072 \\
\end{tabular} & 0.075 & \begin{tabular}{|l|l|}
0.048 \\
\end{tabular} & \begin{tabular}{|c|}
0.0072 \\
\end{tabular} & \begin{tabular}{|l|l|}
2.044 \\
\end{tabular} & 8.2433 & \begin{tabular}{|l|l|}
1.595 \\
\end{tabular} \\
\hline & 68,62 & (n) & & $\cdots$ & 0,0782 & 11,56 & 150 & 0,1049 & 25,652 & 503,00 & 495,80 & 0,9 & 0,90 & 502,10 & 494,90 & 0,1049 & & 0,050 & 0,033 & 0,00495 & \begin{tabular}{|l|}
1,956 \\
\end{tabular} & 5,1938 & 322 \\
\hline-2 & 55,65 & 0,00 & 0,0634 & 0,0782 & 0,14 & 20,96 & 150 & 0,005 & 17,2 & 49 & $49 !$ & 0, & 1,40 & 494 & 49 & 0,0144 & \begin{tabular}{|l|}
0,00118 \\
\end{tabular} & 0,075 & 0,048 & 0,0072 & .724 & 1,0350 & \begin{tabular}{|l|l|}
1,595 \\
\end{tabular} \\
\hline \begin{tabular}{|l|}
$2-3$ \\
\end{tabular} & 109,80 & \begin{tabular}{|l}
0,001139 \\
\end{tabular} & 0,1251 & 0,3837 & 0,5088 & 38,04 & 150 & $-0,0091$ & 7,312 & 495,50 & 496,50 & 1,40 & 3,25 & 494,10 & 493,25 & 0,0077 & $\mid$\begin{tabular}{|l|}
0,00578 \\
\end{tabular} & 0,150 & \begin{tabular}{|l|l|}
0,093 \\
\end{tabular} & 0,01395 & \begin{tabular}{|l|}
0,531 \\
\end{tabular} & 1,0799 & \begin{tabular}{|l|}
2,220 \\
\end{tabular} \\
\hline
\end{tabular}




\begin{tabular}{|c|c|c|c|c|c|c|c|c|c|c|c|c|c|c|c|c|c|c|c|c|c|c|c|}
\hline $2-4$ & 111,35 & 201139 & \begin{tabular}{|c|}
0,1268 \\
\end{tabular} & 0,5088 & 0,6357 & 24,57 & 150 & 0,1455 & 6,299 & 496,50 & 480,30 & 3,25 & 0,90 & 493,25 & 479,40 & 0,1244 & 0,00180 & 0,100 & \begin{tabular}{l|l|}
0,064 \\
\end{tabular} & \begin{tabular}{|l|l|}
0,0096 \\
\end{tabular} & \begin{tabular}{|l}
2,130 \\
\end{tabular} & 11,9407 & \begin{tabular}{|l|l|l|}
1,841 \\
\end{tabular} \\
\hline $2-5$ & \begin{tabular}{|l|}
99,80 \\
\end{tabular} & 0,001139 & 0,1137 & 0,6357 & 0,7493 & 46,88 & 150 & $-0,0030$ & 5,642 & 480,30 & 480,60 & 0,90 & 1,75 & $\begin{array}{r}479,40 \\
\end{array}$ & 478,85 & 0,0055 & $\begin{array}{l}0,01009 \\
\end{array}$ & 0,200 & 0,121 & 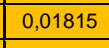 & \begin{tabular}{|l|l}
0,448 \\
\end{tabular} & 1,0003 & \begin{tabular}{|l}
2,532 \\
\end{tabular} \\
\hline \begin{tabular}{|l|}
$2-6$ \\
\end{tabular} & 113,20 & 0,001139 & 0,1290 & 0,7493 & 0,8783 & 36,95 & 150 & 0,0345 & 5,072 & 480,60 & 476,70 & 1,75 & 0,90 & 478,85 & 475,80 & 0,0269 & \begin{tabular}{|l}
0,00535 \\
\end{tabular} & 0,150 & \begin{tabular}{l|l}
0,093 \\
\end{tabular} & \begin{tabular}{|l|l}
0,01395 \\
\end{tabular} & \begin{tabular}{|l|l|}
0,991 \\
\end{tabular} & 3,7586 & 2,220 \\
\hline $40-1$ & 101,45 & 0,001139 & 0,1156 & 0 & 0,1156 & 14,19 & 150 & 0,0749 & 19,741 & 514,00 & 506,40 & 0,90 & 1,10 & 513,10 & 505,30 & 0,0769 & 0,00042 & 0,050 & 0,033 & \begin{tabular}{|l|l}
0,00495 \\
\end{tabular} & 1,675 & 3,8058 & 1,322 \\
\hline 41-1 & 73,05 & \begin{tabular}{|l|l}
0,001139 \\
\end{tabular} & 0,0832 & 0 & 0,0832 & 16,07 & 150 & 0,0178 & 24,599 & 507,70 & 506,40 & 0,90 & 1,10 & 506,80 & 505,30 & 0,0205 & \begin{tabular}{|l|l} 
\\
\end{tabular} & 0,050 & \begin{tabular}{|c|}
0,033 \\
\end{tabular} & \begin{tabular}{|l|l}
0,00495 \\
\end{tabular} & \begin{tabular}{|l|l|}
0,8666 \\
\end{tabular} & 1,0164 & $1,32$. \\
\hline $40-2$ & 113,05 & \begin{tabular}{|l|l}
0,001139 \\
\end{tabular} & 0,1288 & 0,1988 & 0,3276 & 20,54 & 150 & 0,0876 & 9,822 & 506,40 & 496,50 & 1,10 & 0,90 & 505,30 & 495,60 & 0,0858 & 0,00112 & 0,075 & 0,048 & \begin{tabular}{|l|l|}
0,0072 \\
\end{tabular} & 1,769 & 6,1778 & 1,595 \\
\hline 40-3 & 109,30 & 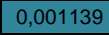 & 0,1245 & 0,3276 & 0,4521 & 23,72 & 150 & 0,0759 & 7,915 & 496,50 & 488,20 & 0,90 & 0,90 & 495,60 & 487,30 & 0,0759 & 0,00164 & 0,075 & \begin{tabular}{|l|}
0,048 \\
\end{tabular} & \begin{tabular}{|l|l|}
0,0072 \\
\end{tabular} & 1,664 & 5,4675 & 1,595 \\
\hline 42-1 & 73,05 & 0,001139 & 0,0832 & 0 & 0,0832 & 13,94 & 150 & 0,0438 & 24,599 & 491,40 & 488,20 & 0,90 & 0,90 & 490,50 & 487,30 & 0,0438 & $0,0,00040$ & 0,050 & \begin{tabular}{|l|}
0,033 \\
\end{tabular} & \begin{tabular}{|l|l}
0,00495 \\
\end{tabular} & \begin{tabular}{|l|l}
1,264 \\
\end{tabular} & 2,1684 & 1,322 \\
\hline \begin{tabular}{|l|}
$40-4$ \\
\end{tabular} & 113,80 & 0,00119 & 0,12 & & 0,6649 & 26,67 & 150 & & 6,112 & 488,2 & 479,40 & 0,91 & 2,10 & 487,30 & 477,30 & 0,0879 & & 0,100 & 0,064 & 0,0 & 1,796 & 8,4359 & $\overline{1,841}$ \\
\hline 43-1 & 64,95 & \begin{tabular}{|l}
0,001139 \\
\end{tabular} & 0,0740 & 0 & 0,0740 & 12,34 & 150 & 0,0477 & 26,615 & 482,50 & 479,40 & 0,90 & 2,10 & 481,60 & 477,30 & 0,0662 & 0,00029 & 0,050 & \begin{tabular}{|l|}
0,033 \\
\end{tabular} & \begin{tabular}{|l|l}
0,00495 \\
\end{tabular} & \begin{tabular}{|l|l}
1,554 \\
\end{tabular} & 3,2771 & \begin{tabular}{|l|l}
1,322 \\
\end{tabular} \\
\hline 44-1 & 73,00 & 0,001139 & 0,0832 & 0 & 0,0832 & 16,06 & 150 & 0,0041 & 24,611 & 479,70 & 479,40 & 0,90 & 2,10 & 478,80 & 477,30 & 0,0205 & 0,00058 & 0,050 & \begin{tabular}{|l|}
0,033 \\
\end{tabular} & \begin{tabular}{|l|l}
0,00495 \\
\end{tabular} & \begin{tabular}{|l|l|}
0,866 \\
\end{tabular} & 1,0171 & 1,322 \\
\hline 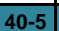 & 101,60 & 0,001139 & 0,1157 & $\overline{1,822}$ & 0,9378 & 42,39 & 150 & 0,0266 & 4,854 & 479,40 & 476,70 & 2,10 & 0,90 & 477,30 & 475,80 & 0,0148 & 0,000772 & 0,175 & \begin{tabular}{|l|l|}
0,107 \\
\end{tabular} & 0 & 0,734 & 2,3696 & 2,381 \\
\hline \begin{tabular}{l|}
$2-7$ \\
\end{tabular} & 111,70 & \begin{tabular}{|l|l}
0,001139 \\
\end{tabular} & 0,1272 & 1,8161 & 1,9433 & 44,91 & 150 & 0,0466 & 2,979 & 476,70 & 471,50 & 0,9 & 0,90 & 475,80 & 470,60 & 0,0466 & \begin{tabular}{|l|l}
0,00901 \\
\end{tabular} & 0,175 & \begin{tabular}{l|l}
0,107 \\
\end{tabular} & 0,01605 & \begin{tabular}{|l|l|}
1,303 \\
\end{tabular} & 7,4718 & 2,381 \\
\hline 45-1 & 100,45 & \begin{tabular}{|l|l}
0,001139 \\
\end{tabular} & 0,1144 & 0 & 0,1144 & 15,51 & 150 & 0,0468 & 19,872 & & & 0,90 & 0,90 & 504,30 & 499,60 & 0,0 & & 0,050 & 0,033 & & \begin{tabular}{|l}
1,307 \\
\end{tabular} & 2,3161 & $\sqrt{10}$ \\
\hline 46-1 & 73,05 & 0,001139 & 0,0832 & 0 & 0,0832 & 13,56 & 150 & 0,0507 & 24,599 & 504,20 & 500,50 & 0,90 & 0,90 & 503,30 & 499,60 & 0,0507 & \begin{tabular}{|l|l|l|}
0,000037 \\
\end{tabular} & 0,050 & $\begin{array}{l}0,033 \\
\end{array}$ & $\mid 0,00495$ & \begin{tabular}{|l|l|}
1,359 \\
\end{tabular} & 2,5072 & 1,$32 ;$ \\
\hline & & & & & & & & & & & & & & & & & & & & & & & \\
\hline 47-1 & 73,00 & \begin{tabular}{|l}
0,001139 \\
\end{tabular} & 0,0832 & 0 & 0,0832 & 13,56 & 150 & 0,0507 & 24,611 & 495,40 & 491,70 & 0,90 & 0,90 & 494,50 & 490,80 & 0,0507 & \begin{tabular}{|l}
0,00037 \\
\end{tabular} & $0,0,050$ & 0,033 & 0,00495 & \begin{tabular}{|l|l}
1,360 \\
\end{tabular} & 2,5089 & 1,322 \\
\hline & & & & & & & & & & & & & & & & & & & & & & & \\
\hline $48-1$ & 73,05 & \begin{tabular}{|l|l}
0,01139 \\
\end{tabular} & 0,0832 & 0 & 0,0832 & 13,78 & 150 & 0,0465 & 24,599 & 486,80 & 483,40 & 0,90 & 0,90 & 485,90 & 482,50 & 0,0465 & \begin{tabular}{|l|l}
0,00039 \\
\end{tabular} & 0,050 & 0,033 & 0,00495 & 1,303 & 2,3039 & 1,322 \\
\hline & & & & & & & & $-0,0105$ & & & & & & & & & & & & & & & \\
\hline 45-5 & 103,15 & \begin{tabular}{|l|l}
0,001139 \\
\end{tabular} & 0,1175 & 0,7502 & 0,8677 & 28,34 & 150 & & 5,114 & 484,60 & 471,50 & 2,85 & 0,90 & 481,75 & 470,60 & 0,1081 & 0,00264 & 0,100 & 0,064 & 0,0096 & 1,986 & 10,3771 & 1,841 \\
\hline \begin{tabular}{|l|}
$2-8$ \\
\end{tabular} & 115,95 & 0,001139 & 0,1321 & 2,8110 & 2,9431 & 63,83 & 150 & 0,0164 & 2,256 & 471,50 & 469,60 & 0,90 & 0,90 & 470,60 & 468,70 & 0,0164 & \begin{tabular}{|l|l|}
0,02299 \\
\end{tabular} & 0,275 & 0,171 & \begin{tabular}{|l|l}
0,02565 \\
\end{tabular} & \begin{tabular}{|l|l|}
0,773 \\
\end{tabular} & 4,2031 & \begin{tabular}{|l}
3,010 \\
\end{tabular} \\
\hline 49-1 & 99,80 & 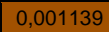 & 0,1137 & 0 & 0,1137 & 13,11 & 150 & 0,1132 & 19,959 & 503,60 & 492,30 & $\begin{array}{l}, 90 \\
\end{array}$ & 0,90 & 502,70 & 491,40 & 0,1132 & 0,00034 & 0,050 & 0,033 & \begin{tabular}{|l|l}
0,00495 \\
\end{tabular} & \begin{tabular}{|l}
2,032 \\
\end{tabular} & 5,6047 & \begin{tabular}{|l|l}
1,322 \\
\end{tabular} \\
\hline 50-1 & 64,90 & $\mid 0,001139$ & 0,0739 & 0 & 0,0739 & 13,87 & 150 & 0,0354 & 26,628 & 494,60 & 492,30 & 0,90 & 0,90 & 493,70 & 491,40 & 0,0354 & $\begin{array}{l}0,000039 \\
\end{array}$ & 0,050 & 0,033 & \begin{tabular}{|l|l}
0,00495 \\
\end{tabular} & \begin{tabular}{|l|l}
1,137 \\
\end{tabular} & 1,7542 & 1,322 \\
\hline 51-1 & 73,05 & \begin{tabular}{|l|l}
0,001139 \\
\end{tabular} & 0,0832 & 0 & 0,0832 & 13,31 & 150 & 0,0561 & 24,599 & 496,40 & $\begin{array}{l}492,30 \\
\end{array}$ & 0,90 & 0,90 & 495,50 & 491,40 & 0,0561 & \begin{tabular}{|l|l}
0,00035 \\
\end{tabular} & 0,050 & \begin{tabular}{|l}
0,033 \\
\end{tabular} & \begin{tabular}{|l|l}
0,00495 \\
\end{tabular} & \begin{tabular}{|l|l|}
1,431 \\
\end{tabular} & 2,7782 & \begin{tabular}{|l|l}
1,322 \\
\end{tabular} \\
\hline 49-2 & 115,70 & 0,001139 & 0,1318 & & 0,4026 & 26,32 & 150 & 0,0346 & 8,554 & 492,30 & 488,30 & 0,90 & 0,90 & 491,40 & 487,40 & & 0,0 & 0,100 & 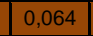 & & 1,123 & 3,3189 & 1,841 \\
\hline 52-1 & 72,70 & \begin{tabular}{|l|l}
0,001139 \\
\end{tabular} & 0,0828 & 0 & 0,0828 & 14,56 & 150 & 0,0344 & 24,679 & 490,80 & 488,30 & 0,90 & 0,90 & 489,90 & 487,40 & 0,0344 & \begin{tabular}{|l}
0,00045 \\
\end{tabular} & 0,050 & 0,033 & \begin{tabular}{|l|l}
0,00495 \\
\end{tabular} & \begin{tabular}{|l}
1,120 \\
\end{tabular} & & \begin{tabular}{|l}
1,322 \\
\end{tabular} \\
\hline $49-4$ & 112,85 & 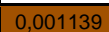 & 0,128 & 485 & 0,6140 & 26,88 & 150 & 0,0718 & 6,447 & 488,30 & 48 & 0,90 & 0,90 & 487,40 & 479,30 & 0,0718 & & 0,100 & 0,064 & & 18 & 6,8906 & \begin{tabular}{|l}
1,841 \\
\end{tabular} \\
\hline 53-1 & 72,65 & 0,001139 & 0,0828 & 0 & 0,0828 & 16,02 & 150 & 0,0206 & 24,690 & 481,70 & 480,20 & 0,90 & 0,90 & 480,80 & 479,30 & 0,0206 & $0,0,0058$ & 0,050 & 0,033 & \begin{tabular}{|l|l}
0,00495 \\
\end{tabular} & \begin{tabular}{|l|l}
0,868 \\
\end{tabular} & 1,0220 & 1,3 \\
\hline \begin{tabular}{|l|}
$49-4$ \\
\end{tabular} & 114,15 & 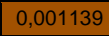 & 0,130 & & 0,8268 & $\begin{array}{l}47,67 \\
\end{array}$ & 150 & 0,0053 & 5,282 & 480,2 & 479,60 & 0,90 & 1,00 & 479,30 & 478,60 & & 0,0 & 0,200 & 0,121 & 0,018 & 0,473 & 1,1130 & 2,532 \\
\hline 54-1 & 72,65 & \begin{tabular}{|l|l}
0,001139 \\
\end{tabular} & 0,0828 & 0 & 0,0828 & 13,59 & 150 & 0,0482 & 24,690 & 483,10 & 479,60 & 0,90 & 1,00 & 482,20 & 478,60 & 0,0496 & & 0,050 & & \begin{tabular}{|l|l}
0,00495 \\
\end{tabular} & 1,345 & 2,4529 & 1,3 \\
\hline $49-5$ & 104,50 & 0,001139 & 0,1190 & & 1,0286 & 30,97 & 150 & 0,0957 & 4,563 & 479,60 & 469,60 & 1,00 & 0,90 & 478,60 & 468,70 & 0,0947 & 0,00334 & 0,125 & 0 & 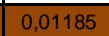 & 1,859 & 11,2263 & 2,046 \\
\hline $2-9$ & 113,05 & \begin{tabular}{|l|l}
0,001139 \\
\end{tabular} & 0,1288 & 3,9717 & 4,1005 & 89,29 & 150 & $-0,0080$ & 1,807 & 469,60 & 470,50 & 0,9 & 2,40 & 468,70 & 468,10 & 0,0053 & 0,05628 & 0,425 & 0,234 & \begin{tabular}{|l|l|}
0,0351 \\
\end{tabular} & \begin{tabular}{|l|l}
0,440 \\
\end{tabular} & 1,8629 & 3,5 \\
\hline $55-1$ & 100,25 & 0,001139 & 0,1142 & 0 & 0,1142 & 13,78 & 150 & 0,0878 & 199,899 & 506,40 & 497,60 & 0,9 & 0,90 & 505,50 & 496,70 & 0,0878 & 0,00039 & 0,050 & 0,033 & \begin{tabular}{|l|l}
0,00495 \\
\end{tabular} & 1,790 & 4,3451 & 1,322 \\
\hline $56-1$ & 56,35 & \begin{tabular}{|l|l}
0,001139 \\
\end{tabular} & 0,0642 & 0 & 0,0642 & 14,06 & 150 & 0,0248 & 29,272 & 499,00 & 497,60 & 0,90 & 0,90 & 498,10 & 496,70 & 0,0248 & \begin{tabular}{|l}
0,00041 \\
\end{tabular} & 0,050 & 0,033 & \begin{tabular}{|l}
0,00495 \\
\end{tabular} & \begin{tabular}{|l|l}
0,952 \\
\end{tabular} & 1,2298 & \begin{tabular}{|l}
1,322 \\
\end{tabular} \\
\hline $55-2$ & 117,25 & 0,001139 & 0,13 & 0,1784 & 0,3120 & 19,61 & 150 & 0,0699 & 10,149 & 497,60 & 489,40 & 0,90 & 4,40 & 496,70 & 485,00 & 0,0998 & 0,000099 & 0,075 & 0,048 & \begin{tabular}{|l|l}
0,0072 \\
\end{tabular} & 1,908 & 7,1846 & 1,595 \\
\hline 57-1 & 56,45 & \begin{tabular}{|l}
0,001139 \\
\end{tabular} & 0,0643 & 0 & 0,0643 & 11,73 & 150 & 0,0035 & $\begin{array}{l}29,237 \\
\end{array}$ & 489,60 & 489,40 & 0,90 & 4,40 & 488,70 & 485,00 & 0,0655 & 0,00025 & 0,050 & 0,033 & \begin{tabular}{|l}
0,00495 \\
\end{tabular} & \begin{tabular}{|l}
1,546 \\
\end{tabular} & 3,2445 & \begin{tabular}{|l}
1,322 \\
\end{tabular} \\
\hline $58-1$ & 72,85 & 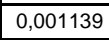 & 0,0830 & 0 & 0,0830 & 16,04 & 150 & $-0,0275$ & 24,644 & 487,40 & 489,40 & 0,90 & 4,40 & 486,50 & 485,00 & 0,0206 & \begin{tabular}{|l|l}
0,00058 \\
\end{tabular} & $0,0,050$ & \begin{tabular}{|l|}
0,033 \\
\end{tabular} & \begin{tabular}{|l}
0,00495 \\
\end{tabular} & \begin{tabular}{|l|l}
0,867 \\
\end{tabular} & 1,0192 & \begin{tabular}{|l}
1,322 \\
\end{tabular} \\
\hline 55-3 & 114,25 & 0,00113 & 0,130 & 0,459 & 0,5894 & 20,30 & 150 & & 6,626 & 489,40 & 477,60 & 4,40 & 1,00 & 485,00 & 476,60 & & 0,00217 & 0,100 & \begin{tabular}{|l|l|}
664 & \\
\end{tabular} & $\overline{0096}$ & 1,638 & & 1,841 \\
\hline 59-1 & 56,60 & \begin{tabular}{|l}
0,001139 \\
\end{tabular} & 0,0645 & 0 & 0,0645 & 14,51 & 150 & 0,0194 & 29,185 & 478,70 & 477,60 & 0,90 & 1,00 & 477,80 & 476,60 & 0,0212 & \begin{tabular}{|l}
0,00044 \\
\end{tabular} & 0,050 & 0,033 & \begin{tabular}{|l}
0,00495 \\
\end{tabular} & \begin{tabular}{|l|l}
0,879 \\
\end{tabular} & 1,0495 & \begin{tabular}{|l}
1,322 \\
\end{tabular} \\
\hline $60-1$ & 72,75 & \begin{tabular}{|l|l}
0,001139 \\
\end{tabular} & \begin{tabular}{|c}
0,0829 \\
\end{tabular} & 0 & 0,0829 & 16,03 & 150 & 0,0192 & 24,667 & 479,00 & 477,60 & 0,90 & 1,00 & 478,10 & 476,60 & 0,0206 & \begin{tabular}{|l|l|l|}
0,00008 \\
\end{tabular} & 0,050 & \begin{tabular}{|l}
0,033 \\
\end{tabular} & \begin{tabular}{|l|l}
0,00495 \\
\end{tabular} & \begin{tabular}{|l|l|}
0,8677 \\
\end{tabular} & 1,0206 & $\begin{array}{ll}1,32 \\
\end{array}$ \\
\hline $55-4$ & 114,00 & 0,0011 & $0,1 i$ & $\sqrt{72 x}$ & 0,86 & 34,67 & 150 & 0,0 & 5,118 & 477,60 & 473 & 1,0 & 0,90 & 476 & 472,40 & 0,0 & 0,00451 & 0,125 & 0,079 & 0,01185 & 1,159 & 4,3658 & 2,046 \\
\hline $61-1$ & 72,75 & \begin{tabular}{|l}
0,001139 \\
\end{tabular} & 0,0829 & 0 & 0,0829 & 13,34 & 150 & 0,0550 & $\begin{array}{l}24,667 \\
\end{array}$ & 477,30 & 473,30 & 0,90 & 0,90 & 476,40 & 472,40 & 0,0550 & $0,0,00035$ & 0,050 & \begin{tabular}{|l|l|}
0,033 \\
\end{tabular} & \begin{tabular}{|l}
0,00495 \\
\end{tabular} & \begin{tabular}{|l}
1,416 \\
\end{tabular} & 2,7216 & \begin{tabular}{|l}
1,322 \\
\end{tabular} \\
\hline 55-5 & 108,05 & \begin{tabular}{|l}
0,001139 \\
\end{tabular} & 0,1231 & 19495 & 1,0726 & 37,01 & 150 & 0,0259 & 4,437 & 473,30 & 470,50 & 0,90 & 2,40 & 472,40 & 468,10 & 0,0398 & 0.00538 & 0,150 & $\begin{array}{l}0,093 \\
\end{array}$ & \begin{tabular}{|l|l|l}
0,01395 \\
\end{tabular} & 1,205 & 5,5516 & 2,220 \\
\hline $2-10$ & 111,90 & 0,001139 & 0,1275 & 5,1730 & 5,3005 & 57,63 & 150 & 0,0 & 1,521 & 470,50 & 459,70 & 2,40 & 1,85 & 468,10 & 457,85 & 0,0916 & \begin{tabular}{|l}
0,01751 \\
\end{tabular} & 0,250 & \begin{tabular}{|l|}
0,147 \\
\end{tabular} & \begin{tabular}{|l|l}
0,02205 \\
\end{tabular} & \begin{tabular}{|l}
1,828 \\
\end{tabular} & 20,1977 & 701 \\
\hline & & & & & & & & $-0,0109$ & & & & & & & 477 & & & & & & & & \\
\hline 63-1 & 76,55 & 0,001139 & 0,0872 & 0 & 0,0872 & 13,76 & 150 & 0,0248 & 23,840 & 482,30 & 480,40 & 0,90 & 2,95 & 481,40 & 477,45 & 0,0516 & $0,0,00038$ & 0,050 & $\begin{array}{l}0,033 \\
\end{array}$ & \begin{tabular}{|l|l}
0,00495 \\
\end{tabular} & \begin{tabular}{|l|l|}
1,372 \\
\end{tabular} & 2,5542 & 1,322 \\
\hline
\end{tabular}




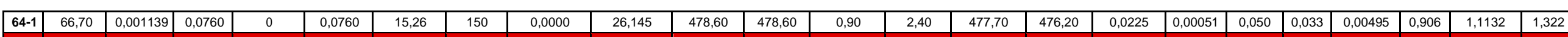

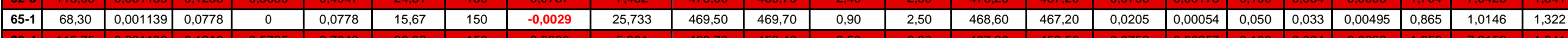

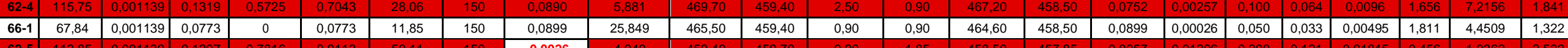

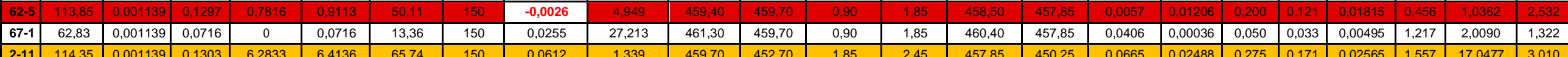

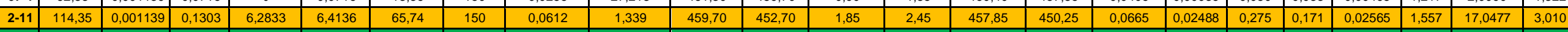

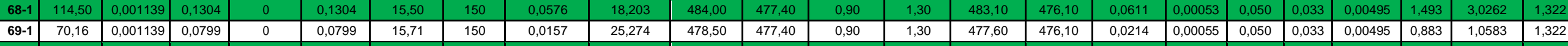

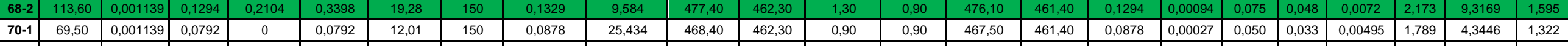

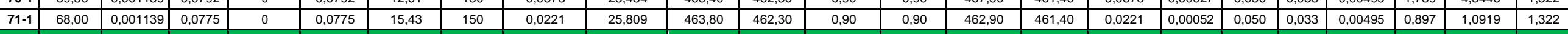

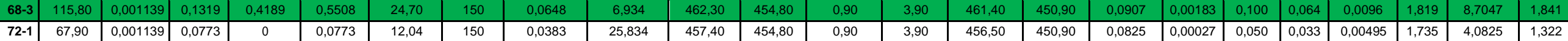

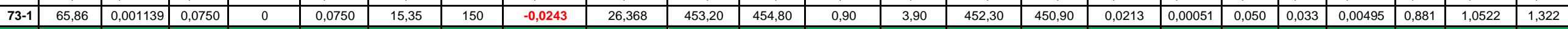

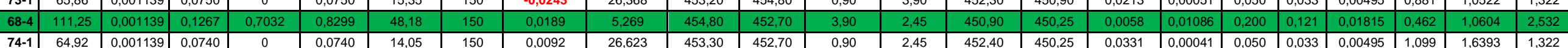

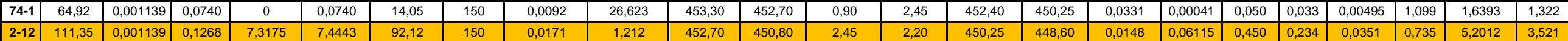

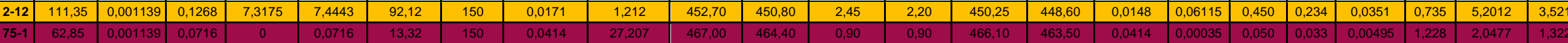

\begin{tabular}{|c|c|c|c|c|c|c|c|c|c|c|c|c|c|c|c|c|c|c|c|c|c|c|c|}
\hline 76-1 & 72,64 & 0,001139 & 0,0827 & 0 & 0,0827 & 12,69 & 150 & 0,0716 & 24,692 & 455,50 & 450,30 & 0,90 & 0,90 & 454,60 & 449,40 & 0,0716 & 0,00031 & 0,050 & 0,033 & 0,00495 & 1,616 & 3,5435 & 1,322 \\
\hline 75-4 & 108,95 & 0,001139 & 0,1241 & 0,4121 & 0,5362 & 39,18 & 150 & $-0,0046$ & 7,060 & 450,30 & 450,80 & 0,90 & 2,20 & 449,40 & 448,60 & 0,0073 & 0,00626 & 0,150 & 0,093 & 0,01395 & 0,518 & 1,0243 & 2,220 \\
\hline $77-1$ & 63,37 & 0,001139 & 0,0722 & 0 & 0,0722 & 12,87 & 150 & 0,0505 & 27,057 & 483,90 & 480,70 & 0,90 & 0,90 & 483,00 & 479,80 & 0,0505 & 0,00032 & 0,050 & 0,033 & 0,00495 & 1,357 & 2,4996 & 1,322 \\
\hline 77-2 & 114,65 & 0,001139 & 0,1306 & 0,0722 & 0,2028 & 20,72 & 150 & 0,0209 & 13,544 & 480,70 & 478,30 & 0,90 & 2,10 & 479,80 & 476,20 & 0,0314 & 0,00114 & 0,075 & 0,048 & 0,0072 & 1,070 & 2,2608 & 1,595 \\
\hline 78-1 & 65,65 & 0,001139 & 0,0748 & 0 & 0,0748 & 15,33 & 150 & 0,0030 & 26,424 & 478,50 & 478,30 & 0,90 & 2,10 & 477,60 & 476,20 & 0,0213 & 0,00051 & 0,050 & 0,033 & 0,00495 & 0,882 & 1,0556 & 1,322 \\
\hline 79-1 & 67,40 & 0,001139 & 0,0768 & 0 & 0,0768 & 12,30 & 150 & 0,0549 & 25,962 & 482,00 & 478,30 & 0,90 & 2,10 & 481,10 & 476,20 & 0,0727 & 0,00028 & 0,050 & 0,033 & 0,00495 & 1,629 & 3,5987 & 1,322 \\
\hline $77-3$ & 114,05 & 0,001139 & 0,1299 & 0,3544 & 0,4843 & 24,26 & 150 & 0,0877 & 7,559 & 478,30 & 468,30 & 2,10 & 0,90 & 476,20 & 467,40 & 0,0772 & 0,00174 & 0,100 & 0,064 & 0,0096 & 1,678 & 7,4073 & 1,841 \\
\hline \begin{tabular}{|l|}
$80-1$ \\
\end{tabular} & 67,70 & 0,001139 & 0,0771 & 0 & 0,0771 & 11,73 & 150 & 0,0945 & 25,885 & 474,70 & 468,30 & 0,90 & 0,90 & 473,80 & 467,40 & 0,0945 & 0,00025 & 0,050 & 0,033 & 0,00495 & 1,857 & 4,6795 & 1,322 \\
\hline $77-4$ & 115,20 & 0,001139 & 0,1312 & 0,5614 & 0,6926 & 25,88 & 150 & 0,1120 & 5,947 & 468,30 & 455,40 & 0,90 & 0,90 & 467,40 & 454,50 & 0,1120 & 0,00207 & 0,100 & 0,064 & 0,0096 & 2,021 & 10,7500 & 1,841 \\
\hline $81-1$ & 70,50 & 0,001139 & 0,0803 & 0 & 0,0803 & 11,56 & 150 & 0,1106 & 25,192 & 463,20 & 455,40 & $0,9 c$ & 0,90 & 462,30 & 454,50 & 0,1106 & 0,00024 & 0,050 & 0,033 & 0,00495 & 2,009 & 5,4766 & 1,322 \\
\hline $77-5$ & 111,70 & 0,001139 & 0,1272 & 0,7729 & 0,9002 & 32,87 & 150 & 0,0412 & 4,989 & 455,40 & 450,80 & 0,90 & 2,20 & 454,50 & 448,60 & 0,0528 & 0,00392 & 0,125 & 0,079 & 0,01185 & 1,388 & 6,2592 & 2,046 \\
\hline \begin{tabular}{|l|}
$2-13$ \\
\end{tabular} & 111,55 & 0,001139 & 0,1271 & 8,8807 & 9,0078 & 119,65 & 150 & $-0,0251$ & 1,066 & 450,80 & 453,60 & 2,20 & 5,60 & 448,60 & 448,00 & 0,0054 & 0,12282 & 0,700 & 0,297 & 0,04455 & 0,443 & 2,3962 & 3,967 \\
\hline \begin{tabular}{|l|}
$82-1$ \\
\end{tabular} & 66,35 & 0,001139 & 0,0756 & 0 & 0,0756 & 14,17 & 150 & 0,0332 & 26,237 & 479,80 & 477,60 & 0,90 & 0,90 & 478,90 & 476,70 & 0,0332 & 0,00042 & 0,050 & 0,033 & 0,00495 & 1,100 & 1,6413 & 1,322 \\
\hline \begin{tabular}{|l|}
$82-2$ \\
\end{tabular} & 117,35 & 0,001139 & 0,1337 & 0,0756 & 0,2093 & 25,49 & 150 & $-0,0401$ & 13,262 & 477,60 & 482,30 & 0,90 & 6,90 & 476,70 & 475,40 & 0,0111 & 0,00199 & 0,100 & 0,064 & 0,0096 & 0,636 & 1,0635 & 1,841 \\
\hline $82-3$ & 114,40 & 0,001139 & 0,1303 & 0,2093 & 0,3396 & 31,95 & 150 & 0,0315 & 9,588 & 482,30 & 478,70 & 6,90 & 4,30 & 475,40 & 474,40 & 0,0087 & 0,00363 & 0,125 & 0,079 & 0,01185 & 0,565 & 1,0358 & 2,046 \\
\hline $82-4$ & 114,55 & 0,001139 & 0,1305 & 0,3396 & 0,4701 & 24,50 & 150 & 0,0986 & 7,711 & 478,70 & 467,40 & 4,30 & 0,90 & 474,40 & 466,50 & 0,0690 & 0,00179 & 0,100 & 0,064 & 0,0096 & 1,586 & 6,6207 & 1,841 \\
\hline \begin{tabular}{|l|}
$82-5$ \\
\end{tabular} & 113,30 & 0,001139 & 0,1291 & 0,4701 & 0,5991 & 22,83 & 150 & 0,1218 & 6,554 & 467,40 & 453,60 & 0,90 & 5,60 & 466,50 & 448,00 & 0,1633 & 0,00148 & 0,075 & 0,048 & 0,0072 & 2,441 & 11,7564 & 1,595 \\
\hline 2-14 & 110,65 & 0,001139 & 0,1260 & 9,6069 & 9,7329 & 125,01 & 150 & 0,0208 & 1,012 & 453,60 & 451,30 & 5,60 & 3,85 & 448,00 & 447,45 & 0,0050 & 0,13805 & 0,750 & 0,302 & 0,0453 & 0,426 & 2,2517 & 4,000 \\
\hline 2-15 & 109,10 & 0,001139 & 0,1243 & 9,7329 & 9,8572 & 123,63 & 150 & 0,0178 & 1,004 & 451,30 & 449,36 & 3,85 & 2,50 & 447,45 & 446,86 & 0,0054 & 0,13404 & 0,750 & 0,302 & 0,0453 & 0,444 & 2,4498 & 4,000 \\
\hline 2-16 & 110,60 & 0,001139 & 0,1260 & 9,8572 & 9,9832 & 71,96 & 150 & 0,1013 & 0,995 & 449,60 & 438,40 & 2,50 & 2,30 & 447,10 & 436,10 & 0,0995 & 0,03166 & 0,325 & 0,194 & 0,0291 & 1,905 & 28,9421 & 3,206 \\
\hline $1-22$ & 63,20 & 0,001139 & 0,0720 & 18,4872 & 18,5592 & 94,78 & 150 & 0,1013 & 0,657 & 438,40 & 432,00 & 2,30 & 0,90 & 436,10 & 431,10 & 0,0791 & 0,06598 & 0,475 & 0,250 & 0,0375 & 1,699 & 29,6677 & 3,639 \\
\hline \begin{tabular}{|l|}
$1-23$ \\
\end{tabular} & 65,30 & 0,001139 & 0,0744 & 18,5592 & 18,6336 & 101,57 & 150 & 0,0551 & 0,655 & 432,00 & 428,40 & 0,90 & 0,90 & 431,10 & 427,50 & 0,0551 & 0,07936 & 0,525 & 0,265 & 0,03975 & 1,418 & 21,9142 & 3,747 \\
\hline $1-24$ & 63,30 & 0,001139 & 0,0721 & 18,6336 & 18,7057 & 156,55 & 200 & $-0,0111$ & 0,653 & 428,40 & 429,10 & 0,90 & 1,95 & 427,50 & 427,15 & 0,0055 & 0,25156 & 0,675 & 0,297 & 0,0594 & 0,449 & 3,2844 & 4,580 \\
\hline $1-25$ & 117,90 & 0,001139 & 0,1343 & 18,7057 & 18,8400 & 119,84 & 200 & 0,0322 & 0,650 & 429,10 & 425,30 & 1,95 & 0,90 & 427,15 & 424,40 & 0,0233 & 0,12336 & 0,500 & 0,250 & 0,05 & 0,922 & 11,6624 & 4,202 \\
\hline \begin{tabular}{|l|}
$1-26$ \\
\end{tabular} & 108,35 & 0,001139 & 0,1234 & 18,8400 & 18,9634 & 159,90 & 200 & $-0,0222$ & 0,648 & 425,30 & 427,70 & 0,90 & 3,85 & 424,40 & 423,85 & 0,0051 & 0,26616 & 0,700 & 0,297 & 0,0594 & 0,430 & 3,0152 & 4,580 \\
\hline \begin{tabular}{|l|}
$1-27$ \\
\end{tabular} & 91,43 & 0,001139 & 0,1042 & 18,9634 & 19,0676 & 158,01 & 200 & $-0,0055$ & 0,645 & 427,70 & 428,20 & 3,85 & 4,85 & 423,85 & 423,35 & 0,0055 & 0,25784 & 0,675 & 0,297 & 0,0594 & 0,447 & 3,2484 & 4,580 \\
\hline
\end{tabular}




\begin{tabular}{|c|c|c|c|c|c|c|c|c|c|c|c|c|c|c|c|c|c|c|c|c|c|c|c|c|}
\hline & 86,19 & 0, & $0,098:$ & 1,06 & & 9,1657 & 159,69 & 200 & - & 0, & 428,20 & 4 & 4,85 & 2,60 & $\frac{15}{5}$ & 46 & 0,0 & 26525 & 0,700 & 0,297 & 0,0594 & 6 & & \\
\hline & 86,21 & 0,1 & \begin{tabular}{|l|l}
0,0 \\
\end{tabular} & 19 & & 9,2639 & 105 & 200 & & & & 42 & & 0 & & 4 & 0,0 & 0,09700 & & 0,215 & & 99 & & \\
\hline & & & & & & & & & & & & & & & & & & & & & & & & \\
\hline
\end{tabular}
17072 


\section{ANEXO - F}

\begin{tabular}{|c|c|c|c|c|c|c|c|c|c|c|c|c|c|c|c|c|c|c|c|}
\hline & \multirow{2}{*}{\multicolumn{5}{|c|}{ PLANILHÁ, DE CŔLCULO DA, REDE DE ESGOTOS }} & \multicolumn{7}{|c|}{ PROJETO TECNICO DO INTERRCEPTORESGOTOS SANNITRERIOS } & \multirow{2}{*}{\multicolumn{3}{|c|}{ C\&LLCULO: }} & \multirow{2}{*}{\multicolumn{4}{|c|}{ DATA: }} \\
\hline & & & & & & \multicolumn{4}{|l|}{\begin{tabular}{|l|} 
BACCIA: \\
EMPRESA:
\end{tabular}} & \multicolumn{3}{|c|}{ SUB-BACCIA: } & & & & & & & \\
\hline TRECHO & EXTENSA, & $\begin{array}{c}\text { VAZZOOA } \\
\text { MONTANT } \\
\text { E }\end{array}$ & $\left|\begin{array}{|}\text { VAZZOOA } \\
\text { JUSANTE }\end{array}\right|$ & $\operatorname{Qir}(1)^{4 / 2}$ & \begin{tabular}{|c|} 
DI, \&,METRO \\
USADOO
\end{tabular} & 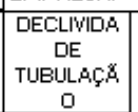 & \multirow{2}{*}{$\begin{array}{c}\text { L\&MMINA } \\
\text { LíQUIDA } \\
\text { (YID) }\end{array}$} & \multirow[t]{2}{*}{$\mathrm{V} f(m+s)$} & $\begin{array}{l}\text { TENSEOO } \\
\text { TRATTVA }\end{array}$ & $v_{c}$ & $\begin{array}{c}\text { COTADO } \\
\text { TERRENO } \\
\text { (m) }\end{array}$ & $\begin{array}{l}\text { COTA DO } \\
\text { TERRENO } \\
\text { (m) }\end{array}$ & $\begin{array}{l}\text { PROF. DO } \\
\text { INTERCEP. } \\
\text { (m) }\end{array}$ & $\begin{array}{l}\text { PROF.DO } \\
\text { INTERCEF. } \\
\text { (m) }\end{array}$ & \begin{tabular}{|} 
COTADO \\
INTERCEF. \\
$(\mathrm{m})$
\end{tabular} & $\begin{array}{l}\text { COTADO } \\
\text { INTERCEF. } \\
\text { (m) }\end{array}$ & \multirow[t]{2}{*}{ RHHD } & \multirow{2}{*}{$\begin{array}{c}\text { RAALIO } \\
\text { HIDRAUULI } \\
\text { CO RHID } \\
\times \text { D }\end{array}$} & \multirow{2}{*}{\begin{tabular}{|c} 
DECLIV \\
DADE \\
TUEDUA \\
CRDO \\
USADA
\end{tabular}} \\
\hline N. & (m) & $(L t s)$ & $(L t s)$ & (mm) & $(\mathrm{mm})$ & (mim) & & & (Pa) & $(m+s)$ & \begin{tabular}{|l|} 
MONTANTE \\
\end{tabular} & JUSANTE & MONTANTE & JUSANTE & \begin{tabular}{|l|} 
MONTANTE \\
\end{tabular} & JUSANTE & & & \\
\hline $\mid-1$ & 100 & 19,37 & 19,98 & 0,2826 & 300 & 0,0005 & 0,375 & 0,427 & 3,225 & 4,773 & 419,2 & 421,0 & 0,90 & 3,20 & 418,30 & 417,80 & 0,215 & 0,0645 & 0,0050 \\
\hline $1-2$ & 100 & 19,98 & 20,68 & 0,2312 & 300 & 0,0005 & 0,350 & 0,540 & 4,656 & 4,534 & 421,0 & 417,9 & 3,20 & 0,90 & 417,80 & 417,00 & 0,194 & 0,0582 & 0,0080 \\
\hline $1-3$ & 100 & 20,68 & 21,38 & 0,0920 & 300 & 0,0005 & 0,275 & 1,404 & 27,702 & 4,256 & 417,9 & 412,5 & 0,90 & 0,90 & 417,00 & 411,60 & 0,171 & 0,0513 & 0,0540 \\
\hline
\end{tabular}




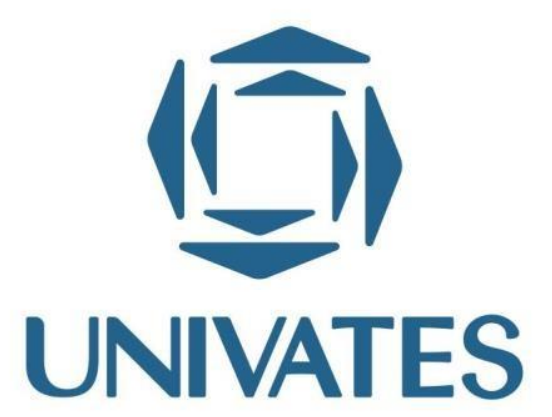

R. Avelino Talini, 171 | Bairro Universitário | Lajeado | RS | Brasil CEP 95914.014 | Cx. Postal 155 | Fone: (51) 3714.7000 www.univates.br | 08007070809 